\title{
REacH: Randomized Evaluation of HIV/FP Service Models
}

\author{
Paul C. Hewett \\ Population Council \\ Mutinta Nalubamba \\ Fiammetta Bozzani \\ Mardieh Dennis \\ Population Council \\ Jean Digitale \\ Population Council
}

See next page for additional authors

Follow this and additional works at: https://knowledgecommons.popcouncil.org/departments_sbsr-hiv

Part of the Demography, Population, and Ecology Commons, Family, Life Course, and Society Commons, and the International Public Health Commons How does access to this work benefit you? Let us know!

\section{Recommended Citation}

Hewett, Paul C., Mutinta Nalubamba, Fiammetta Bozzani, Mardieh Dennis, Jean Digitale, Lung Vu, Eileen Yam, and Mary Nambao. 2015. "REacH: Randomized Evaluation of HIV/FP Service Models." New York: Population Council. 


\section{Authors}

Paul C. Hewett, Mutinta Nalubamba, Fiammetta Bozzani, Mardieh Dennis, Jean Digitale, Lung Vu, Eileen Yam, and Mary Nambao 


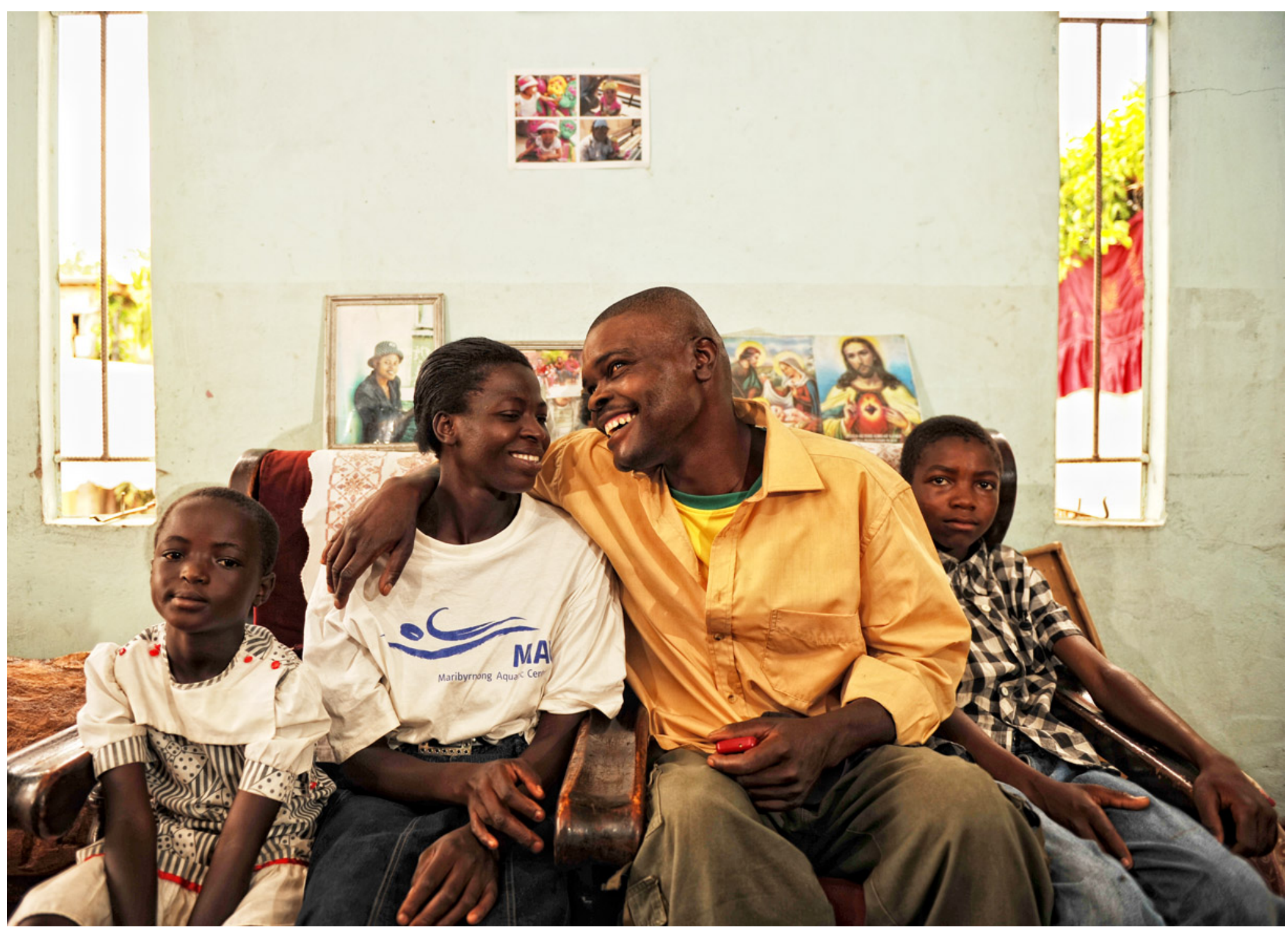

STUDY RESEARCH REPORT

REacH: RANDOMIZED

EVALUATION OF HIV/FP SERVICE

MODELS

USAID PSil 


\section{psi}

PSI is a global non-profit organization dedicated to improving the health of people in the developing world by focusing on serious challenges like a lack of family planning, HIV and AIDS, barriers to maternal health, and the greatest threats to children under five, including malaria, diarrhea, pneumonia and malnutrition. www.psi.org; Twitter: www.twitter.com/PSIHealthyLives; Blog: blog.psiimpact.com; Impact Magazine: psiimpact.com.

\section{Headquarters}

Population Services International (PSI) 1120 19th St. NW, Suite 600

Washington, DC 20002. Tel: +1 202 785-0072, Fax: +1 202 785-0120

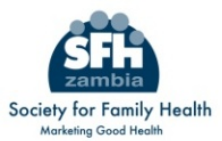

SFH enables the underserved and at-risk Zambians to lead healthier lives in line with the Government of Zambia's national priorities. We do this using a social marketing perspective, working with the private and public sectors to promote healthy behaviour and the use of quality, affordable health products and services. www.sfh.org.zm; Facebook: https://www.facebook.com/SFHZambia; Twitter handle: @SFHZambia; YouTube channel: Communications SFH Zambia

\section{Headquarters}

Society for Family, Plot No. 549 Ituna Road, Box 50770, Lusaka, Zambia. Tel: +260 211 257407. Email: contact@sfh.org.zm

\section{POPULATION COUNCIL}

Ideas. Evidence. Impact.

The Population Council confronts critical health and development issues-from stopping the spread of HIV to improving reproductive health and ensuring that young people lead full and productive lives. Through biomedical, social science, and public health research in 50 countries, we work with our partners to deliver solutions that lead to more effective policies, programs, and technologies that improve lives around the world. Established in 1952 and headquartered in New York, the Council is a nongovernmental, nonprofit organization governed by an international board of trustees.

\section{Headquarters}

Population Council

One Dag Hammarskjold Plaza

New York, New York 10017

Tel: +1 2123390500

Fax: +1 2127556052

Website: popcouncil.org

\section{Zambia}

Population Council Plot 3670, No 4. Mwaleshi Road Olympia Park, Lusaka

Zambia

Tel: +260 211295925

Mobile: +260 969276076

email: info.zambia@popcouncil.org 


\section{Author affiliations}

\section{Corresponding authors}

Paul C. Hewett, Ph.D.

Senior Associate

Population Council

Lusaka, Zambia

phewett@popcouncil.org

\section{Contributing authors}

Fiammetta Bozzani, Ph.D.

Research Fellow

Department of Global Health and Development

London School of Hygiene and Tropical Medicine

London, U.K

\section{Jean Digitale, M.P.H}

Data Analyst/Research Coordinator

Population Council

New York, U.S.A.

Eileen Yam, Ph.D.

Associate

Population Council

Washington D.C.
Mutinta Nalubamba, MMeD, M.P.H

Health Services Director

Society for Family Health

Lusaka, Zambia

mutintan@sfh.org.zm

\section{Mardieh Dennis, M.S.P.H}

Social and Operations Research Manager

Population Council

Lusaka, Zambia

Lung Vu, Ph.D.

Associate

Population Council

Washington D.C.

Mary Nambao, MBChB, M.P.H.

Deputy Director Mother Health

Ministry of Health

Lusaka, Zambia

Suggested citation: Hewett, Paul C., Mutinta Nalubamba, Fiammetta Bozzanni, Mardieh Dennis, Jean Digitale, Lung Vu, Eileen Yam, Mary Nambao. 2015. REacH: Randomized Evaluation of HIV/FP Service Models Final Study Report. New York: Population Council. 


\section{Table of Contents}

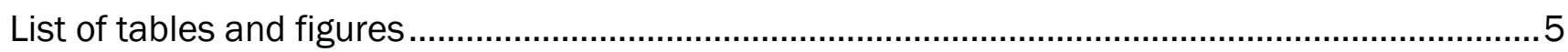

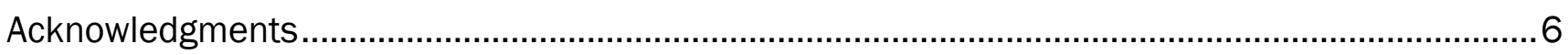

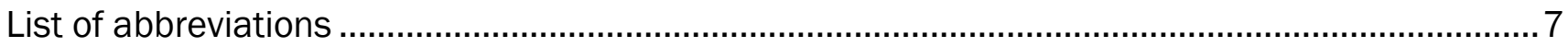

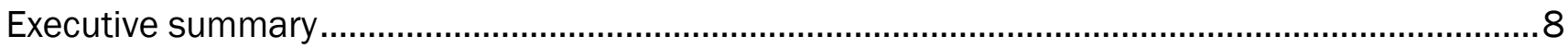

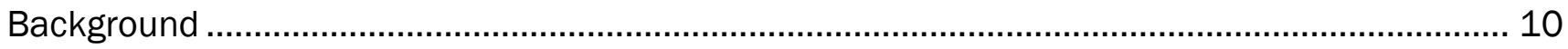

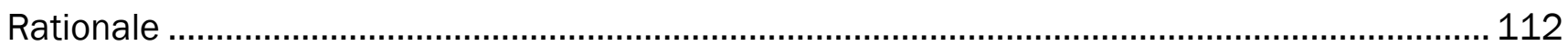

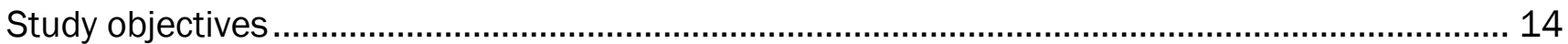

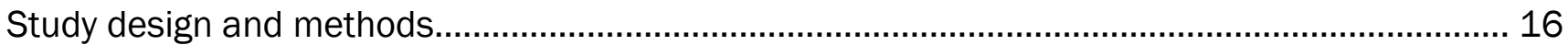

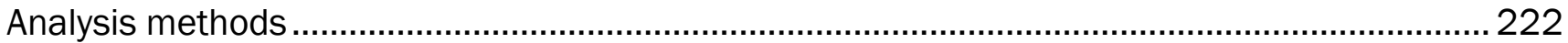

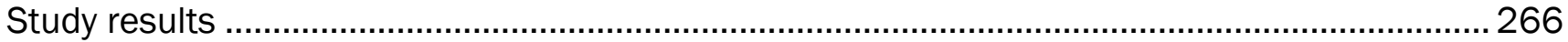

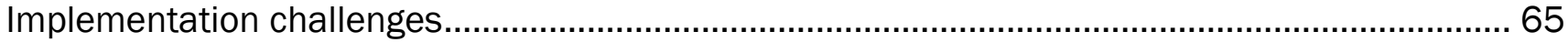

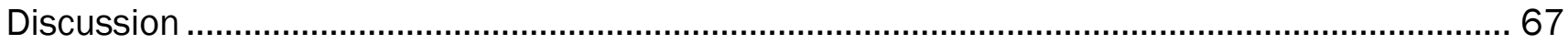

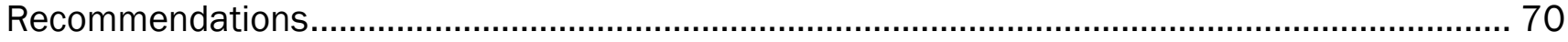

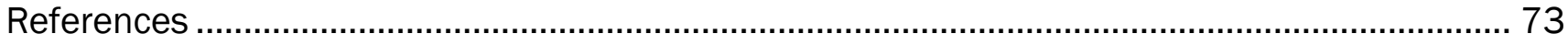

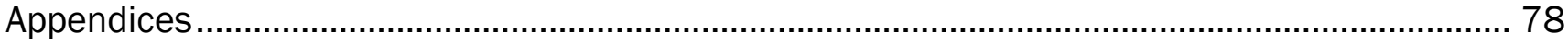




\section{List of tables and figures}

Table 1 Study outcomes by client eligibility

Table 2 Description of service sites and services costed

Table 3 DALY model parameter assumptions

Table $4 \quad$ Study recruitment rates by site and entry point

Table 5 Baseline demographic characteristics of study participants by sex

Table 6 Baseline demographic characteristics of study participants by sex and study arm

Table $7 \quad$ Baseline characteristics of study participants by study entry point

Table 8 Survey response rates at six-weeks and six-months by gender, study arm and entry point

Table 9 Descriptive statistics of service uptake outcomes at six weeks by study arm

Table 10 Descriptive statistics of service uptake outcomes at six months by study arm

Table 11 Descriptive statistics of client behavioral outcomes at six months by study arm

Table 12 Multivariable logistic regression of impact of intervention on uptake outcomes at six months

Table 13 Client qualitative interviews sample by study arm \& entry point

Table 14 Cost per client of vertical services in urban and rural service sites compared to integrated provision

Table 15 Cost per client of vertical services in urban and rural service sites compared to integrated provision

Figure 1 Summary of client discussions of referral, follow-up, and uptake

Figure 2 Client reasons for non-uptake of add-on service

\section{Appendices}

Table A1 Study service entry points and referral points

Table A2 Baseline demographic characteristics of study participants by sex and entry point service

Table A3 Logistic regressions of study participant attrition, by interview date

Table A4 Descriptive statistics of client behavioral outcomes at six weeks by study arm

Table A5 Multivariable logistic regression of impact of intervention on six-week service uptake outcomes

Table A6 Multivariable logistic regression of impact of intervention on service uptake outcomes

Table A7 Multiple imputation multivariable logistic regression of impact of intervention on six-week service uptake outcomes

Table A8 Multiple imputation multivariable logistic regression of impact of intervention on six-month service uptake outcomes 


\section{Acknowledgrments}

This technical report would not be possible without the support and hard work of a diverse group of staff and advisers over the years.

We would like to thank the USAID REacH Management team for their oversight of the project and grant.

\section{At Population Services International}

Special thanks are due to Hayden Hawry and Kuyosh Kadirov at SFH/PSI who were instrumental in the conception of the study funding proposal and implementation design. We thank Dr. Nina Hasen, Rebecca Livingstone, Navendu Shekhar and Noah Taruberekera for their valuable review and technical assistance on this manuscript, while also acknowledging the assistance of the PSI Southern Africa Regional Support team in coordinating and managing all communication between all partners.

\section{At Society for Family Health}

We thank Bernard Banda who served as study manager and Nicholas Shiliya who served as the study principal investigator at the start of implementation. We also thank Clement Mwale and Handson Manda who served as regional managers for Lusaka and Eastern provinces and provided local oversight for the project implementation. We would also like to acknowledge the SFH finance, administrative and human resources teams for support provided in their respective areas.

\section{At the Population Council}

We thank Saziso Mulenga who served as study coordinator. Thanks to Drosin Mulenga and Lyson Phiri, who served as study coordinators for the qualitative study. We would also like to thank Chama Mapulanga and Angel Chelwa who served on the quality assurance team. Special thanks to Barbara Miller from the New York Council office, who served as document editor and expenditure analyst. We would also like to acknowledge the efforts of the finance and administrative team at the Population Council, Zambia, including Masida Chisambi, Swedish Sianyaka, Khukhie Makukisi and Memory Sichizuwe. Additional thanks to Samir Souidi and Stan Mierzwa at the Population Council headquarters for development of the study client database and the tabletbased electronic data capture tools.

Finally, we are grateful to the men and women who served as research assistants and drivers during data collection.

This study report is made possible by the generous support of the American people through the United States Agency for International Development (USAID). The study was conducted under a subgrant from Population Services International (PSI). We thank the United States Agency for International Development (USAID) for its support, in particular the project management team. The contents are the responsibility of Population Services International and do not necessarily reflect the views of USAID or the United States Government. 


\section{List of abbreviations}

ACASI

ART

ATT

CAPI

CCS

CSO

DALYS

GEE

FP

GMM

GRZ

HTC

IDI

ITT

IRR

IV

LARC

$\mathrm{MCH}$

$\mathrm{MCDMCH}$

$\mathrm{MI}$

$\mathrm{MOH}$

PC

PSI

RCT

SFH

STI

TOT

USAID

VIA

VMMC

WHO

Audio computer-assisted self-interview

Antiretroviral therapy

Average treatment effect on treated

Computer-assisted personal interview

Cervical cancer screening

Central Statistical Office

Disability-adjusted life years

Generalized estimating equations

Family planning

Generalized method of moments

Government of the Republic of Zambia

HIV testing and counselling

In-depth interview

Intent-to-treat

Incidence rate ratio

Instrumental variable

Long acting reversible contraception

Maternal and child health

Ministry of Community Development, Mother and Child Health

Motivational interviewing

Ministry of Health

Population Council

Population Services International

Randomized controlled trial

Society for Family Health

Sexually transmitted infection

Treatment-on-the-treated

United States Agency for International Development

Visual inspection with acetic acid

Voluntary medical male circumcision

World Health Organization 


\section{Executive summary}

The provision of HIV prevention and family planning services (FP) in Zambia can be generally characterized by discrete service programming with tenuous client referral and linkage systems between services. Fragmented public sector coordination and overburdened primary care facilities have also limited the effectiveness of HIV and FP service linkage efforts. The evidence in the literature to-date points to gaps in the continuity of care for HIV and FP clients, leading to missed opportunities for averting new HIV infections and unintended pregnancies. Poor tracking and follow-up of HIV positive clients has also likely resulted in lower uptake of HIV monitoring and antiretroviral therapy (ART). Meanwhile, inconsistent demand in Zambia for services such as voluntary medical male circumcision (VMMC) and long-acting reversible contraception (LARC) at existing vertical service sites undermines the costefficiency of these programs. Strengthened cross-referrals and service linkages have the potential to increase uptake of add-on FP and HIV services among current FP, VMMC and HIV testing and counseling (HTC) clients, as well as among their partners and children.

Population Services International (PSI), and its Zambian network partner, Society for Family Health (SFH), together with Population Council (PC) implemented REacH: Randomized Evaluation of HIV/FP Service Models, a randomizedcontrolled implementation science research study to compare health service uptake of two experimental models of HIV prevention and FP service linkage and integration. Clients accessing services and voluntarily enrolling were randomized into one of three study arms that offered a different package of services: 1) the standard model of service provision at FP, HTC and VMMC sites (control); 2) an enhanced client counseling and referral to add-on service arm, with client follow-up; and 3) an enhanced client add-on service referral and follow-up arm with the addition of an offer of immediate escort to the add-on service. For clients in the two intervention arms, if they did not access the add-on referral services within seven days, they were called and provided additional encouragement and counselling to improve their likelihood of add-on service uptake.

Study personnel interviewed participants at the study sites at baseline, six weeks and six months post-enrollment. At the follow-up interviews at six weeks and six months all study participants were asked questions regarding their uptake of an array of add-on services, as well as questions about behaviors and satisfaction with the health services received. Qualitative in-depth interviews conducted among participants and providers from experimental and control sites sought to identify facilitators and barriers to the implementation of enhanced FP and HIV service linkage and integration models. Detailed cost data from entry-point and referral sites, including incremental capital and recurrent costs and valuated provider time related to service provision was collected to conduct a technical efficiency and a cost-effectiveness analysis of the study interventions.

The study's results indicated that the enhanced client add-on service referral and follow-up arm with and without the escort had an impact on many, but not all of the primary study outcomes. In particular, the intervention increased the uptake of HTC services among women who had entered at FP care entry points. The effect of the intervention was greater in the shorter term, improving uptake within six weeks, but nonetheless remained important through six months. As knowing one's HIV status early is important for getting clients into care and treatment as soon as possible after HIV acquisition, these results indicate that the intervention can increase the numbers of HIV positives diagnosed and potentially into treatment. The intervention also significantly increased the uptake of VMMC services among men, at times doubling the odds of uptake when compared to the standard models of service delivery. Given that VMMC is an invasive HIV prevention medical intervention and the barriers to increasing the demand for VMMC are high, the study results point to the value of the offering add-on services through comprehensive counselling at HTC sites for improving VMMC uptake. The study's economic evaluation indicates that offering such add-on services is highly cost-effective as an HIV prevention approach. 
The study findings indicated marginal improvements in HIV positive clients accessing HIV care and treatment in the intervention arms, although this result does not consistently reach the designated levels of statistical significance. For those who have accessed HIV care and treatment during the study observation period, the intervention does indicate an increase in access to TB and CD4 testing services. For instance, by six months post-enrollment the enhanced referral arm with escort had a $20 \%$ higher prevalence of HIV positive women accessing TB testing services compared to the standard-of-care. Similar differences were observed in the prevalence of males accessing CD4 testing. Further, the embedded economic evaluation indicated that the interventions are cost-effective in reducing the HIV and AIDS disease burden. While drawing definitive conclusions is not possible due the small sample sizes and the lack of consistency in the results, these findings do provide a rationale for future studies that include all or some of the elements of the intervention among HIV positive populations where higher sample sizes can be achieved.

The REacH evaluation also revealed significant increases in uptake when enhanced services were offered to women for screening for cervical cancer. Women who presented for services at HTC sites and at MCH clinics in Lusaka and Chipata were provided detailed information about cervical cancer and asked if they would be interested in being screened. The study results indicated that when cervical cancer was the focus of enhanced package of counselling, referral and follow-up services for every one woman screened in the standard of care, three women were screened in the enhanced services and referrals models. These positive results were also independent of the type of site that the women had entered. As with the package of HIV prevention and care and treatment services, the economic evaluation showed that the provision of these services was highly cost-effective in the Zambian context.

One area in which the intervention was not successful in improving outcomes was in the provision of add-on FP services for women at HTC sites. The study's intervention did not realize any gains in the uptake of FP services among women and at the end of six months in the intervention arms women were not more likely to use modern contraception, or use a long-acting contraception more specifically, than the women in the standard of care, as was expected. The results for recruited client's partners and children aged 15 years and older were also somewhat less promising, although certainly affected by a small number of observations for the children. For instance, very few spouses of male clients were reached through the enhanced services and referrals to increase uptake of HTC, FP, cervical cancer screening (CCS) or HIV care and treatment. That said, spouses of female clients were, at times, more likely to access HTC and VMMC services. This latter finding provides some promise for future evaluations to further delineate how best to reach men through counselling and providing referrals through women.

The Government of the Republic of Zambia (GRZ) and PEPFAR are eager to identify the most cost-efficient and effective mix of HIV and FP service linkage and integration strategies suitable for large-scale implementation. The $\mathrm{REacH}$ study addressed these interests by evaluating two distinct models of enhanced service provision and referrals in the Zambian context. We believe that the results of this evaluation will contribute to the evidence-base used to inform FP and HIV service integration programming in Zambia and in other PEPFAR priority countries as it suggests that integrated services are a cost-effective mechanism from which to reach the population with life sustaining interventions. 
Existing data indicate that the integration of family planning (FP) and human immunodeficiency virus (HIV) services is most likely to be cost-effective in generalized HIV epidemic settings with significant unmet need for modern contraception.[1, 2] With a hyper-endemic HIV prevalence of over $13 \%$ and roughly one out of five married women reporting an unmet need for $\mathrm{FP},[3]$ conditions in Zambia are ripe for exploring effective strategies for the integration of FP and HIV services. Nonetheless, critical client entry points such as (1) HIV testing and counseling (HTC), (2) voluntary medical male circumcision (VMMC) and (3) FP are dominated by services that tend to address acute service delivery gaps through vertical programming and service specialization. Government-led FP and HIV programs in Zambia are governed by distinct management structures, established according to historical precedence.[4] In practice, this has resulted in parallel service models, requiring clients to make multiple visits to separate locations to access comprehensive information about add-on FP or HIV services.[5, 6]

In Zambia, where $18 \%$ of women age 15-49 who have ever had sex are living with HIV, many of the shared client outcome goals of FP and HIV programs are unlikely to be fully met through discrete models of service provision. $[7,8]$ The lack of cohesive provider-initiated referral and linkage systems within the public and NGO sectors has effectively limited uptake of FP as well as prevention, treatment and support services for HIV positive clients, potentially curbing the population-level health benefits of existing FP and HIV interventions.[9, 10] There is strong consensus among policy makers as well as cooperating partners within Zambia that better linkages between FP and HIV services are essential to synergize health impact and greater net cost savings for the health sector.[11, 12] The Government of the Republic of Zambia (GRZ) has identified reduction of unintended pregnancies among HIV positive individuals as a vital component of prevention of mother-to-child transmission (PMTCT), and as vital to achieving the country's Millennium Development Goals.[13, 14] The rapid scale-up of VMMC and the emphasis of couples HTC under Zambia's National HIV Prevention Strategy for 2012-2015 offer new opportunities for encouraging male and female involvement in decisions related to uptake of FP and HIV services.

Most NGO-led FP and HIV programs in Zambia provide services within public clinics, where limited referral and tracking mechanisms often fail to ensure that clients access relevant add-on services, such as VMMC for male HIV negative HTC clients, HIV testing for FP clients, or CD4 testing and anti-retroviral therapy (ART) for HIV positive HTC clients. In most public health facilities, add-on FP and HIV services are offered sporadically and in separate buildings. Navigating the maze of available service schedules and locations usually requires basic literacy, significant time, and persistent client effort; all potential barriers to health service uptake in Zambia.[15-18] A severe shortage of human resources and an overburdened and under-resourced public health sector have exacerbated weaknesses in existing linkage and referral systems.[19]

Society for Family Health (SFH), a locally-registered Zambian affiliate of Population Services International (PSI), implemented a five-year USAID-funded project entitled Partnership for Integrated Social Marketing (PRISM) from 2009-2014, which brought together a consortium of local and international partners to support the government's reproductive health, maternal and child health, and HIV prevention priorities. This initiative included large-scale provision of HTC, VMMC and long-acting reversible contraception (LARC) services at hundreds of locations country wide. By the end of 2014, more than one million individuals were tested for HIV through PSI/SFH's New Start HTC program; $19 \%$ were tested as couples and $6 \%$ with sero-discordant results and $75 \%$ of all clients testing for the first time. The New Start HTC program thus represents a vital entry point for add-on FP and HIV services. Unfortunately, cross-referrals and linkages between this program and other publicly-offered vertical services are tenuous and poorly documented.[20]

Not all services are equally suited for on-site integration; maternal and child health ( $\mathrm{MCH}$ ) and FP services, as well as prevention of mother-to-child transmission (PMTCT) services have been shown to provide synergistic benefits 
when integrated at shared service points, while FP and STI service integration efforts have shown mixed results.[21, 22] Also noteworthy is observational evidence that suggests adult and adolescent males are not attracted to FP service sites that primarily serve women.[23] Where fully integrated on-site services are not feasible, stronger provider-initiated referral and linkage systems have also been shown to increase uptake of HTC services and enhance client perceptions of service quality.[24-30] Implementation strategies therefore need to strike the right balance between integration, specialization and service linkage, in order to provide clients with a beneficial continuum of FP and HIV services in a cost-effective manner.[31] 
There are limited evaluation data to support rigorous evidence-based decision making on the most efficient and cost-effective models for integrating FP and HIV services.[32] According to recent systematic reviews of published and unpublished studies, less than five peer-reviewed studies have experimentally compared more than two FP and HIV service linkage and integration models; few have included multiple add-on service uptake outcomes; and no peer-reviewed studies offer empirical cost-effectiveness or cost-efficiency comparisons between partially and fullyintegrated FP and HIV service models.[33, 34] No studies to date have explored the relative costs or effects of partial or complete integration of FP or HTC with VMMC services. Myriad experts and policy makers concur that additional research is needed to identify the most effective and cost-efficient models for large-scale FP, HTC, and VMMC service linkage and integration.[35-38] Results from the implementation science research documented in this report addresses some of these critical evidence gaps, and will help to inform government and NGO-led service delivery efforts and national policies on FP and HIV integration, including nascent VMMC policies and programs.

Renewed attention by the United States government through PEPFAR and the Global Health Initiative (GHI) and other donors working in Zambia on the missed opportunities inherent in vertical FP and HIV programming has set the stage for exploring large-scale service linkage and integration approaches. Effective service models are needed that offer a more holistic approach to meeting individuals' primary and preventive health care needs, especially for women and girls.[39] Existing research suggests that FP and HIV service linkage and integration efforts can increase uptake of add-on services and improve health outcomes, risk behavior outcomes and perceptions of quality among service beneficiaries.[34, 40, 41] Documented experiences in Zambia and other African countries indicate that community-stakeholders, clients, service providers and health administrators recognize integrated FP and HIV services as feasible and a desirable objective of health service provision.[42-45]

The REacH study used client-level randomization to compare the costs and effects of an enhanced client referral and follow-up model and a similar model of services and the addition of an immediately available escort to the addon service compared to the standard of care. The latter was simulated by offering add-on services to clients presenting at study entry points, and then accompanying interested clients to receive add-on services at nearby service locations. This "long hallway" approach aims to conservatively estimate the effectiveness of an integrated services model, and was chosen in lieu of evaluating fully-integrated service sites due to four contextual limitations: (1) it would be unethical to randomize clients at the existing fully-integrated service sites because it would lower the standard of care by denying services for clients in the control arm; (2) it would be cost-prohibitive to fully integrate vertical service sites for the purposes of a controlled experiment; (3) the implementation context and resource limitations do not allow for the randomization of service sites; and (4) non-randomized methods do not afford the level of rigor and attribution desired in assessing impact and effectiveness.

The REacH service delivery models are designed to enhance clients' readiness to utilize add-on health services, as well as facilitate actual service uptake. The selection and design of these service delivery models were informed by the Health Belief Model, a health behavior theory that has been used since the 1950 s to promote health service utilization.[46, 47] The Health Belief Model predicates that interventions should address clients' perceived benefits of referral services as well as the perceived barriers to care, by way of enhanced counseling and cues to action. Specifically, in both the REacH enhanced client referral and follow-up model and the enhanced client referral model with escort, providers conducted standardized needs assessments and motivational interviewing to influence clients' perceptions of the benefits of add-on services. After the initial visit, in both experimental models, a follow-up phone call or home visit to the participant provides a cue to action that can further encourage uptake of referral services. Finally, in the integrated services model, the additional component of provider accompaniment to the referral service provides not only a supplementary cue to action, but also serves to overcome barriers clients perceived to receiving add-on services. By accompanying the client to the add-on service, the provider can minimize 
barriers such as a client's perception that $\mathrm{s} /$ he does not know where to go for care, that s/he lacks the time for services, or that the services are not available nearby. Provider accompaniment of HTC clients to FP services was included as a component of a broader package of interventions in a "facilitated referral" model in Tanzania.[48] With the integrated services model, the REacH study isolated the effect of the provider escort on use of add-on services. 


\section{Study objectives}

The purpose of the REacH study was to contribute to the existing evidence base for best practices in FP, HIV and VMMC service linkage and integration, and thereby inform FP and HIV programming in keeping with PEPFAR's health service integration priorities.[20] The goal of this study was to determine which service linkage and integration models are most cost effective and efficient in the Zambian context and merit implementation at scale.

The specific aim of the REacH study was to experimentally compare incremental costs and service uptake and utilization outcomes of enhanced service linkage models with those of existing vertical services. Incremental costs were measured by the net added costs associated with the provision and utilization of the enhanced service models, from a societal perspective.[45] Incremental uptake and utilization outcomes resulting from exposure to one of the enhanced service linkage models was derived from self-reported behavioral data. The ratio of incremental costs to incremental uptake and utilization outcomes associated with each service model was used to compare the relative cost-effectiveness of each model, measured in United States dollars (USD) per disability-adjusted life years (DALYs) averted.

The REacH randomized experimental evaluation compared a provider-initiated referral and client follow-up model (study arm two); a provider-initiated referral and client follow-up model with an escort to the referral service (study arm three); and existing vertical services model (control). The primary objectives (POs) of the study were to:

- Determine whether provider-initiated referral models increase add-on service uptake compared with an existing vertical service model.

- Determine whether comprehensive provider-initiated referral models are more cost-effective, compared with an existing vertical service model.

In addition to a randomized evaluation of the primary objectives, mixed qualitative and quantitative methods were used to evaluate key secondary objectives (SOs), including to:

- Identify structural and ideational barriers to client uptake and utilization of add-on FP and HIV services among enhanced service and integration models.

- Compare client satisfaction levels and perceptions of service quality across existing and enhanced service and integration models.

- Explore potential client and institutional barriers, including resources limitations and provider attitudes, to scaled-up implementation of experimental service linkage and integration models.

\section{STUDY OUTCOMES}

The primary referral service uptake outcomes that served to assess the primary objectives of this study are listed in Table 1 below. The outcomes were measured for recruited clients, their partners and any of their children aged 15 years and older, if applicable. Uptake was defined as clients or their family members availing themselves of add-on services after being recruited into the study. Whether or not an outcome could be measured for a particular client was dependent upon the entry point at which she or he came for services. For instance, uptake of HTC as a referral service could only be observed among females recruited at FP sites. In addition to being offered at HTC clinics, HTC are also offered as part of routine VMMC services. Therefore, HTC as an add-on service could not be measured among men in the study, because they received such services at initial recruitment entry points, although the outcome could be measured for their spouses or their children aged 15 years and older. 


\begin{tabular}{|c|c|c|c|}
\hline & $\begin{array}{l}\text { Entry points } \\
\text { eligible }\end{array}$ & Gender eligible & Notes \\
\hline \multicolumn{4}{|l|}{ Client outcomes } \\
\hline HIV testing and counselling & $\mathrm{FP}$ & Female & \\
\hline Family planning & HTC & Female & $\begin{array}{l}\text { Among all not pregnant and able to have } \\
\text { children at baseline }\end{array}$ \\
\hline Voluntary medical male circumcision & HTC & Male & \\
\hline Cervical cancer screening & FP, HTC & Female & \\
\hline \multicolumn{4}{|l|}{ HIV \& STI care and treatment outcomes } \\
\hline HIV care and treatment & FP, VMMC, HTC & Male, Female & \\
\hline STI care and treatment & FP, VMMC, HTC & Male, Female & \\
\hline Psychosocial counselling & FP, VMMC, HTC & Male, Female & Among all who got HIV care and treatment \\
\hline TB testing & FP, VMMC, HTC & Male, Female & Among all who got HIV care and treatment \\
\hline CD4 testing & FP, VMMC, HTC & Male, Female & Among all who got HIV care and treatment \\
\hline Initiated ARV & FP, VMMC, HTC & Male, Female & $\begin{array}{l}\text { Among those who were tested for CD4 counts } \\
\text { and were eligible for ARV }\end{array}$ \\
\hline \multicolumn{4}{|l|}{ Partner outcomes } \\
\hline HIV testing and counselling & FP, VMMC, HTC & Male, Female & Among those with primary sex partners \\
\hline Family planning & VMMC, HTC & Male & Among those with primary sex partners \\
\hline Voluntary medical male circumcision & FP, HTC & Female & Among those with primary sex partners \\
\hline Cervical cancer screening & VMMC, HTC & Male & Among those with primary sex partners \\
\hline HIV care and treatment & FP, VMMC, HTC & Male, Female & Among those with primary sex partners \\
\hline STI care and treatment & FP, VMMC, HTC & Male, Female & Among those with primary sex partners \\
\hline \multicolumn{4}{|l|}{ Child outcomes } \\
\hline HIV testing and counselling & FP, VMMC, HTC & Male, Female & Among those with children aged 15 or older \\
\hline Family planning & FP, VMMC, HTC & Male, Female & Among those with children aged 15 or older \\
\hline Voluntary medical male circumcision & FP, VMMC, HTC & Male, Female & Among those with children aged 15 or older \\
\hline Cervical cancer screening & FP, VMMC, HTC & Male, Female & Among those with children aged 15 or older \\
\hline HIV care and treatment & FP, VMMC, HTC & Male, Female & Among those with children aged 15 or older \\
\hline STI care and treatment & FP, VMMC, HTC & Male, Female & Among those with children aged 15 or older \\
\hline
\end{tabular}

The primary outcomes for the client included the uptake of the following add-on services: 1) HTC services; 2) FP services; 3) VMMC services; and 4) cervical cancer screening. These key outcomes were measured for the client and for his/her spouse or partner, as well as any referred child, if appropriate. A second set of outcomes included the uptake of HIV and STI care and treatment services, dependent on a positive HIV test or an assessment of an STI through syndromic diagnosis. Additional, add-on HIV care and treatment services included: 1) participation in a psychosocial support group; 2) tuberculosis (TB) testing; 3) CD4 count testing; and 4) initiation of antiretroviral therapy (ART). Some more detailed measures of HIV care and treatment were not measured, however, for partners and their children aged 15 years and older because detailed reporting of uptake of HIV care and treatment services by the client were not considered reliable.

Additional outcomes, not indicated in Table 1 but presented in the results, were measured for the client in terms of use, behavior, or statuses (e.g., circumcision status). Clients were asked if they had ever been tested for HIV and male clients were asked whether they were circumcised. Female clients were asked details about their use of contraception, including whether they had ever used contraception, whether they were currently using, whether they were currently using modern methods, and whether they were using a long-acting reversible method. All clients' sexual risk behaviors were also observed, including unprotected sex, multiple sexual partners, and total number of sexual partners. Finally, clients were asked about their satisfaction with each of the add-on services they received. 


\section{Study design and methods}

\section{ETHICAL REVIEW}

Study protocols were reviewed and approved by the PSI Institutional Review Board (IRB), Department of Health and Human Services (DHHS) federal wide assurance number FWA00009154, whose established procedures adhere to the U.S. Federal guidelines for human subjects as set forth in the Title 45, Part 46 of the Code of Federal Regulations (Department of Health and Human Services 1991). Human subjects approval was also obtained from the University of Zambia Biomedical Research Ethics Committee (UNZA-BREC) with FWA00000338. Additional approvals were obtained from the Zambia Ministry of Health. All study investigators and staff were certified in human subject protection training prior to study initiation.

\section{STUDY SITES}

\section{Experimental study sites}

A total of seven health service entry-points sites were initially used within two districts in Zambia, Lusaka and Chipata. A table of study service entry points and referral points that were used in the study in both study sites can be found in Appendix Table A1. An additional two entry-point sites were added mid-way through data collection to address low recruitment rates. ${ }^{1}$ The study entry-point sites were selected based on the existence of SFH services and the availability of nearby service sites for each entry and referral point, since proximity was required for the "long-hallway" approximation of integrated service sites.

Each study location originally had three service entry points: 1) an SFH-operated New Start or MOH/MCDMCH HTC center; 2) an SFH- or MOH/MCDMC-operated FP service within a public clinic/hospital; 3) an SFH-operated or partner NGO-operated VMMC service within a public clinic/hospital. As dictated by the services offered at the entry point sites, for the FP sites recruitment was limited to women, while for the VMMC sites recruitment was limited to men. HTC sites, on the other hand, allowed the recruitment of either sex. Client recruitment at each entry point varied significantly. Recruitment at HTC sites was significantly higher than at FP or VMMC sites, despite having a lower proportion of eligible clients willing to participate. Recruitment of men at VMMC sites was slower than expected, which corresponded to national patterns of lower-than-expected demand for VMMC services.

A number of external service locations were also used as primary referral endpoints for add-on services not available within the three types of study sites. These referral sites include SFH-operated integrated service centers, public hospitals/clinics, and partner NGO-run service centers, and all were mapped and located within walking distance of the study's experimental entry point locations. Although the study specified sites for referred services, it is possible that participants recruited into the study instead went to health facilities that were not participating in the study.

\section{External comparator site}

One existing fully-integrated health facility in Lusaka - YWCA - was used to make comparisons of service costs and client outcomes for the cost-effectiveness assessment. No experimental or service intervention was implemented at YWCA, rather clients received the standard integrated service package, including: VMMC, HTC, Couples HTC, LARC and short-term FP methods, syndromic STI management, rapid TB testing, and rapid CD4 count testing using

${ }^{1}$ This issue is discussed further in the Implementation Challenges section of the report. 
PIMA(, an automated, image-based immune hematology test. Costing and client utilization data were gleaned from SFH internal records, while client data were collected using identical baseline, six week and six month interview surveys used at control and experimental sites.

\section{INCLUSION/EXCLUSION CRITERIA}

Inclusion criteria: The following are inclusion criteria for the recruitment of participants in the study:

Presenting at one of the service entry points during the study enrollment period

18 years or older

Sexually active, defined as having sex within the past 12 months

Plan to reside within the study catchment area for the next six months

Exclusion criteria: The following are exclusion criteria for the recruitment of participants in the study:

Unable or unwilling to provide informed consent

Unable or unwilling to provide contact information

Determined not to be eligible based on the inclusion criteria

\section{STUDY ARMS AND INTERVENTIONS}

\section{Study arm 1: Standard of care (control)}

Clients randomized to the control received the existing standard of care of HTC, FP and/or VMMC services offered at the study sites. Given the differing implementation environments, including public health facilities (clinics, hospitals) and NGO managed sites (SFH), the standard of care varied to some degree by type. That said, the existing service model generally included the following elements:

Standard client assessment and counseling

Ad-hoc referrals to add-on services

No transition or linkage between services

No follow-up of clients

For example, with existing services female FP clients could on their own ask a nurse counselor about HTC services and be referred for HIV testing, usually at a nearby NGO-operated service center or through existing government channels; however, no systematic needs assessment on a client-by-client basis was conducted consistently across an array of services. Similarly, HIV-negative male HTC clients could be referred for VMMC services, and HIV-positive HTC and VMMC clients could be referred for TB diagnosis, CD4 count testing, psycho-social support, PMTCT and ART; however, clients were not systematically linked to services and client follow-up was limited if they did not access the services.

\section{Study arm 2: Enhanced referrals with client follow-up (intervention)}

Clients randomized to this group at each study site received comprehensive, provider-initiated, standardized needs assessment and counseling referrals for relevant add-on services. Specific components of this experimental arm included: 
Standardized assessment of need

Dedicated counseling time and informational materials for add-on services

Use of motivational interviewing techniques

Standardized referral

Follow-up of clients

Standardized assessment of need: For each client at each entry point, a standardized assessment tool was used to determine whether the client should receive add-on service sensitization, counseling and referral. The assessment tool provided the counselor a systematic way of assessing need, as well as a method for ensuring that each client received the appropriate service referrals.

Dedicated counseling time and materials: Existing providers were trained to provide sensitization counseling for addon services with the understanding that the time be in addition to that for the entry point service. Appropriate informational and promotional materials for the add-on service were also provided to the client for reflection and further contemplation at home.

Motivational interviewing (MI): Providers in the experimental arms were trained in techniques to engage clients in iterative discussions in which they elicited and addressed structural and ideational barriers to the uptake of relevant add-on services. $\mathrm{Ml}$ is a client-centered and directed approach to behavioral counseling designed to enhance a client's readiness for change by eliciting his/her own motivations by working with clients to address potential barriers to service uptake. MI has been shown to significantly increase client engagement, intention and self-efficacy related to the adoption of new health practices, including utilization of HTC and ART adherence [49-51].

Standardized referral: In the experimental arms every client determined to be eligible for add-on services and who expressed interest received a detailed written and verbal referral with information for relevant add-on service(s) at location(s) within a short distance from the entry point facility.

Client follow-up: If a client failed to appear at the referral facility within seven days of the referral, he or she was contacted via mobile phone within 7 to 14 days. ${ }^{2}$ Clients contacted by phone received reinforced referral counseling using $\mathrm{MI}$ techniques. A "centralized call center" model, built upon an existing collaboration with the Comprehensive HIV/AIDS Management Program (CHAMP) was used to call eligible clients. ${ }^{3}$ PSI/SFH and CHAMP developed a confidential participant call-out protocol to follow up proactively with clients referred for add-on services.

\section{Study arm 3: Enhanced referrals with client follow-up \& escort (intervention)}

Clients randomized to this final group received the same algorithm-based, provider-initiated comprehensive referral counseling described in the first experimental arm, each component using the same protocols. The only difference between this experimental arm and the former is the addition of an escort provided at the entry point site, highlighted below:

- Standardized assessment of need

- Dedicated counseling time and informational materials for add-on services

- Use of motivational interviewing techniques

- Standardized referral

\footnotetext{
${ }^{2}$ Referral calls were made only in cases where clients were referred for services; the calls did not apply to referrals for spouse or children.

${ }^{3}$ CHAMP operates a national toll-free hotline service where trained psycho-social counselors address various health questions from the public using internationally-recognized telephone-counseling techniques and computerized data collection systems.
} 
- Follow-up of clients

\section{- Escort to add-on services}

Escort to add-on services: Clients who were referred for an add-on service and who agreed were provided an escort who would guide them to the referral site. The escort physically walked the client to the add-on service and introduced the client to the site and processes, including registration. For practical and ethical reasons, however, the client did not receive preferential access to add-on services at referral sites. If there were other clients waiting for these services, the study participant was expected to wait. For relevant add-on services not used immediately (e.g., VMMC services for husbands and/or sons aged 15 years and older of FP clients, FP for female partners of VMMC clients), providers encouraged clients to return with the secondary beneficiary to either the entry point for escort to the services or to proceed directly to the referral site.

Randomization procedures: A block randomization scheme, stratified by site was used to randomly assign participants to control and intervention arms to ensure balance across study arms. Participant IDs were generated at assignment to study arm. Upon registration at the study entry-point if a determination of eligibility for research was made, the client name and contact information was entered into a client database. Once registered, the random assignment was revealed to the research staff member who then ensured that the client received the appropriate services.

\section{DATA COLLECTION TOOLS AND INSTRUMENTS}

The sources of data collected as part of the study included: 1) a client information registry and tracking database; 2) quantitative client baseline and follow-up interviews at six weeks and six months; 3) qualitative semi-structured client interviews; 4) qualitative semi-structured provider interviews, and 5) and service implementation cost data.

\section{Client information registry and tracking database (CTD)}

Each study entry and referral site contained a computer with a client information registry and tracking database. The client information registry included the client name, national registration card number (NRC), study identification number, service entry point, contact information, and service voucher IDs. The CTD imputed client service utilization at the entry and referral points. ${ }^{4}$ The CTD included site specific information regarding service uptake and referrals, e.g., visit date, time of visit start, time of visit end and services used. Based on Microsoft SQL architecture, the CTD was synchronized with a central server using USB $3 G / 4 G$ modems so that a single CTD was maintained across all participating sites. The synchronization provided real time information about clients across service sites.

\section{Client baseline interview (CBI)}

All study clients were interviewed by a trained enumerator at the client entry point after recruitment, but prior to service provision. Collected baseline information included socio-demographic characteristics, residential and household information, recent health service utilization, recent sexual behavior, other HIV risk behaviors, selfassessments of health status, recent STD diagnosis, treatment and symptoms; fertility desires and contraceptive use. The baseline interviews were electronically data captured and audio-computer assisted self-interviewing (ACASI) was used for the sexual behavior questions.

\footnotetext{
${ }^{4}$ Due to implementation issues that arose during the course of fieldwork, the quality of information for clients in the standard of care was compromised. The data from the CTD was therefore not used in the analysis of study outcomes presented in this report. More information on this topic is provided in the Implementation Challenges section below.
} 


\section{Client follow-up interviews}

All study clients were tracked at six weeks and six months post-enrollment for a survey interview that included questions about service utilization and uptake at study and non-study health facilities - specifically, use of FP, VMMC, and HIV testing and treatment services obtained; satisfaction with, and associated costs of services. Clients were asked about recent sexual behavior; other HIV risk behaviors; self-assessments of health status; recent STI diagnosis, treatment and symptoms; fertility desires and contraceptive use. The follow-up interviews were electronically data captured and audio-computer assisted self-interviewing (ACASI) was used for the sexual behavior questions. Intensive efforts were made to retain study participants. All participants, regardless of study arm, were provided KW 50 (approximately US $\$ 10$ at the time) to offset the costs of travel and time for participation at follow-up interviews. Participants who failed to return to the clinic for their follow-up visits were called as a reminder of the importance of their scheduled follow-up. Participants were visited at home if they failed to come to the clinic for the follow-up interviews.

\section{QUALITATIVE METHODS}

Qualitative interviews with clients and providers were collected for the purpose of understanding service referral success and failure through a close look at specific cases. Specifically, understanding how and why integration interventions did or did not lead to the uptake of add-on services was sought from both client and provider perspectives. Reflecting the theoretical assumptions about integration, our qualitative samples of both clients and providers were purposively assembled to parallel the larger three-arm study design. By drawing participants from the three study arms - control and two experimental - we sampled for exposure to the intervention rather than for fixed client characteristics.

\section{Qualitative semi-structured client interviews}

A subset of clients drawn randomly from those enrolled in the $\mathrm{REacH}$ evaluation was selected to participate in semistructured qualitative interviews. Interviews were conducted over a six-month period from September 2014 to February 2015. Clients were interviewed six to seven months after their initial visit. Most interviews took place at the study entry site following the completion of the six-month quantitative interview. Those who could not be interviewed at the clinic were interviewed at home.

The interviews were conducted in English, Nyanja, and Bemba by a team of five qualitative interviewers. All interviews were voice-recorded and transcribed verbatim, with simultaneous transcription and translation into English when required.

\section{Qualitative semi-structured provider interviews}

Semi-structured interviews were conducted with providers who participated in the REacH study. All participating providers were invited for an interview; however, at the time of data collection, some providers had been laid off due to lack of funding. Interviews were conducted by one qualitative interviewer in English, Nyanja, and Bemba. All interviews were voice-recorded and transcribed, with simultaneous transcription and translation into English when required.

\section{ECONOMIC EVALUATION}

Economic evaluation, defined as the "comparative analysis of alternative courses of action in terms of both their costs and their consequences," [49] allows planners to make decisions on which interventions to fund based on their 
value for money. By assessing the total costs of inputs for producing an additional unit of service and the effects each unit generates, economic evaluation assists decisions on which programs to prioritize and identifies where technical efficiency gains are to be made.

The economic evaluation of the REacH study comprised two components, described below. The research objectives of the economic evaluation were to:

Estimate the mean costs per patient of the different experimental models. Costs were estimated from the provider perspective.

Undertake standard statistical analysis on client specific cost estimates.

Compare the difference in costs and effects per client served of all trial alternatives.

\section{Component 1: Technical efficiency analysis}

Technical efficiency has to do with minimizing waste in the production of a given service and is achieved when the desired output is produced with the least inputs.[50] The first component of the economic evaluation was conducted to test the hypothesis that the cost-effectiveness of interventions varies depending on whether they are delivered separately or together. In other words, this component of the economic analysis assessed whether SFH could gain in technical efficiency by providing all its services under one roof, as opposed to operating stand-alone, vertical service sites. Our secondary hypothesis was that certain combinations of interventions may be more cost-effective than others. This hypothesis would require that there are cost savings and/or multiplier effects for related health outcomes if interventions are combined.

\section{Component 2: Cost-effectiveness analysis of interventions}

The second component of the economic evaluation comprised a standard cost-effectiveness analysis to assess the value for money of the two intervention arms of the REacH trial compared to the standard of care. In economic evaluation, costs are always expressed in monetary terms but there are a number of options for measuring and valuing effects. A cost-benefit analysis places a monetary value on health effects. In a cost-effectiveness analysis (CEA), health effects are measured in natural units, such as number of infections or deaths, while in a cost-utility (CUA) analysis the outcome measure is expressed in terms of morbidity and mortality combined in a single unit. The two most common units are Quality Adjusted Life Years (QALYs) and Disability Adjusted Life Years (DALYs). Costutility analysis is a broader form of analysis than CEA but still a variant of the same general approach and for this reason it is often discussed under the heading of cost-effectiveness analysis.[51] Cost-utility analysis was therefore used for the second component of the REacH trial economic evaluation, since the health outcomes of interest (HIV infection, onset of AIDS and cervical cancer) predominantly affect morbidity in the short run and DALYs averted by the different interventions can be calculated. 


\section{Analysis methods}

\section{CONSIDERATIONS OF STATISTICAL POWER}

Power analysis was performed to determine the study sample sizes required to statistically assess minimally detectable treatment effects. For each health service domain entry point (FP, HTC, VMCC), a select number of key outcomes indicators for the primary outcomes were specified for the power and sample size estimation. The sample size required for each study entry point depended on the outcome being analyzed, how it was measured, its estimated standard deviation, an estimate of its value at baseline or in the control, and the expectation of treatment effect from the intervention(s). Baseline estimates were based on existing SFH service data or, where available, the 2007 Zambia Demographic and Health Surveys for urban areas in Lusaka and Eastern Province. If data were lacking, qualitative assessments were made to complete the calculations. For the calculations performed, a standard power of 0.80 and a significance level of 0.05 were specified. The sample size was generated for an acceptable minimally detectable effect size for each indicator. ${ }^{5}$ Power calculations were performed such that each of the two experimental arms could be statistically evaluated against the control arm, as well as against each other. The calculations were performed to obtain a conservative estimate statistical power for the study indicators and did not account for covariate controls, which tend to reduce the standard errors of the estimated treatment effects.

\section{QUANTITATIVE EVALUATION OF EXPERIMENTAL DATA}

The REacH study is a client-level randomized evaluation whose design offers a high degree of internal validity for assessing the primary objective by comparison of service uptake and behavioral outcomes for clients across study arms. The randomized design assures the highest degree of rigor and attribution in assessing the impact of experimental treatments on study outcomes. Randomization provides control for both observable and unobservable factors that may affect study outcomes by equally distributing these across both control and treatment groups. If randomization is successful, relatively simple statistical methods can be used to estimate the parameters required to assess intervention impact.

The empirical assessment of the quantitative data was based on an intent-to-treat (ITT) analysis approach. The ITT analysis empirically assessed all cases according to their original randomization whether or not they actually received the services in their assigned arm as per-protocol. In cases where a number of participants crossed-over from arm-to-arm or where there was low compliance to the treatment/intervention, the ITT analysis would differ from a treatment-on-treated (TOT) or per protocol analysis. The ITT analysis is considered to be the more rigorous, albeit more conservative, approach to analyzing randomized trials.[52] ${ }^{6}$ Given that the REacH study implementation staff documented only one cross-over case from the standard of care to one of the intervention arms, in this study, the ITT analysis would be virtually equivalent to the per-protocol analysis. That said, because there was reporting of potential cross-over services in the qualitative data (reviewed below) that may have been undocumented and given that clients vary in the degree to which they were exposed to different components of the intervention due to interest, eligibility and other factors, the ITT analysis is the appropriate statistical approach for assessing impact. ${ }^{7}$

\footnotetext{
${ }^{5}$ As some of the outcome measures could only be experienced by a subgroup of persons, sample sizes were inflated by a factor that accounted for how many people were potentially eligible to experience a particular outcome.

${ }^{6}$ In other words, the ITT is less likely to lead to a Type I hypothesis testing error (rejecting a true null hypothesis that the intervention has no impact), but under certain circumstances more likely to lead to a Type II hypothesis testing error (not rejecting the null hypothesis that the intervention has no impact).

7 The intervention had different components associated with it, including a needs assessment, dedicated counseling time and materials for add-on services, MI techniques, referrals, and follow-up. Clients varied in the ways they were exposed to the experimental services models, with some exposures dependent on previous ones. As a result of the potential selectivity of exposure based on client characteristics, needs, interests, all eligible persons were included in the primary ITT analysis. For example, we did not exclude non-
} 
To assess client characteristics and program impact via the ITT analysis, differences in the means for continuous indicators are assessed using t-tests of significance, while pairwise chi-square tests were used to assess differences between study arms for binary indicators; Fisher's exact test was used as an alternative when cell sizes were small. To explore the data a bit further, logistic regression multivariable models were used to assess treatment impact. The first model included indicators for just the experimental study arms, with the standard of care as reference. A second model was estimated with the experimental arms and site fixed effect indicators to explore whether certain study sites had better outcomes on average than others. Finally, a model that included the experimental arms, site fixed effects, and a limited number of covariates was presented to assess whether the precision of the parameters measuring impact were improved with more information empirically modeled. A separate generalized estimating equations (GEE) analysis was conducted to assess whether within site clustering may have affected the parameter standard errors and statistical tests. As the conclusions that were drawn from the GEE models did not differ in any meaningful way from the more standard statistical assessments, the GEE results were not presented nor discussed further.

The empirical assessment of the primary outcome indicators in Table 1 were based on client interviews that were conducted at approximately six-weeks and six-months. ${ }^{8}$ As discussed above, the analysis was based on the uptake of an array of services and behavior and statuses at each of the follow-up visits. One aspect of the ITT analysis is that it requires that complete information be obtained for all study participants and, as will be noted below in more detail, approximately $20 \%$ of the behavioral data are missing at six-weeks and six-months due to loss-to-follow-up. An assumption is made here, however, that the unobserved data are missing at random, in that it is reasonable to expect that the intervention components did not alter the probability of being observed. We do not believe, therefore, that the missing data impact the inferences drawn from the study conclusions. That said, a sensitivity analysis was conducted using multiple imputation methods for missing values to determine if any conclusions drawn might have changed if the sample were fully observed.

\section{QUALITATIVE ASSESSMENT}

All qualitative data were imported into NVivo version 10 for data management and analysis. For both the provider and client interviews, the lead qualitative researcher reviewed a subset of transcripts and inductively developed preliminary coding frameworks. Two members of the research team then coded the same subsets of transcripts using these frameworks, compared results, added additional codes as necessary, and reached consensus on the client and provider codebooks. Once all of the interviews were coded, the text data were analyzed thematically, with a particular focus on factors affecting uptake and utilization of add-on services. To facilitate descriptive quantitative analysis of the semi-structured interviews, thematically coded data were transformed into binary variables, indicating the presence or absence of a particular event in the participant's responses.

\section{ECONOMIC EVALUATION}

\section{Component 1: Technical efficiency analysis}

Service cost data collection was undertaken alongside trial implementation at six SFH and government-operated FP, VMMC and VCT vertical service entry points. YWCA, an existing SFH-operated site offering fully-integrated FP and HIV

sexually active clients from HTC analysis, nor those clients not reporting an unmet need from the FP analysis. Sub-group analyses were conducted and provided in Appendix Table A6, but similar to treatment-on-the-treated analysis, they need to be interpreted with caution.

${ }^{8}$ In the study protocol, the primary analysis was originally based on data from both the CTD and the behavioral survey data. Due to issues that arose during study implementation, discussed in subsequent sections, only the behavioral data were relied on to draw inferences about program impact. 
services, was included to obtain operational costs estimates for an external comparator of an integrated service site. The services costed at each site are summarized in Table 2.

TABLE 2 Description of service sites and services costed

\begin{tabular}{|c|c|c|c|c|c|}
\hline Service site & Ownership & Type & Service & Location & Cost data collected \\
\hline YWCA & SFH & Standalone & HTC, VMMC, FP & Lusaka & As below for specific services \\
\hline Cairo & SFH & Entry & HTC & Lusaka & Consultation plus test \\
\hline ChaChaCha & SFH & Entry & VMMC & Lusaka & $\begin{array}{l}\text { Full procedure plus review } \\
\text { consultation }\end{array}$ \\
\hline Chawama & SFH & Entry & $\mathrm{FP}$ & Lusaka & Full procedure \\
\hline Chawama & Gov & Referral & CD4 & Lusaka & Consultation plus test \\
\hline Chawama & Gov & Referral & $\begin{array}{l}\text { HIV Care and } \\
\text { Treatment }\end{array}$ & Lusaka & Consultation only minus cost of test \\
\hline Chawama & Gov & Referral & TB testing & Lusaka & $\begin{array}{l}\text { Consultation plus sputum smear } \\
\text { microscopy* }\end{array}$ \\
\hline Chawama & Gov & Referral & STI treatment & Lusaka & Consultation only \\
\hline Chawama & Gov+NGO & Referral & $\begin{array}{l}\text { Cervical cancer } \\
\text { Screening }\end{array}$ & Lusaka & Consultation plus test \\
\hline New Start Platform & SFH & Entry & HTC & Chipata & Consultation plus test \\
\hline Kapata & Gov & Entry & $\mathrm{FP}$ & Chipata & Full procedure \\
\hline Chipata GH & Gov & Entry & VMMC & Chipata & Full Procedure + review consultation \\
\hline
\end{tabular}

*US\$ 0.26 per sputum smear microscopy. Source: [53]

Client-specific resource utilization data were collected from the trial client tracking database for HCT, FP and VMMC. Data on the uptake of add-on services, including cervical cancer screening (CCS) and HIV care and treatment services, were used to calculate estimated disability-adjusted life years (DALYs) averted as a result of exposure to each experimental and control service linkage and integration intervention.

The health outcomes for the calculation of DALYs averted by the trial interventions include HIV infections averted and deaths averted from AIDS and from cervical cancer. Primary uptake and utilization outcomes were converted into net DALY gains for each experimental intervention arm using the following formula:

DALYs averted $=\Delta Y L L s+\Delta Y L D s$, where

$$
\begin{gathered}
\Delta Y L D(x)=\sum_{t} \sum_{i} N_{t i} * w_{i} *(1-d)^{1-t} \\
\Delta Y L L(x)=\sum_{t} \sum_{a} D_{t a} * L E_{a} *(1-d)^{1-t}
\end{gathered}
$$

$\begin{array}{lll}\mathbf{X}=\text { intervention arm } & \mathbf{N}=\text { number alive } & \mathbf{D}=\text { number deaths } \\ \mathbf{i}=\text { health state } & \mathbf{a}=\text { age } & \mathrm{t}=\text { year } \\ \mathbf{W}=\text { disability weight } & \mathbf{d}=\text { discount rate } & \text { LE = life expectancy }\end{array}$

According to Murray and Lopez: "one DALY can be thought of as one lost year of healthy life and the burden of disease as a measure of the gap between current health status and an ideal situation where everyone lives into old age free from disease and disability."[54] DALYs are thus the sum of years of life lost due to premature mortality 
(YLL) and the equivalent 'healthy' years lost due to disability (YLD). Discounted YLLs, reflecting the higher value placed by society on health gains accrued at the present time rather than in the future, were calculated as the sum of expected deaths in the Zambian population over time based on the life expectancy in different age groups. Discounted YLDs were calculated as the sum of the years lost by the Zambian population due to the disability caused by the outcomes of interest (HIV infection, onset of AIDS and cervical cancer). The number of Zambians experiencing different health states at time $t$ was calculated based on the incidence and mortality estimates for the outcomes of interest as well as the probability of treatment success and mortality and morbidity reduction from the different interventions, summarised in Table 3.

The disability weights used for symptomatic pre-AIDS HIV, AIDS with and without ART, and cancer (diagnosis and primary therapy) were from the Global Burden of Disease Study 2010. Discounted DALY measures and projected lifetime treatment costs derived
TABLE 3 DALY model parameter assumptions

\begin{tabular}{|c|c|c|c|}
\hline Parameter & \multicolumn{2}{|c|}{ Assumption } & \multirow{2}{*}{$\begin{array}{l}\text { Source } \\
\text { WHO recommendation }\end{array}$} \\
\hline Discount rate & & 0.03 & \\
\hline HIV incidence in Zambian pop. & Male & Female & $\begin{array}{l}\text { UNAIDS Zambia } \\
2014[55]\end{array}$ \\
\hline $15-24$ & $0.45 \%$ & $0.98 \%$ & \\
\hline $25-29$ & $0.01 \%$ & $0.05 \%$ & \\
\hline $30-34$ & $0.00 \%$ & $0.00 \%$ & \\
\hline $35-39$ & $0.00 \%$ & $0.01 \%$ & \\
\hline $40+$ & $0.00 \%$ & $0.01 \%$ & \\
\hline HIV mortality (no ART) & & 0.0214 & Lozano 2012[56] \\
\hline \multicolumn{4}{|l|}{ Incidence reduction from $\mathrm{HCT}$} \\
\hline Discordant couple & & $74.00 \%$ & Allen 2014[57] \\
\hline M-F couple & & $91.00 \%$ & Allen 2014[57] \\
\hline Mortality reduction from ART & & $11.40 \%$ & $\begin{array}{l}\text { UNAIDS Zambia } \\
2014[55]\end{array}$ \\
\hline ART coverage & & $90.00 \%$ & $\begin{array}{l}\text { UNAIDS Zambia } \\
2014[55]\end{array}$ \\
\hline \multicolumn{3}{|l|}{ Prevalence reduction from VMMC } & \multirow{6}{*}{$\begin{array}{l}\text { UNAIDS Zambia } \\
2014[55]\end{array}$} \\
\hline $15-24$ & & $1.10 \%$ & \\
\hline $25-29$ & & $-7.00 \%$ & \\
\hline $30-34$ & & $2.30 \%$ & \\
\hline $35-39$ & & $13.70 \%$ & \\
\hline $40+$ & & $22.90 \%$ & \\
\hline Cervical cancer incidence & & 0.09 & $\begin{array}{l}\text { Sankanarayanan } \\
2006[58]\end{array}$ \\
\hline Cervical cancer mortality & & 0.04 & $\begin{array}{l}\text { Sankanarayanan } \\
2006[58]\end{array}$ \\
\hline Mortality reduction from CCS & & $81.00 \%$ & Mandelblatt 2002[59] \\
\hline
\end{tabular}

from these intermediate outcomes were used to calculate incremental cost-effectiveness ratios, which provide forthright cost comparisons between the experimental and control service models. 


\section{Study results}

\section{SAMPLE}

As can be observed in Table 4, 3,963 men and women were recruited to participate in the study. Approximately $42 \%$ of the sample was recruited from health facilities in Lusaka, and $58 \%$ of clients recruited from the Chipata health facilities. A total of 2,043 women (representing $52 \%$ of the sample) were recruited from FP and HTC sites, while a total of 1,920 men (representing $48 \%$ of sample) were recruited from VMMC and HTC sites. While the absolute number of women recruited to participate was nearly equally divided between FP and HTC sites, only $27 \%$ of the men recruited to participate in REacH came from VMMC sites, with the remainder coming from the study HTC sites. The proportion of men from VMMC sites was significantly below the $47 \%$ estimated for the sample prior to the initiation of recruitment. ${ }^{9} \mathrm{~A}$ total of 205 participants were recruited from the YWCA comparator site.

TABLE 4 Study recruitment rates by site and entry point

\begin{tabular}{rccc|ccc|ccc|ccc}
\hline & \multicolumn{3}{c|}{ Lusaka } & \multicolumn{3}{c|}{ Chipata } & \multicolumn{3}{c|}{ Total experimental } & \multicolumn{3}{c}{ External comparator } \\
& Male & Female & Total & Male & Female & Total & Male & Female & Total & Male & Female & Total \\
\hline FP & 0 & 489 & 489 & 0 & 545 & 545 & 0 & 1,034 & 1,034 & 0 & 68 & 68 \\
HTC & 525 & 394 & 919 & 873 & 615 & 1,488 & 1,398 & 1,009 & 2,407 & 44 & 24 & 68 \\
VMMC & 245 & 0 & 245 & 277 & 0 & 277 & 522 & 0 & 522 & 69 & 0 & 69 \\
Total & 770 & 883 & 1,653 & 1,150 & 1,160 & 2,310 & 1,920 & $\mathbf{2 , 0 4 3}$ & $\mathbf{3 , 9 6 3}$ & 113 & 92 & $\mathbf{2} 205$ \\
\hline
\end{tabular}

REacH study participants were block randomized to one of the three study arms at each of the participating sites. ${ }^{10}$ The distribution of participants included 1,319 participants who were recruited to the standard of care or control arm (study arm 1), 1,323 recruited to the enhanced services with follow-up (study arm 2) and 1,321 in the enhanced services with follow-up and escort (study arm 3). In addition to the study experimental sample, a total of 205 clients were recruited at the external YWCA comparator site, a fully-integrated health facility. As discussed above, these clients were not part of the experimental evaluation and hence were not randomized to receive any intervention. Of the clients recruited, $92(45 \%)$ were women and $113(55 \%)$ were men. Of the women, approximately $74 \%$ were recruited through FP services, while $26 \%$ were recruited from HTC services, $61 \%$ of the men were recruited from VMMC services and 39\% through HTC services.

\section{SAMPLE CHARACTERISTICS}

\section{Baseline demographic characteristics by sex}

Table 5 provides an overview of the demographic characteristics of the sample, by participant sex. The mean age of study participants was 26.5 years of age, with a slightly younger sample of males (26.1) than females (26.8). This difference may be attributable to the fact that younger men are more apt to receive male circumcision services than are older men in Zambia. This observation is also reflected in the age group breakdown, as the majority of male participants are in the 18-24 age range (51\%), with a decreasing prevalence of men across the remaining age

\footnotetext{
${ }^{9}$ The issue of recruitment at VMMC sites is discussed more thoroughly in the Implementation Challenges section of the report.

10 The randomization blocks were of size 9 , with a third of each block assigned to one of the three study arms. There are a total of 84 possible combinations of block assignments. The assignment to study arm was blinded to research staff and only revealed after the client information was recorded in the client database.
} 
ranges. A similar pattern is observed for females, with the plurality of females seeking FP and HTC services (44\%) coming from the youngest age group and only $5 \%$ of participants aged 40 years or older. Males are also more likely to currently attend school (29\%), relative to females (14\%). This fact is likely driven by the gender differences observed in schooling attainment at secondary and tertiary levels,[3] as well as the fact that a larger number of males in the study are younger and therefore of school-going age, particularly at the tertiary level. The mean grade of schooling attainment is nine, which is one year into secondary school in Zambia. Males on average were more likely to have entered secondary than were females, with the latter having a mean years of attainment of eight compared with a mean grades of attainment for males over ten. ${ }^{11}$

${ }^{11}$ The school system in Zambia includes seven years of primary, with an exam determining placement in secondary. This is followed by two years of junior secondary, with an exam determining placement in senior secondary. 
TABLE 5 Baseline demographic characteristics of study participants by sex (percentages unless otherwise indicated)

\begin{tabular}{|c|c|c|c|}
\hline & Males & Females & Total \\
\hline Sample size & 1,920 & 2,043 & 3,963 \\
\hline Mean age in years & 26.1 & 26.8 & 26.5 \\
\hline \multicolumn{4}{|l|}{ Age groups } \\
\hline $18-24$ & 51.0 & 44.8 & 47.8 \\
\hline $25-29$ & 22.4 & 23.8 & 23.1 \\
\hline $30-34$ & 13.6 & 17.2 & 15.5 \\
\hline $35-39$ & 7.9 & 9.3 & 8.6 \\
\hline $40+$ & 5.1 & 4.8 & 4.9 \\
\hline \multicolumn{4}{|l|}{ Schooling } \\
\hline Currently attending & 28.7 & 13.9 & 21.1 \\
\hline Mean grade completed & 10.4 & 8.0 & 9.2 \\
\hline \multicolumn{4}{|l|}{ Marital status } \\
\hline Never married & 58.9 & 23.7 & 40.7 \\
\hline Currently married/living with partner & 31.1 & 63.8 & 48.0 \\
\hline Divorced/separated/widowed & 10.0 & 12.5 & 11.3 \\
\hline \multicolumn{4}{|l|}{ Among unmarried, has regular sexual partnera } \\
\hline No & 33.6 & 29.6 & 32.2 \\
\hline Yes & 66.4 & 70.4 & 67.8 \\
\hline Mean number of biological children & 1.0 & 2.5 & 1.8 \\
\hline \multicolumn{4}{|l|}{ Residence } \\
\hline Urban & 93.2 & 95.4 & 94.4 \\
\hline Rural & 6.8 & 4.6 & 5.6 \\
\hline \multicolumn{4}{|l|}{ Tribe } \\
\hline Lozi & 3.2 & 3.5 & 3.4 \\
\hline Ngoni & 28.5 & 32.7 & 30.6 \\
\hline Tonga & 5.5 & 5.4 & 5.4 \\
\hline Bemba & 13.5 & 14.2 & 13.8 \\
\hline Other & 49.3 & 44.3 & 46.7 \\
\hline \multicolumn{4}{|l|}{ Religion } \\
\hline Catholic & 21.3 & 17.0 & 19.1 \\
\hline Christian & 72.9 & 78.9 & 76.0 \\
\hline Other & 5.8 & 4.1 & 4.9 \\
\hline \multicolumn{4}{|l|}{ Employment status } \\
\hline Not working & 43.6 & 63.8 & 54.0 \\
\hline Currently working & 56.4 & 36.2 & 46.0 \\
\hline Mean number of household assets (0-15) & 8.3 & 7.1 & 7.7 \\
\hline \multicolumn{4}{|l|}{ Household assets } \\
\hline Lowest quintile & 16.4 & 28.0 & 22.4 \\
\hline Middle quintiles & 69.1 & 64.1 & 66.5 \\
\hline Highest quintile & 14.5 & 7.9 & 11.1 \\
\hline \multicolumn{4}{|l|}{ Has own mobile phone } \\
\hline No & 12.4 & 21.4 & 17.1 \\
\hline Yes & 87.6 & 78.6 & 82.9 \\
\hline \multicolumn{4}{|l|}{ Type of water source } \\
\hline Piped & 81.9 & 79.9 & 80.9 \\
\hline Well/Spring & 8.9 & 9.5 & 9.2 \\
\hline Borehole & 8.9 & 9.6 & 9.3 \\
\hline Other & 0.3 & 1.0 & 0.7 \\
\hline Mean time to water source (minutes) & 2.7 & 3.0 & 2.9 \\
\hline \multicolumn{4}{|l|}{ Type of transport to health facility } \\
\hline Walking & 60.6 & 59.7 & 60.1 \\
\hline Bicycle & 5.9 & 2.3 & 4.0 \\
\hline Bus & 30.6 & 37.0 & 33.9 \\
\hline Car/Taxi & 2.9 & 1.1 & 2.0 \\
\hline Mean distance to health facilityb & 4.7 & 2.7 & 3.8 \\
\hline
\end{tabular}

Note: All tests are chi-square for categorical outcomes or t-tests for continuous outcomes, unless otherwise noted.

a Those who are living together considered "married".

b $38 \%$ don't know distance, are missing on this variable. 
Differences in were also observed between males and females in marital status and current sexual relationship status at baseline. For instance, nearly two out of three females were currently married or living with their partners, and three out of four had ever been married. The majority of males (59\%), however, had never been married and $41 \%$ had ever been married. Women who were unmarried were also more likely to have a regular sexual partner $(70 \%)$ compared to unmarried men (66\%). As with education, the distribution was driven by broader demographic differences between males and females in the age of marriage[3], as well as the younger cohort of males in the study. These relationship patterns were further reflected in the significantly higher mean number of children ever born to females, with males having only one child on average and female participants having more than two children on average.

Additional demographic characteristics show less difference between the male and female study participants. For instance, similar distributions are observed for urban and rural residence, with a prevalence of $94 \%$ of the study sample living in urban areas. Ethnic (tribal) and religious differences were also relatively minor with a significant array of tribal groups represented; the most prominent were Ngoni at 31\%. The overwhelming majority of participants were Christian, with nearly one in five Christians being Catholic. Differences between males and females in working for pay were observed, with more than a majority of males and a third of females working for cash. Males were also more likely to own a large number of household assets ( 8 versus 7 on average), have a higher prevalence in the highest quintile of assets (15\% versus $8 \%$ ) and own their own mobile phone ( $88 \%$ versus $79 \%)$. No differences, however, are observed how clients came to the clinic on the day of recruitment, with $60 \%$ walking and the largest percentage of the remainder taking a minibus. It does seem, however, that men traveled about $2 \mathrm{~km}$ longer on average than did females to come to the health facility.

\section{Baseline demographic characteristics by study arm}

Table 6 presents a breakdown of participant demographic characteristics by sex and study arm and shows a statistical assessment of whether there were significant differences in the participant characteristics across arms by sex. The randomization and the large sample size were expected to distribute the client characteristics evenly by study arm and any differences observed that are significant were expected to be due to chance. ${ }^{12}$ Given that assignment to study arm was only revealed to study staff after the client was registered in the client database, there is a high degree of confidence that systematic reassignment of participants did not occur in the study implementation. The success of the randomization process is displayed for observed client characteristics, as shown in Table 6.

${ }^{12}$ For instance, with 18 indicators and a statistical significance of $p<.05$, one would expect at least one indicator to be significant $60 \%$ of the time. 
TABLE 6 Baseline demographic characteristics of study participants by sex and study arm (percentages unless otherwise indicated)

\begin{tabular}{|c|c|c|c|c|c|c|c|c|c|c|c|c|c|c|c|}
\hline \multirow[b]{2}{*}{ Arm } & \multicolumn{4}{|c|}{ Male } & \multicolumn{4}{|c|}{ Female } & \multicolumn{4}{|c|}{ Total } & \multicolumn{3}{|c|}{ Tests } \\
\hline & $\begin{array}{c}1 . \\
\text { Standard } \\
\text { of care }\end{array}$ & $\begin{array}{c}2 . \\
\text { Enhanced } \\
\text { referral }\end{array}$ & $\begin{array}{c}3 . \\
\text { Enhanced } \\
\text { referral \& } \\
\text { escort }\end{array}$ & $\begin{array}{l}\text { Total } \\
\text { sample }\end{array}$ & $\begin{array}{c}1 . \\
\text { Standard } \\
\text { of care }\end{array}$ & $\begin{array}{c}2 . \\
\text { Enhanced } \\
\text { referral }\end{array}$ & $\begin{array}{c}3 . \\
\text { Enhanced } \\
\text { referral \& } \\
\text { escort }\end{array}$ & $\begin{array}{l}\text { Total } \\
\text { sample }\end{array}$ & $\begin{array}{c}1 . \\
\text { Standard } \\
\text { of care }\end{array}$ & $\begin{array}{c}2 . \\
\text { Enhanced } \\
\text { referral }\end{array}$ & $\begin{array}{c}3 . \\
\text { Enhanced } \\
\text { referral \& } \\
\text { escort }\end{array}$ & $\begin{array}{l}\text { Total } \\
\text { sample }\end{array}$ & Males & Females & Total \\
\hline Sample size & 641 & 638 & 641 & 1,920 & 678 & 685 & 680 & 2,043 & 1,319 & 1,323 & 1321 & 3,963 & 1920 & 2043 & 3963 \\
\hline Mean age in years & 26.0 & 26.4 & 26.0 & 26.1 & 27.0 & 26.7 & 26.9 & 26.8 & 26.5 & 26.5 & 26.4 & 26.5 & & & \\
\hline \multicolumn{16}{|l|}{ Age groups } \\
\hline $18-24$ & 52.9 & 49.8 & 50.2 & 51.0 & 45.1 & 43.8 & 45.6 & 44.8 & 48.9 & 46.7 & 47.8 & 47.8 & & & \\
\hline $25-29$ & 20.3 & 21.8 & 25.1 & 22.4 & 22.9 & 25.8 & 22.8 & 23.8 & 21.6 & 23.9 & 23.9 & 23.1 & & & \\
\hline $30-34$ & 13.6 & 15.4 & 12.0 & 13.6 & 17.6 & 17.2 & 16.9 & 17.2 & 15.6 & 16.3 & 14.5 & 15.5 & & & \\
\hline $35-39$ & 8.0 & 7.4 & 8.4 & 7.9 & 9.3 & 9.3 & 9.1 & 9.3 & 8.6 & 8.4 & 8.8 & 8.6 & & & \\
\hline $40+$ & 5.3 & 5.6 & 4.2 & 5.1 & 5.2 & 3.8 & 5.6 & 4.8 & 5.2 & 4.7 & 4.9 & 4.9 & & & \\
\hline \multicolumn{16}{|l|}{ Schooling } \\
\hline Currently attending & 29.0 & 26.8 & 30.4 & 28.7 & 17.1 & 12.1 & 12.4 & 13.9 & 22.9 & 19.2 & 21.1 & 21.1 & & $A * *, B *$ & $A^{*}$ \\
\hline Mean grade completed & 10.3 & 10.6 & 10.3 & 10.4 & 8.0 & 8.0 & 8.0 & 8.0 & 9.1 & 9.2 & 9.1 & 9.2 & & & \\
\hline \multicolumn{16}{|l|}{ Marital status } \\
\hline Never married & 59.1 & 59.1 & 58.3 & 58.9 & 25.1 & 24.2 & 21.8 & 23.7 & 41.7 & 41.0 & 39.5 & 40.7 & & & \\
\hline $\begin{array}{l}\text { Currently married/living with } \\
\text { partner }\end{array}$ & 32.1 & 31.5 & 29.8 & 31.1 & 63.8 & 62.5 & 65.1 & 63.8 & 48.4 & 47.5 & 48.0 & 48.0 & & & \\
\hline Divorced/separated/widowed & 8.7 & 9.4 & 11.9 & 10.0 & 11.1 & 13.3 & 13.1 & 12.5 & 9.9 & 11.4 & 12.5 & 11.3 & & & \\
\hline $\begin{array}{l}\text { Among unmarried, has } \\
\text { regular sexual partner }\end{array}$ & & & & & & & & & & & & & $\mathrm{C}+$ & & $A \dagger, C^{*}$ \\
\hline No & 34.7 & 30.2 & 35.8 & 33.6 & 30.9 & 26.8 & 31.2 & 29.6 & 33.3 & 28.9 & 34.2 & 32.2 & & & \\
\hline Yes & 65.3 & 69.8 & 64.2 & 66.4 & 69.1 & 73.2 & 68.8 & 70.4 & 66.7 & 71.1 & 65.8 & 67.8 & & & \\
\hline $\begin{array}{l}\text { Mean number of } \\
\text { biological children }\end{array}$ & 1.0 & 1.1 & 1.0 & 1.0 & 2.5 & 2.4 & 2.5 & 2.5 & 1.8 & 1.8 & 1.7 & 1.8 & & & \\
\hline \multicolumn{16}{|l|}{ Residence } \\
\hline Urban & 92.5 & 93.9 & 93.3 & 93.2 & 95.6 & 95.3 & 95.4 & 95.4 & 94.1 & 94.6 & 94.4 & 94.4 & & & \\
\hline Rural & 7.5 & 6.1 & 6.7 & 6.8 & 4.4 & 4.7 & 4.6 & 4.6 & 5.9 & 5.4 & 5.6 & 5.6 & & & \\
\hline Tribe & & & & & & & & & & & & & $\mathrm{B} \dagger$ & & \\
\hline Lozi & 2.8 & 3.1 & 3.7 & 3.2 & 3.5 & 2.9 & 4.0 & 3.5 & 3.2 & 3.0 & 3.9 & 3.4 & & & \\
\hline Ngoni & 28.7 & 26.5 & 30.3 & 28.5 & 33.6 & 32.6 & 31.8 & 32.7 & 31.2 & 29.6 & 31.1 & 30.6 & & & \\
\hline Tonga & 4.7 & 5.6 & 6.1 & 5.5 & 5.0 & 6.3 & 4.9 & 5.4 & 4.9 & 6.0 & 5.5 & 5.4 & & & \\
\hline Bemba & 12.0 & 13.3 & 15.1 & 13.5 & 12.5 & 16.1 & 13.8 & 14.2 & 12.3 & 14.7 & 14.5 & 13.8 & & & \\
\hline Other & 51.8 & 51.4 & 44.8 & 49.3 & 45.3 & 42.2 & 45.5 & 44.3 & 48.4 & 46.6 & 45.2 & 46.7 & & & \\
\hline Religion & & & & & & & & & & & & & A $\dagger$ & & $A^{*}$ \\
\hline Catholic & 20.3 & 23.8 & 19.8 & 21.3 & 17.6 & 17.1 & 16.3 & 17.0 & 18.9 & 20.3 & 18.0 & 19.1 & & & \\
\hline Christian & 75.4 & 69.7 & 73.6 & 72.9 & 78.9 & 77.7 & 80.1 & 78.9 & 77.2 & 73.8 & 77.0 & 76.0 & & & \\
\hline Other & 4.4 & 6.4 & 6.6 & 5.8 & 3.5 & 5.3 & 3.5 & 4.1 & 3.9 & 5.8 & 5.0 & 4.9 & & & \\
\hline \multicolumn{16}{|l|}{ Employment status } \\
\hline Not working & 43.8 & 42.0 & 45.1 & 43.6 & 65.1 & 62.0 & 64.3 & 63.8 & 54.8 & 52.3 & 55.0 & 54.0 & & & \\
\hline Currently working & 56.2 & 58.0 & 54.9 & 56.4 & 34.9 & 38.0 & 35.7 & 36.2 & 45.2 & 47.7 & 45.0 & 46.0 & & & \\
\hline $\begin{array}{l}\text { Mean number of } \\
\text { household assets (0-15) }\end{array}$ & 8.4 & 8.2 & 8.2 & 8.3 & 7.2 & 7.1 & 7.0 & 7.1 & 7.8 & 7.6 & 7.6 & 7.7 & & & \\
\hline
\end{tabular}


TABLE 6 Baseline demographic characteristics of study participants by sex and study arm (percentages unless otherwise indicated) (con't)

\begin{tabular}{|c|c|c|c|c|c|c|c|c|c|c|c|c|c|c|c|}
\hline \multirow[b]{2}{*}{ Arm } & \multicolumn{4}{|c|}{ Male } & \multicolumn{4}{|c|}{ Female } & \multicolumn{4}{|c|}{ Total } & \multicolumn{3}{|c|}{ Tests } \\
\hline & $\begin{array}{c}1 . \\
\text { Standard } \\
\text { of care }\end{array}$ & $\begin{array}{c}2 . \\
\text { Enhanced } \\
\text { referral }\end{array}$ & $\begin{array}{l}3 . \\
\text { Enhanced } \\
\text { referral \& } \\
\text { escort }\end{array}$ & $\begin{array}{c}\text { Total male } \\
\text { sample }\end{array}$ & $\begin{array}{c}1 . \\
\text { Standard } \\
\text { of care }\end{array}$ & $\begin{array}{c}2 . \\
\text { Enhanced } \\
\text { referral }\end{array}$ & $\begin{array}{l}3 . \\
\text { Enhanced } \\
\text { referral \& } \\
\text { escort }\end{array}$ & $\begin{array}{l}\text { Total } \\
\text { female } \\
\text { sample }\end{array}$ & $\begin{array}{c}1 . \\
\text { Standard } \\
\text { of care }\end{array}$ & $\begin{array}{c}2 . \\
\text { Enhanced } \\
\text { referral }\end{array}$ & $\begin{array}{l}3 . \\
\text { Enhanced } \\
\text { referral \& } \\
\text { escort }\end{array}$ & $\begin{array}{l}\text { Total } \\
\text { sample }\end{array}$ & Males & Females & Total \\
\hline Sample size & 641 & 638 & 641 & 1,920 & 678 & 685 & 680 & 2,043 & 1,319 & 1,323 & 1,321 & 3,963 & 1,920 & 2,043 & 3,963 \\
\hline $\begin{array}{l}\text { Mean number of } \\
\text { Household assets }(0-15)\end{array}$ & 8.4 & 8.2 & 8.2 & 8.3 & 7.2 & 7.1 & 7.0 & 7.1 & 7.8 & 7.6 & 7.6 & 7.7 & & & \\
\hline \multicolumn{16}{|l|}{ Household assets } \\
\hline Lowest quintile & 15.8 & 17.6 & 15.9 & 16.4 & 27.1 & 27.6 & 29.4 & 28.0 & 21.6 & 22.8 & 22.9 & 22.4 & & & \\
\hline Middle quintiles & 69.0 & 69.7 & 68.6 & 69.1 & 64.5 & 64.7 & 63.1 & 64.1 & 66.6 & 67.1 & 65.8 & 66.5 & & & \\
\hline Highest quintile & 15.3 & 12.7 & 15.4 & 14.5 & 8.4 & 7.7 & 7.5 & 7.9 & 11.8 & 10.1 & 11.4 & 11.1 & & & \\
\hline Has own mobile phone & & & & & & & & & & & & & & $c+$ & \\
\hline No & 12.2 & 12.5 & 12.6 & 12.4 & 21.1 & 19.6 & 23.5 & 21.4 & 16.8 & 16.2 & 18.2 & 17.1 & & & \\
\hline Yes & 87.8 & 87.5 & 87.4 & 87.6 & 78.9 & 80.4 & 76.5 & 78.6 & 83.2 & 83.8 & 81.8 & 82.9 & & & \\
\hline Type of water source & & & & & & & & & & & & & $A^{*}$ & & $A^{*}$ \\
\hline Piped & 82.4 & 79.9 & 83.3 & 81.9 & 80.5 & 79.6 & 79.7 & 79.9 & 81.4 & 79.7 & 81.4 & 80.9 & & & \\
\hline Well/spring & 7.2 & 11.4 & 8.1 & 8.9 & 8.8 & 9.9 & 9.7 & 9.5 & 8.0 & 10.7 & 8.9 & 9.2 & & & \\
\hline Borehole & 10.3 & 8.3 & 8.1 & 8.9 & 9.9 & 8.9 & 10.0 & 9.6 & 10.1 & 8.6 & 9.1 & 9.3 & & & \\
\hline Otherb & 0.2 & 0.3 & 0.5 & 0.3 & 0.7 & 1.6 & 0.6 & 1.0 & 0.5 & 1.0 & 0.5 & 0.7 & & & \\
\hline $\begin{array}{l}\text { Mean time to water source } \\
\text { (min) }\end{array}$ & 2.5 & 2.6 & 2.9 & 2.7 & 3.2 & 3.2 & 2.8 & 3.0 & 2.8 & 2.9 & 2.9 & 2.9 & & & \\
\hline $\begin{array}{l}\text { Type of transport to health } \\
\text { facility }\end{array}$ & & & & & & & & & & & & & & $A^{*}$ & $\mathrm{~A} \dagger$ \\
\hline Walking & 59.4 & 59.7 & 62.8 & 60.6 & 62.2 & 56.9 & 59.9 & 59.7 & 60.8 & 58.2 & 61.3 & 60.1 & & & \\
\hline Bicycle & 5.3 & 6.9 & 5.5 & 5.9 & 2.5 & 2.2 & 2.2 & 2.3 & 3.9 & 4.5 & 3.8 & 4.0 & & & \\
\hline Bus & 31.5 & 30.9 & 29.3 & 30.6 & 33.7 & 40.2 & 37.0 & 37.0 & 32.6 & 35.7 & 33.2 & 33.9 & & & \\
\hline Car/taxi & 3.7 & 2.5 & 2.5 & 2.9 & 1.6 & 0.7 & 0.9 & 1.1 & 2.7 & 1.6 & 1.7 & 2.0 & & & \\
\hline $\begin{array}{l}\text { Mean distance to health } \\
\text { facilityc }^{c}\end{array}$ & 4.7 & 5.1 & 4.3 & 4.7 & 2.9 & 2.8 & 2.4 & 2.7 & 3.9 & 4.0 & 3.5 & 3.8 & & $\mathrm{~B} \dagger$ & $\mathrm{C} \dagger$ \\
\hline
\end{tabular}

$* * * p<.001 ; * * p<.01 ; * \mathrm{p}<.05 ; \dagger \mathrm{p}<.10$

$A=\operatorname{Arms~} 1 \& 2, B=$ Arms $1 \& 3, C=$ Arms $2 \& 3$

a Those who are living together considered "married."

"Excluded from analysis due to small sample size.

c $38 \%$ don't know distance, are missing on this variable. 
As expected, for most indicators the differences are marginal, in magnitude of a few percentage points. The test statistics show no systematic differences across the study arms. Only four of the eighteen indicators in the "Total" sample (males and females combined) are significantly different at the $p<.05$ level. The control arm has a slightly higher prevalence (by nearly 4\%) of participants attending school compared to study arm 2, a marginally smaller (by $2 \%$ ) number of non-Christians and a slightly higher prevalence (by about $2 \%$ ) of participants whose house has piped water. Finally, the two experimental arms differ by $5 \%$ on whether an unmarried client had a regular sexual partner. There are also few systematic differences in the indicators of statistical significance for the male and female sample separately, with only two indicators (currently enrolled in school, type of transport to health facility) for females and one indicator (type of water source) significantly different across arms at the $p<.05$ level. Overall these significant differences are likely due to chance alone and provide confidence in the equivalency in baseline demographic characteristics across the study arms.

\section{Baseline characteristics by study entry point}

As the REacH study recruited from three different entry points (FP, VMMC, HTC), it is likely that the clients entering the sites varied by characteristics that are informative. For instance, as can be observed in Table 7, women recruited from FP clinics had markedly different fertility intentions than women recruited at HTC centers. Clients at FP sites were significantly more likely to want no more children than women at HTC sites (36\% versus $29 \%$ ). The difference in fertility intentions for males was also significantly different by HTC and VMMC entry point, despite not being directly related to the entry point services. These differences in fertility intentions for men were likely due to the sample composition of men recruited, with those at VMMC sites being on average younger (24 years of age) than those at the HTC sites (27 years of age). ${ }^{13}$ This is reflected by the fact that more than twice the number of men at VMMC sites reported they were undecided about having additional children.

${ }^{13}$ Baseline demographic characteristics by sex and entry-point service are provided in Appendix Table A2. 
TABLE 7 Baseline characteristics of study participants by study entry point (percentages unless otherwise indicated)

\begin{tabular}{|c|c|c|c|c|c|c|c|c|c|c|c|c|}
\hline & \multicolumn{3}{|c|}{ Male } & \multicolumn{3}{|c|}{ Female } & \multicolumn{4}{|c|}{ Total } & \multicolumn{2}{|c|}{ Tests } \\
\hline & HTC & VMMC & Total & FP & HTC & Total & FP & HTC & VMMC & Total & Males & Females \\
\hline Sample size & 1,398 & 522 & 1,920 & 1,034 & 1,009 & 2,043 & 1,034 & 2,407 & 522 & 3,963 & 1,920 & 2,043 \\
\hline Fertility intentions & & & & & & & & & & & $A^{* * *}$ & $\mathrm{~B} * * *$ \\
\hline Wants no more & 14.6 & 13.1 & 14.2 & 36.3 & 28.6 & 32.6 & 36.3 & 20.4 & 13.1 & 23.7 & & \\
\hline Wants another child & 75.3 & 68.2 & 73.3 & 53.8 & 64.1 & 58.8 & 53.8 & 70.6 & 68.2 & 65.8 & & \\
\hline Can't have childrena & 1.2 & 0.8 & 1.1 & 1.5 & 2.1 & 1.8 & 1.5 & 1.6 & 0.8 & 1.5 & & \\
\hline Undecided & 8.9 & 17.9 & 11.4 & 8.4 & 5.2 & 6.9 & 8.4 & 7.4 & 17.9 & 9.1 & & \\
\hline \multicolumn{13}{|l|}{ Contraception } \\
\hline $\begin{array}{l}\text { Heard of at least one modern method of } \\
\text { contraception }\end{array}$ & $\mathrm{n} / \mathrm{a}$ & $\mathrm{n} / \mathrm{a}$ & $\mathrm{n} / \mathrm{a}$ & 99.5 & 99.5 & 99.5 & 99.5 & $\mathrm{n} / \mathrm{a}$ & $\mathrm{n} / \mathrm{a}$ & $\mathrm{n} / \mathrm{a}$ & $\mathrm{n} / \mathrm{a}$ & \\
\hline Ever used modern contraception & $\mathrm{n} / \mathrm{a}$ & $\mathrm{n} / \mathrm{a}$ & $\mathrm{n} / \mathrm{a}$ & 92.3 & 93.7 & 92.9 & 92.3 & $\mathrm{n} / \mathrm{a}$ & $\mathrm{n} / \mathrm{a}$ & $\mathrm{n} / \mathrm{a}$ & $\mathrm{n} / \mathrm{a}$ & \\
\hline Currently using contraception & $\mathrm{n} / \mathrm{a}$ & $\mathrm{n} / \mathrm{a}$ & $\mathrm{n} / \mathrm{a}$ & 41.8 & 61.4 & 51.0 & 41.8 & $\mathrm{n} / \mathrm{a}$ & $\mathrm{n} / \mathrm{a}$ & $\mathrm{n} / \mathrm{a}$ & $\mathrm{n} / \mathrm{a}$ & $\mathrm{B} * * *$ \\
\hline Currently using modern contraceptionb & $\mathrm{n} / \mathrm{a}$ & $\mathrm{n} / \mathrm{a}$ & $\mathrm{n} / \mathrm{a}$ & 36.7 & 57.9 & 46.7 & 36.7 & $\mathrm{n} / \mathrm{a}$ & $\mathrm{n} / \mathrm{a}$ & $\mathrm{n} / \mathrm{a}$ & $\mathrm{n} / \mathrm{a}$ & $\mathrm{B} * * *$ \\
\hline Currently using long acting contraceptionc & $\mathrm{n} / \mathrm{a}$ & $\mathrm{n} / \mathrm{a}$ & $\mathrm{n} / \mathrm{a}$ & 3.7 & 10.8 & 7.1 & 3.7 & $\mathrm{n} / \mathrm{a}$ & $\mathrm{n} / \mathrm{a}$ & $\mathrm{n} / \mathrm{a}$ & $\mathrm{n} / \mathrm{a}$ & $\mathrm{B} * * *$ \\
\hline Perceived risk of HIV & & & & & & & & & & & $A^{*}$ & $\mathrm{~B} * * *$ \\
\hline No risk & 19.2 & 19.9 & 19.4 & 30.6 & 13.2 & 22.0 & 30.6 & 16.7 & 19.9 & 20.8 & & \\
\hline Low & 28.5 & 28.7 & 28.5 & 13.5 & 19.5 & 16.5 & 13.5 & 24.7 & 28.7 & 22.3 & & \\
\hline Moderate & 24.0 & 19.9 & 22.9 & 12.0 & 28.5 & 20.1 & 12.0 & 25.9 & 19.9 & 21.5 & & \\
\hline High & 20.7 & 25.5 & 22.0 & 26.3 & 23.9 & 25.1 & 26.3 & 22.1 & 25.5 & 23.6 & & \\
\hline $\mathrm{HIV}+\mathrm{a}$ & 0.1 & 1.1 & 0.4 & 6.8 & 0.3 & 3.6 & 6.8 & 0.2 & 1.1 & 2.0 & & \\
\hline Doesn't know & 7.4 & 4.8 & 6.7 & 10.9 & 14.6 & 12.7 & 10.9 & 10.4 & 4.8 & 9.8 & & \\
\hline \multicolumn{13}{|l|}{ Knowledge of HIV } \\
\hline Comprehensive knowledge & 50.2 & 43.7 & 48.4 & 43.3 & 47.1 & 45.2 & 43.3 & 48.9 & 43.7 & 46.8 & $A^{*}$ & $\mathrm{~B}+$ \\
\hline $\begin{array}{l}\text { Knowledge of mother to child } \\
\text { transmissione }\end{array}$ & 47.5 & 37.9 & 44.9 & 51.7 & 54.9 & 53.3 & 51.7 & 50.6 & 37.9 & 49.2 & $A^{* * *}$ & \\
\hline \multicolumn{13}{|l|}{ HIV testing and counselling } \\
\hline Ever tested & 78.5 & 73.9 & 77.2 & 97.3 & 86.0 & 91.7 & 97.3 & 81.6 & 73.9 & 84.7 & $A^{*}$ & $\mathrm{~B} * * *$ \\
\hline Tested within last 6 months & 37.2 & 40.9 & 38.2 & 51.7 & 31.9 & 41.9 & 51.7 & 35.0 & 40.9 & 40.1 & & $\mathrm{~B} * * *$ \\
\hline Tested within last year & 54.1 & 56.8 & 54.8 & 77.2 & 53.3 & 65.4 & 77.2 & 53.8 & 56.8 & 60.2 & & $\mathrm{~B} * * *$ \\
\hline Ever been tested with partner & 33.6 & 32.7 & 33.4 & 65.2 & 39.7 & 53.5 & 65.2 & 36.2 & 32.7 & 44.5 & & $\mathrm{~B} * * *$ \\
\hline \multicolumn{13}{|l|}{ Circumcisionf } \\
\hline Currently circumcised & 38.3 & 0.4 & 28.0 & 33.1 & 39.1 & 35.8 & 33.1 & 38.6 & 0.4 & 31.8 & $\mathrm{n} / \mathrm{a}$ & $\mathrm{B}^{* *}$ \\
\hline Don't know (females only) & $\mathrm{n} / \mathrm{a}$ & $\mathrm{n} / \mathrm{a}$ & $\mathrm{n} / \mathrm{a}$ & 1.2 & 1.9 & 1.5 & 1.2 & 0.7 & $\mathrm{n} / \mathrm{a}$ & 0.7 & $\mathrm{n} / \mathrm{a}$ & \\
\hline Of circumcised, medically circumcised & 89.4 & 100.0 & 89.5 & 81.7 & 86.8 & 84.4 & 81.7 & 88.5 & 100.0 & 86.9 & $\mathrm{n} / \mathrm{a}$ & \\
\hline $\begin{array}{l}\text { Of uncircumcised, thought about getting } \\
\text { circumcised }\end{array}$ & 65.8 & 95.8 & 77.1 & 61.0 & 62.5 & 61.7 & 61.0 & 64.6 & 95.8 & 70.1 & $A^{* * *}$ & \\
\hline \multicolumn{13}{|l|}{$\begin{array}{l}\text { Sexual Activity (among sexually active in } \\
\text { past } 12 \text { months) }\end{array}$} \\
\hline Sexually active in last 7 days & 32.2 & 30.4 & 31.7 & 40.8 & 39.7 & 40.3 & 40.8 & 35.4 & 30.4 & 36.2 & & \\
\hline Sexually active in last 30 days & 60.6 & 60.9 & 60.7 & 77.8 & 74.2 & 76.0 & 77.8 & 66.3 & 60.9 & 68.6 & & $\mathrm{~B}+$ \\
\hline Unprotected sex at last sex in past 12 & & & & & & & & & & & & \\
\hline months & 54.2 & 51.7 & 53.5 & 62.6 & 62.4 & 62.5 & 62.6 & 57.6 & 51.7 & 58.1 & & \\
\hline
\end{tabular}


TABLE 7 Baseline characteristics of study participants by study entry point (percentages unless otherwise indicated) (con't)

\begin{tabular}{|c|c|c|c|c|c|c|c|c|c|c|c|c|}
\hline & \multicolumn{3}{|c|}{ Male } & \multicolumn{3}{|c|}{ Female } & \multicolumn{4}{|c|}{ Total } & \multicolumn{2}{|c|}{ Tests } \\
\hline & HTC & VMMC & Total & FP & HTC & Total & FP & HTC & VMMC & Total & Males & Females \\
\hline Sample size & 1,398 & 522 & 1,920 & 1,034 & 1,009 & 2,043 & 1,034 & 2,407 & 522 & 3,963 & 1,920 & 2,043 \\
\hline $\begin{array}{l}\text { Mean number of sexual partners last } 12 \\
\text { months }\end{array}$ & 3.4 & 2.5 & 3.1 & 1.6 & 2.2 & 1.9 & 1.6 & 2.9 & 2.5 & 2.5 & $A * * *$ & $\mathrm{~B} * * *$ \\
\hline $\begin{array}{l}\text { Mean number of lifetime sexual partners } \\
\text { Health status }\end{array}$ & 6.0 & 4.3 & 5.5 & 2.6 & 3.6 & 3.1 & 2.6 & 5.0 & 4.3 & 4.3 & $A * * *$ & $B * * *$ \\
\hline $\begin{array}{l}\text { Mean rating in past month }(1-10) \\
\text { Mean number of health problems in }\end{array}$ & 8.0 & 8.2 & 8.0 & 8.2 & 7.7 & 7.9 & 8.2 & 7.8 & 8.2 & 8.0 & $A^{*}$ & $\mathrm{~B} * * *$ \\
\hline past month $(0-7)$ & 1.3 & 1.2 & 1.3 & 0.9 & 1.4 & 1.1 & 0.9 & 1.4 & 1.2 & 1.2 & & $\mathrm{~B} * * *$ \\
\hline Covered by health scheme & 6.0 & 9.1 & 6.9 & 1.3 & 4.1 & 2.7 & 1.3 & 5.2 & 9.1 & 4.7 & $A^{*}$ & $B * * *$ \\
\hline
\end{tabular}

$* * * p<.001 ; * * p<.01 ; * p<.05 ; \dagger p<.10$

$A=H T C \& V M M C, B=F P \& H T C$

Note: All tests are chi-square for categorical outcomes or ttests for continuous outcomes, unless otherwise noted.

a Excluded from analysis due to small sample size.

b Excluding those pregnant, those who can't have children, and those who want a child now. Methods include male or female condom, oral contraceptive pill, injectable, diaphragm, foam/jelly, IUD,

implant, lactational amenorrhea and sterilization.

c Excluding those pregnant, those who can't have children, and those who want a child now. Methods include IUD, implant, and sterilization.

d Based on the Zambia 2013 DHS definition: knowing that consistent use of condoms during sexual intercourse and having just one uninfected faithful partner can reduce the chances of getting the AIDS virus, knowing that a healthy-looking person can have HIV, and rejecting the two most common local misconceptions about HIV transmission (that the AIDS virus can be transmitted by mosquito

bites and that a person can become infected by sharing food with someone who has the AIDS virus).

e Defined as knowing that HIV can be transmitted during pregnancy, delivery and breastfeeding.

${ }^{f}$ All males and females with partners answered these questions. 
There is no discernible difference in women at FP and HTC in terms of knowledge or ever use of contraception. Knowledge of modern contraception ${ }^{14}$ is universal in both samples (>99\%) and is similar to levels observed in the Zambian Demographic and Health Surveys.[3] Women at HTC sites, however, are significantly more likely to be currently using contraception in general and using modern contraception specifically. Contraceptive use patterns for HTC clients in the sample are comparable, albeit slightly higher, than those of urban women in the DHS, while those for FP clients are significantly below the general population of urban women.[3] As expected, these data point to the unmet need of women who are seeking FP services at the study entry points.

For both males and females, there is an unambiguous relationship between risky sexual behavior and clients seeking HTC services. For instance, at HTC sites a statistically significant higher percentage of men had multiple sexual partners in the past 12 months than VMMC clients, a higher mean number of sexual partners in the past 12 months and a higher mean number of lifetime sexual partners. For females, the pattern is similar, with women at HTC sites nearly twice as likely to have had multiple sexual partners in the last 12 months as FP clients, with significantly higher mean numbers of sexual partners in the last 12 months and sexual partners throughout their lifetime. For comparison, the ZDHS 2013-2014 data indicates that among urban men 15-49, only $12 \%$ reported two or more partners in the last 12 months; this number dropped to around $2 \%$ of urban women of the same age. It should be noted that the sexual behavior data in this study were collected using audio-computer assisted selfinterviews (ACASI), while the ZDHS interviews were implemented in a face-to-face interview. Studies have shown that ACASI can elicit significantly higher reporting of stigmatizing sexual behaviors.[60]

\section{SURVEY INTERVIEWS AT SIX WEEKS AND SIX MONTHS}

\section{Response rates}

After recruitment, participants were interviewed at six weeks and six months. Information collected from the clients at the follow-up interviews included questions about service utilization and satisfaction, general health assessments and sexual behavior. Of the sample recruited, 3,267 (82\%) were tracked and interviewed at six weeks, including 1,553 males ( $81 \%$ of males) and 1,714 (84\% of females). At six-months, a total of 3,206 (81\%) of the respondents were tracked and interviewed, including 1,541 males ( $80 \%$ of males) and 1,665 females ( $82 \%$ of females). The differences between males and females were statistically significant at the six-week mark, but those differences dissipated by the six-month mark, as fewer women were trackable at six months relative to six weeks.

${ }^{14}$ Modern contraception includes male or female condom, oral contraceptive pill, injectable, diaphragm, foam/jelly, IUD, implant, lactational amenorrhea and sterilization. 


\begin{tabular}{|c|c|c|c|c|c|c|}
\hline & \multicolumn{6}{|c|}{ Response rates } \\
\hline & \multicolumn{3}{|c|}{6 weeks } & \multicolumn{3}{|c|}{6 months } \\
\hline & $\mathrm{N}$ & $\%$ & Tests & $\mathrm{N}$ & $\%$ & Tests \\
\hline Completed interview & 3,267 & 82.4 & & 3,206 & 80.9 & \\
\hline No interview & 672 & 17.0 & & 722 & 18.2 & \\
\hline Withdrew & 20 & 0.5 & & 28 & 0.7 & \\
\hline \multirow[t]{4}{*}{ Deceased } & 4 & 0.1 & & 7 & 0.2 & \\
\hline & \multicolumn{6}{|c|}{ Characteristics of respondents } \\
\hline & \multicolumn{3}{|c|}{6 weeks } & \multicolumn{3}{|c|}{6 months } \\
\hline & $\mathrm{N}$ & $\%$ & Tests & $\mathrm{N}$ & $\%$ & Tests \\
\hline Gender & & & * & & & \\
\hline Male & 1,553 & 80.9 & & 1,541 & 80.3 & \\
\hline Female & 1,714 & 83.9 & & 1,665 & 81.5 & \\
\hline Study arm & & & $\mathrm{B}+$ & & & \\
\hline 1. Standard of care & 1,107 & 83.9 & & 1,071 & 81.2 & \\
\hline 2. Enhanced referral & 1,089 & 82.3 & & 1,081 & 81.7 & \\
\hline 3. Enhanced referral \& escort & 1,071 & 81.1 & & 1,054 & 79.8 & \\
\hline Entry point & & & $B^{*}$ & & & \\
\hline $\mathrm{FP}$ & 875 & 84.6 & & 839 & 81.1 & \\
\hline HTC & 1,956 & 81.3 & & 1,941 & 80.6 & \\
\hline VMMC & 436 & 83.5 & & 426 & 81.6 & \\
\hline External site & 146 & 71.2 & & 136 & 66.3 & \\
\hline Male & 77 & 68.1 & & 71 & 62.8 & \\
\hline Female & 69 & 75.0 & & 65 & 70.7 & \\
\hline
\end{tabular}

$* * * p<.001 ; * * p<.01 ; * p<.05 ; \dagger p<.10$

$A=\operatorname{Arms~} 1 \& 2, B=\operatorname{Arms~} 1 \& 3, C=\operatorname{Arms} 2 \& 3$

$C=H T C \& V M M C, B=F P \& H T C$

Note: All tests are chi-square tests.

Table 8 also provides the interview response rates by study arm and by entry point. There were no meaningful differences between the follow-up interview response rates across study arms at either the six-week or six-month interview mark. Those in the standard-of-care arm were slightly more trackable than those in the other two arms at the six-week interview, with the greatest difference (3\%) between the control and the enhanced referral and escort arm. These statistically significant differences, however, do not exist at the six-month mark. This is an important result, as it implies that differential attrition by study arm does not exist in the sample. One might expect that because a greater investment was made in clients in the intervention arms, they would be more willing to participate in the research process than clients receiving standard-of-care services. The finding of no statistically significant differences in follow-up over time provides greater confidence in the experimental assessment of outcomes reported in the behavioral data.

There are marginal differences in follow-up by entry point, as those at HTC sites are less trackable at six weeks than either FP or VMMC sites. These differences, however, were at maximum 3\% at six weeks and also dissipated by the six-month interview, with virtually equivalent percentages of clients tracked by entry point at six months. 
Of the additional 205 participants recruited at the external comparator site (YWCA), 146 (71\%) were interviewed at six weeks and $133(65 \%)$ at six months. The follow-up rates were much lower in the external sites than was observed in the main study sites. Anecdotally, the site caters to young students who often come for services during the school holidays and then return to school, both in and outside of Lusaka. ${ }^{15}$

\section{Attrition assessment}

To assess whether there are any systematic differences in the baseline versus follow-up sample, multivariable logistic attrition analyses were conducted to assess differences between those interviewed and those not interviewed. The results are reported in Appendix Table A2. The follow-up sample differed by some client demographic characteristics. For instance, women were significantly less likely to be lost to follow-up than were men, with $28 \%$ lower odds of not being interviewed at six weeks and $22 \%$ lower odds at six months. There was no pattern associated with loss-to-follow-up and age at six weeks; however, by six months the older participants were easier to track than the younger participants. Other characteristics that were associated with attrition over time were lower educational attainment, being divorced, separated or widowed (at six weeks), being Catholic (at six weeks) and not owning a mobile phone (at six weeks).

As is indicated in the bivariate results in Table 8 and the results in the Appendix Table A3, loss-to-follow-up does not differ significantly at the $p<.05$ level between the study arms when other factors are considered. While the results for study Arm 3 are marginally significant $(p<.10)$ at six weeks, the differences dissipate by the six-month mark, particularly after site controls are introduced. As is indicated, in addition to the demographic indicators associated with loss-to-follow-up, the individual sites do differ significantly in terms of response rates. In general, relative to the SFH HTC site at Cairo Road (reference), which proved to be one of the more challenging sites to implement the study in, many of the other study sites have lower rates of loss-to-follow-up, ranging from $11 \%$ (Chawama VMMC) to $41 \%$ (Kapata Urban $\mathrm{MCH}$ clinic) lower odds at six months.

\section{EXPERIMENTAL EVALUATION}

\section{Utilization of services and behavior by six weeks}

Table 9 documents the ITT bivariate analysis of the uptake of key study service utilization outcomes by study arm for the client, and, if applicable, his/her spouse, and/or his/her child. As was discussed previously (Table 1), the indicators are limited to those who are eligible for the uptake services. For instance, since HTC and VMMC clients are offered HTC services at the recruitment entry point, they are excluded from the assessment of HTC uptake at six weeks. This applies only to the indicators for the client, as all spouses and all children are eligible for receiving additional services.

As can be observed in Table 9, the intervention arms did not have a consistent impact on the uptake of services by six weeks for both genders. Impacts, however, are observed for a selection of indicators. For instance, individuals who were exposed to enhanced referral arm with an escort (study arm 3) were more likely to have received HTC than the control arm by six weeks. The enhanced referral service arm with escort had a nearly $7 \%$ difference in uptake of HTC for female clients and the difference is statistically significant at the $p<.05$ level. Compared to the standard of care, the enhanced referral service arm (study arm 2) had almost $4 \%$ greater prevalence of uptake of HTC, although the difference was not statistically significant. Overall, the bivariate results for HTC can be taken to confirm that the intervention enhanced the uptake of testing services among clients.

15 Information provided by SFH study coordinator. 
TABLE 9 Descriptive statistics of service uptake outcomes at six weeks by study arm

\begin{tabular}{|c|c|c|c|c|c|c|c|c|c|c|c|c|c|c|c|}
\hline \multirow{2}{*}{$\begin{array}{l}\text { Uptake of services at } 6 \text { weeks } \\
\text { Arm }\end{array}$} & \multicolumn{4}{|c|}{ Males } & \multicolumn{4}{|c|}{ Females } & \multicolumn{4}{|c|}{ Totals } & \multicolumn{3}{|c|}{ Tests } \\
\hline & $\begin{array}{c}1 . \\
\text { Standard } \\
\text { of care }\end{array}$ & $\begin{array}{c}2 . \\
\text { Enhanced } \\
\text { referral }\end{array}$ & $\begin{array}{l}3 . \\
\text { Enhanced } \\
\text { referral \& } \\
\text { escort }\end{array}$ & Total & $\begin{array}{c}1 . \\
\text { Standard } \\
\text { of care }\end{array}$ & $\begin{array}{c}2 . \\
\text { Enhanced } \\
\text { referral }\end{array}$ & $\begin{array}{c}3 . \\
\text { Enhanced } \\
\text { referral \& } \\
\text { escort }\end{array}$ & Total & $\begin{array}{c}1 . \\
\text { Standard } \\
\text { of Care }\end{array}$ & $\begin{array}{l}2 . \\
\text { Enhanced } \\
\text { Referral }\end{array}$ & $\begin{array}{c}3 . \\
\text { Enhanced } \\
\text { Referral \& } \\
\text { Escort }\end{array}$ & Total & Males & Females & Total \\
\hline Client ( $\mathrm{n}$ range) & 385 & 363 & 362 & 1110 & $279-577$ & $283-574$ & $276-562$ & $838-1713$ & $n / a$ & $\mathrm{n} / \mathrm{a}$ & $\mathrm{n} / \mathrm{a}$ & $\mathrm{n} / \mathrm{a}$ & 1110 & $838-1713$ & $\mathrm{n} / \mathrm{a}$ \\
\hline HIV testing and counselling & $\mathrm{n} / \mathrm{a}$ & $\mathrm{n} / \mathrm{a}$ & $\mathrm{n} / \mathrm{a}$ & $\mathrm{n} / \mathrm{a}$ & 13.4 & 17.2 & 21.3 & 17.3 & $\mathrm{n} / \mathrm{a}$ & $\mathrm{n} / \mathrm{a}$ & $\mathrm{n} / \mathrm{a}$ & $\mathrm{n} / \mathrm{a}$ & $\mathrm{n} / \mathrm{a}$ & $B^{*}$ & $\mathrm{n} / \mathrm{a}$ \\
\hline Family planning & $\mathrm{n} / \mathrm{a}$ & $\mathrm{n} / \mathrm{a}$ & $\mathrm{n} / \mathrm{a}$ & $\mathrm{n} / \mathrm{a}$ & 15.4 & 19.3 & 10.6 & 15.2 & $\mathrm{n} / \mathrm{a}$ & $\mathrm{n} / \mathrm{a}$ & $\mathrm{n} / \mathrm{a}$ & $\mathrm{n} / \mathrm{a}$ & $\mathrm{n} / \mathrm{a}$ & $C * *$ & $\mathrm{n} / \mathrm{a}$ \\
\hline $\begin{array}{l}\text { Voluntary medical male } \\
\text { circumcision }\end{array}$ & 4.7 & 8.8 & 12.2 & 8.5 & $\mathrm{n} / \mathrm{a}$ & $\mathrm{n} / \mathrm{a}$ & $\mathrm{n} / \mathrm{a}$ & $\mathrm{n} / \mathrm{a}$ & $\mathrm{n} / \mathrm{a}$ & $\mathrm{n} / \mathrm{a}$ & $\mathrm{n} / \mathrm{a}$ & $\mathrm{n} / \mathrm{a}$ & $A^{*}, B^{* * *}$ & $\mathrm{n} / \mathrm{a}$ & $\mathrm{n} / \mathrm{a}$ \\
\hline Cervical cancer screening & $\mathrm{n} / \mathrm{a}$ & $\mathrm{n} / \mathrm{a}$ & $\mathrm{n} / \mathrm{a}$ & $\mathrm{n} / \mathrm{a}$ & 4.2 & 21.3 & 24.6 & 16.6 & $\mathrm{n} / \mathrm{a}$ & $\mathrm{n} / \mathrm{a}$ & $\mathrm{n} / \mathrm{a}$ & $\mathrm{n} / \mathrm{a}$ & $\mathrm{n} / \mathrm{a}$ & $\begin{array}{l}A^{* * *} \\
B^{* * *}\end{array}$ & $\mathrm{n} / \mathrm{a}$ \\
\hline $\begin{array}{l}\text { HIV and STI care and treatment } \\
\text { (n range) }\end{array}$ & $9-528$ & $10-512$ & $9-508$ & $28-1547$ & $14-576$ & $27-573$ & $23-560$ & $64-1711$ & 23-1104 & $37-1084$ & $32-1070$ & $92-3258$ & $28-1547$ & 64-1711 & $92-3258$ \\
\hline HIV care and treatment & 7.2 & 6.8 & 7.9 & 7.3 & 9.7 & 11.7 & 13.2 & 11.5 & 8.5 & 9.4 & 10.7 & 9.5 & & $\mathrm{~B} \dagger$ & $\mathrm{B} \dagger$ \\
\hline STI care and treatment & 4.9 & 5.3 & 4.1 & 4.8 & 2.8 & 4.0 & 4.3 & 3.7 & 3.8 & 4.6 & 4.2 & 4.2 & & & \\
\hline TB testinga & 15.8 & 5.7 & 10.0 & 10.6 & 22.8 & 29.9 & 21.6 & 24.7 & 20.0 & 21.6 & 17.5 & 19.6 & & & \\
\hline CD4 testing & 36.8 & 42.9 & 37.5 & 38.9 & 45.6 & 60.3 & 45.9 & 50.8 & 42.1 & 54.4 & 43.0 & 46.5 & & $\mathrm{C}+$ & $\mathrm{A} \dagger$ \\
\hline Initiated ARVa & 100.0 & 100.0 & 88.9 & 96.4 & 92.9 & 81.5 & 87.0 & 85.9 & 95.7 & 86.5 & 87.5 & 89.1 & & & \\
\hline Psychosocial support & 34.2 & 22.9 & 22.5 & 26.5 & 30.9 & 16.7 & 23.6 & 23.3 & 32.3 & 18.8 & 23.2 & 24.5 & & $\mathrm{~A} \dagger$ & $A^{*}$ \\
\hline Partner (n) & 361 & 381 & 357 & 1094 & 519 & 510 & 489 & 1518 & 872 & 882 & 832 & 2586 & 1094 & 1518 & 2586 \\
\hline HIV testing and counselling & 22.5 & 27.5 & 22.4 & 24.2 & 20.0 & 19.8 & 23.4 & 21.1 & 21.0 & 23.2 & 23.0 & 22.4 & & & \\
\hline Family planning & 16.3 & 17.0 & 17.9 & 17.1 & $\mathrm{n} / \mathrm{a}$ & $\mathrm{n} / \mathrm{a}$ & $\mathrm{n} / \mathrm{a}$ & $\mathrm{n} / \mathrm{a}$ & $\mathrm{n} / \mathrm{a}$ & $\mathrm{n} / \mathrm{a}$ & $\mathrm{n} / \mathrm{a}$ & $\mathrm{n} / \mathrm{a}$ & & $\mathrm{n} / \mathrm{a}$ & $\mathrm{n} / \mathrm{a}$ \\
\hline $\begin{array}{l}\text { Voluntary medical male } \\
\text { circumcision }\end{array}$ & $\mathrm{n} / \mathrm{a}$ & $n / a$ & $\mathrm{n} / \mathrm{a}$ & $\mathrm{n} / \mathrm{a}$ & 3.9 & 3.7 & 5.5 & 4.3 & $\mathrm{n} / \mathrm{a}$ & $\mathrm{n} / \mathrm{a}$ & $\mathrm{n} / \mathrm{a}$ & $\mathrm{n} / \mathrm{a}$ & $\mathrm{n} / \mathrm{a}$ & & $\mathrm{n} / \mathrm{a}$ \\
\hline Cervical cancer screening & 7.6 & 6.5 & 10.5 & 8.2 & $\mathrm{n} / \mathrm{a}$ & $\mathrm{n} / \mathrm{a}$ & $\mathrm{n} / \mathrm{a}$ & $\mathrm{n} / \mathrm{a}$ & $\mathrm{n} / \mathrm{a}$ & $\mathrm{n} / \mathrm{a}$ & $\mathrm{n} / \mathrm{a}$ & $\mathrm{n} / \mathrm{a}$ & $\mathrm{C}+$ & $\mathrm{n} / \mathrm{a}$ & $\mathrm{n} / \mathrm{a}$ \\
\hline HIV care and treatment & 8.1 & 6.6 & 9.2 & 7.9 & 7.6 & 8.9 & 8.9 & 8.5 & 7.8 & 7.9 & 9.0 & 8.2 & & & \\
\hline STI care and treatment & 5.6 & 6.3 & 5.4 & 5.8 & 4.9 & 3.6 & 4.4 & 4.3 & 5.2 & 4.8 & 4.8 & 4.9 & & & \\
\hline Child aged $15+(n)$ & 32 & 28 & 32 & 92 & 107 & 93 & 107 & 307 & 139 & 121 & 139 & 399 & 92 & 307 & 399 \\
\hline HIV testing and counsellinga & 13.8 & 10.7 & 9.4 & 11.2 & 12.9 & 14.3 & 17.0 & 14.8 & 13.1 & 13.4 & 15.2 & 14.0 & & & \\
\hline Family planninga & 9.7 & 3.6 & 0.0 & 4.4 & 5.9 & 5.6 & 4.8 & 5.4 & 6.8 & 5.1 & 3.7 & 5.2 & & & \\
\hline $\begin{array}{l}\text { Voluntary medical male } \\
\text { circumcisiona }\end{array}$ & 6.3 & 3.6 & 6.3 & 5.4 & 3.7 & 3.2 & 2.8 & 3.3 & 4.3 & 3.3 & 3.6 & 3.8 & & & \\
\hline Cervical cancer screeninga & 0.0 & 0.0 & 3.1 & 1.1 & 2.9 & 4.3 & 7.6 & 5.0 & 2.2 & 3.3 & 6.6 & 4.1 & & & \\
\hline HIV care and treatment ${ }^{a}$ & 12.9 & 3.6 & 0.0 & 5.6 & 6.9 & 14.4 & 8.4 & 9.7 & 8.3 & 11.9 & 6.5 & 8.8 & & & \\
\hline STI care and treatment & 3.3 & 3.6 & 0.0 & 2.2 & 3.9 & 5.6 & 2.8 & 4.0 & 3.8 & 5.1 & 2.2 & 3.6 & & & \\
\hline
\end{tabular}

$* * * p<.001 ; * * p<.01 ; * p<.05 ; \dagger p<.10 ; n / a=$ not applicable for outcome

$A=\operatorname{Arms~} 1 \& 2, B=\operatorname{Arms} 1 \& 3, C=$ Arms $2 \& 3$

Note: Five cases are excluded for answering these questions for a 6-month window instead of a 6-week window.

Note: Sample sizes for client outcomes vary as each outcome is restricted to certain entry sites and a few participants 
Note: All tests are chi-square tests, unless otherwise noted.

a Tested using Fisher's exact test due to small cell sizes. 
The uptake of FP, however, revealed only a marginally significant $(p<.10)$, less than $4 \%$ difference between the standard of care and study arm 2 suggesting an improvement in the uptake of FP services, but not a significant gain from the intervention. The result for study arm 3 relative to the standard of care was counter-intuitive, as the intervention arm had a significantly lower prevalence of the uptake of FP services by about $5 \%$.

There are quite significant differences in the models in terms of impact on the uptake of VMMC and CCS in the sixmonth window. The results for VMMC intervention arms reveal statistically significant differences in uptake between the control and two experimental arms at the $p<.05$ and $p<.001$ levels. About $5 \%$ of men in the standard of care arm report having received VMMC services at the six-week interview. This prevalence was $4 \%$ higher in the enhanced referral arm and about $8 \%$ higher in the enhanced referral arm plus escort. These bivariate results for VMMC can be taken to imply that the intervention enhanced the uptake of services among male clients in meaningful ways.

The impact of the intervention on cervical cancer screening for female clients is even more promising. In the standard-of-care, only $4 \%$ of the sample reported that they received cervical cancer screening in the previous six weeks, while in the two experimental arms, the prevalence of uptake was $21 \%$ and $25 \%$ respectively. The results indicated that the percentage of women reached for CCS was more than five times higher when enhanced assessment and referral services were provided to such women. These differences were statistically significant at the $p<.001$ level and although the difference between intervention arms (arm 2 versus arm 3 ) was not statistically significant, the provision of an escort did seem to enhance uptake among an additional $3 \%$ of women compared to the intervention arm with no escort. Overall these bivariate results provide strong evidence of a link between uptake of CCS and the intensity of assessment and referral services.

For other indicators, there were either no meaningful or inconsistent statistically significant differences between the standard of care and the intervention arms. For HIV care and treatment outcomes (in general), there was a consistent pattern for females of slightly higher uptake of care and treatment services among the two experimental arms relative to the standard of care, but the differences were only marginally significant at the $p<.10$ level and range from 1.9\% to 3.5\% higher. Furthermore, uptake of CD4 testing among women was higher in study arm 2, but was only marginally significant at $p<.10$ level. In addition, the standard of care revealed higher uptake of psychosocial support among women. Overall, it should be noted that the available analytic samples sizes were quite small for these indicators with larger confidence intervals (not shown). It is likely that these tests were underpowered and inferences to be drawn are limited.

Table 9 also reveals few observed differences between the study arms in the uptake of health services for the spouses of clients or their children aged 15 and older. For instance, the client-based intervention had no discernible impact on the reported uptake of services by client partners for either gender. This too was the case for the children aged 15 and older of clients, as the results do not indicate any meaningful change in the uptake of services.

\section{Utilization of services by six months}

Table 10 reveals a similar pattern of results in the ITT analysis with the reported uptake of service indicators at six months. For HTC services among female clients, there exist meaningful differences between the standard of care and the intervention arms, with the latter showing a higher prevalence of utilization of services by about $7 \%$. With the slightly smaller samples sizes at six months, however, the difference is only marginally statistically significant at the $p<.10$ level. For VMMC, men in the intervention arms still reported higher levels of uptake than those in the standard of care. For instance, approximately $12 \%$ of men reported taking up male circumcision in the escort intervention arm relative to $4 \%$ of those in the control arm, which was statistically different at the $p<.05$ level. Another way of explaining this result is that three times the percentage of men received VMMC services in the 
enhanced referral arm with an escort; a much smaller difference was observed between the standard of care and the enhanced referral arm without an escort. 
TABLE 10 Descriptive statistics of service uptake outcomes at six months by study arm

\begin{tabular}{|c|c|c|c|c|c|c|c|c|c|c|c|c|c|c|c|}
\hline \multirow{2}{*}{$\begin{array}{l}\text { Uptake of services at } 6 \text { months } \\
\text { Arm }\end{array}$} & \multicolumn{4}{|c|}{ Males } & \multicolumn{4}{|c|}{ Females } & \multicolumn{4}{|c|}{ Totals } & \multicolumn{3}{|c|}{ Tests } \\
\hline & $\begin{array}{c}1 . \\
\text { Standard } \\
\text { of care }\end{array}$ & $\begin{array}{l}2 . \\
\text { Enhanced } \\
\text { referral }\end{array}$ & $\begin{array}{c}3 . \\
\text { Enhanced } \\
\text { referral } \\
\text { \& escort }\end{array}$ & Total & $\begin{array}{c}1 . \\
\text { Standard } \\
\text { of care }\end{array}$ & $\begin{array}{l}2 . \\
\text { Enhanced } \\
\text { referral }\end{array}$ & $\begin{array}{c}3 . \\
\text { Enhanced } \\
\text { referral } \\
\& \text { escort }\end{array}$ & Total & $\begin{array}{c}1 . \\
\text { Standard } \\
\text { of care }\end{array}$ & $\begin{array}{l}2 . \\
\text { Enhanced } \\
\text { referral }\end{array}$ & $\begin{array}{c}3 . \\
\text { Enhanced } \\
\text { referral } \\
\text { \& escort }\end{array}$ & Total & Males & Females & Total \\
\hline Client ( $\mathrm{n}$ range) & 371 & 375 & 364 & 1110 & 283-559 & $273-555$ & $273-547$ & $\begin{array}{l}822- \\
1663\end{array}$ & $n / a$ & $\mathrm{n} / \mathrm{a}$ & $n / a$ & $n / a$ & 1110 & $822-1663$ & $n / a$ \\
\hline HIV testing and counselling & $\mathrm{n} / \mathrm{a}$ & $\mathrm{n} / \mathrm{a}$ & $\mathrm{n} / \mathrm{a}$ & $\mathrm{n} / \mathrm{a}$ & 28.3 & 34.9 & 33.9 & 32.3 & $\mathrm{n} / \mathrm{a}$ & $\mathrm{n} / \mathrm{a}$ & $\mathrm{n} / \mathrm{a}$ & $\mathrm{n} / \mathrm{a}$ & $\mathrm{n} / \mathrm{a}$ & $\mathrm{A} \dagger$ & $\mathrm{n} / \mathrm{a}$ \\
\hline Family planning & $\mathrm{n} / \mathrm{a}$ & $\mathrm{n} / \mathrm{a}$ & $\mathrm{n} / \mathrm{a}$ & $\mathrm{n} / \mathrm{a}$ & 23.7 & 19.3 & 22.3 & 21.8 & $\mathrm{n} / \mathrm{a}$ & $\mathrm{n} / \mathrm{a}$ & $\mathrm{n} / \mathrm{a}$ & $\mathrm{n} / \mathrm{a}$ & $\mathrm{n} / \mathrm{a}$ & & $\mathrm{n} / \mathrm{a}$ \\
\hline $\begin{array}{l}\text { Voluntary medical male } \\
\text { circumcision }\end{array}$ & 4.3 & 6.1 & 11.5 & 7.3 & $\mathrm{n} / \mathrm{a}$ & $\mathrm{n} / \mathrm{a}$ & $\mathrm{n} / \mathrm{a}$ & $\mathrm{n} / \mathrm{a}$ & $\mathrm{n} / \mathrm{a}$ & $\mathrm{n} / \mathrm{a}$ & $\mathrm{n} / \mathrm{a}$ & $\mathrm{n} / \mathrm{a}$ & $\begin{array}{l}\mathrm{B}^{* * *} \\
\mathrm{C}^{* *}\end{array}$ & $\mathrm{n} / \mathrm{a}$ & $\mathrm{n} / \mathrm{a}$ \\
\hline Cervical cancer screening & $\mathrm{n} / \mathrm{a}$ & $\mathrm{n} / \mathrm{a}$ & $\mathrm{n} / \mathrm{a}$ & $\mathrm{n} / \mathrm{a}$ & 9.7 & 22.2 & 23.6 & 18.4 & $\mathrm{n} / \mathrm{a}$ & $\mathrm{n} / \mathrm{a}$ & $\mathrm{n} / \mathrm{a}$ & $\mathrm{n} / \mathrm{a}$ & $\mathrm{n} / \mathrm{a}$ & $\begin{array}{l}\mathrm{A}^{* * *} \\
\mathrm{~B}^{* * *}\end{array}$ & $\mathrm{n} / \mathrm{a}$ \\
\hline $\begin{array}{l}\text { HIV and STI care and treatment } \\
\text { ( } \mathrm{n} \text { range) }\end{array}$ & $7-509$ & $18-525$ & $13-507$ & $\begin{array}{c}38- \\
1541\end{array}$ & $36-561$ & $39-555$ & $40-547$ & $\begin{array}{l}115- \\
1663\end{array}$ & $43-1070$ & $57-1080$ & $53-1054$ & $153-3204$ & $38-1541$ & $115-1663$ & $\begin{array}{l}153- \\
3204\end{array}$ \\
\hline HIV care and treatment & 5.1 & 5.9 & 6.3 & 5.8 & 10.7 & 13.0 & 13.3 & 12.3 & 8.0 & 9.5 & 10.0 & 9.2 & & & \\
\hline STI care and treatment & 5.1 & 4.2 & 4.3 & 4.5 & 3.9 & 4.0 & 4.6 & 4.1 & 4.5 & 4.1 & 4.5 & 4.3 & & & \\
\hline TB testing & 23.1 & 25.8 & 40.0 & 29.9 & 16.9 & 23.9 & 36.1 & 26.2 & 18.8 & 24.5 & 37.3 & 27.3 & & $B^{*}$ & $B * *, C *$ \\
\hline CD4 testing & 53.8 & 77.4 & 70.0 & 67.8 & 67.8 & 71.8 & 72.2 & 70.8 & 63.5 & 73.5 & 71.6 & 69.9 & A† & & \\
\hline Initiated ARVa & 85.7 & 100.0 & 100.0 & 97.4 & 94.4 & 100.0 & 97.5 & 97.4 & 93.0 & 100.0 & 98.1 & 97.4 & & & $\mathrm{~A} \dagger$ \\
\hline Psychosocial support & 23.1 & 22.6 & 20 & 21.8 & 11.9 & 8.6 & 15.3 & 11.9 & 15.3 & 12.9 & 16.7 & 14.9 & & & \\
\hline Partner (n) & 371 & 399 & 361 & 1146 & 494 & 492 & 482 & 1468 & 857 & 873 & 849 & 2579 & 1146 & 1468 & 2579 \\
\hline HIV testing and counselling & 40.5 & 40.7 & 42.8 & 41.3 & 28.9 & 30.6 & 36.4 & 31.9 & 33.9 & 35.1 & 39.2 & 36.0 & & $\mathrm{~B}^{*}, \mathrm{C} \dagger$ & $\mathrm{B}^{*}, \mathrm{C} \dagger$ \\
\hline Family planning & 25.1 & 23.9 & 21.4 & 23.4 & $\mathrm{n} / \mathrm{a}$ & $\mathrm{n} / \mathrm{a}$ & $\mathrm{n} / \mathrm{a}$ & $\mathrm{n} / \mathrm{a}$ & $\mathrm{n} / \mathrm{a}$ & $\mathrm{n} / \mathrm{a}$ & $\mathrm{n} / \mathrm{a}$ & $\mathrm{n} / \mathrm{a}$ & & $\mathrm{n} / \mathrm{a}$ & $\mathrm{n} / \mathrm{a}$ \\
\hline $\begin{array}{l}\text { Voluntary medical male } \\
\text { circumcision }\end{array}$ & $\mathrm{n} / \mathrm{a}$ & $\mathrm{n} / \mathrm{a}$ & $\mathrm{n} / \mathrm{a}$ & $\mathrm{n} / \mathrm{a}$ & 3.6 & 6.3 & 5.4 & 5.1 & $\mathrm{n} / \mathrm{a}$ & $\mathrm{n} / \mathrm{a}$ & $\mathrm{n} / \mathrm{a}$ & $\mathrm{n} / \mathrm{a}$ & $\mathrm{n} / \mathrm{a}$ & A† & $\mathrm{n} / \mathrm{a}$ \\
\hline Cervical cancer screening & 12.6 & 14.9 & 13.7 & 13.8 & $\mathrm{n} / \mathrm{a}$ & $\mathrm{n} / \mathrm{a}$ & $\mathrm{n} / \mathrm{a}$ & $\mathrm{n} / \mathrm{a}$ & $\mathrm{n} / \mathrm{a}$ & $\mathrm{n} / \mathrm{a}$ & $\mathrm{n} / \mathrm{a}$ & $\mathrm{n} / \mathrm{a}$ & & $\mathrm{n} / \mathrm{a}$ & $\mathrm{n} / \mathrm{a}$ \\
\hline HIV care and treatment & 5.5 & 7.4 & 6.3 & 6.4 & 8.7 & 9.1 & 10.2 & 9.3 & 7.3 & 8.3 & 8.5 & 8.0 & & & \\
\hline STI care and treatment & 4.3 & 4.5 & 4.2 & 4.4 & 4.1 & 2.3 & 4.2 & 3.6 & 4.2 & 3.3 & 4.2 & 3.9 & & $\mathrm{C} \dagger$ & \\
\hline
\end{tabular}


TABLE 10 Descriptive statistics of service uptake outcomes at six months by study arm (cont'd)

\begin{tabular}{|c|c|c|c|c|c|c|c|c|c|c|c|c|c|c|c|}
\hline \multirow{2}{*}{$\begin{array}{l}\text { Uptake of services at } 6 \\
\text { months } \\
\text { Arm }\end{array}$} & \multicolumn{4}{|c|}{ Males } & \multicolumn{4}{|c|}{ Females } & \multicolumn{4}{|c|}{ Total } & \multicolumn{3}{|c|}{ Tests } \\
\hline & $\begin{array}{l}1 . \\
\text { Standard } \\
\text { of care }\end{array}$ & $\begin{array}{l}2 . \\
\text { Enhanced } \\
\text { referral }\end{array}$ & $\begin{array}{l}3 . \\
\text { Enhanced } \\
\text { referral } \\
\text { \& escort }\end{array}$ & Total & $\begin{array}{l}1 . \\
\text { Standard } \\
\text { of care }\end{array}$ & $\begin{array}{l}2 . \\
\text { Enhanced } \\
\text { referral }\end{array}$ & $\begin{array}{l}3 . \\
\text { Enhanced } \\
\text { referral } \\
\& \text { escort }\end{array}$ & Total & $\begin{array}{l}1 . \\
\text { Standard } \\
\text { of care }\end{array}$ & $\begin{array}{l}2 . \\
\text { Enhanced } \\
\text { referral }\end{array}$ & $\begin{array}{l}3 . \\
\text { Enhanced } \\
\text { referral } \\
\text { \& escort }\end{array}$ & Total & Males & Females & Total \\
\hline Child aged 15+ (n) & 35 & 41 & 29 & 105 & 109 & 86 & 101 & 294 & 144 & 127 & 130 & 401 & 105 & 294 & 401 \\
\hline HIV testing and counselling & 14.7 & 23.5 & 32.1 & 22.9 & 23.3 & 24.4 & 26.0 & 24.6 & 21.2 & 24.1 & 27.4 & 24.1 & & & \\
\hline Family planninga & 0.0 & 0.0 & 3.6 & 1.0 & 5.6 & 2.4 & 8.9 & 5.8 & 4.2 & 1.7 & 7.8 & 4.6 & & & $\mathrm{C} \dagger$ \\
\hline $\begin{array}{l}\text { Voluntary medical male } \\
\text { circumcisiona }\end{array}$ & 14.7 & 9.8 & 13.3 & 12.4 & 4.6 & 3.5 & 8.0 & 5.4 & 7.0 & 5.5 & 9.2 & 7.3 & & & \\
\hline Cervical cancer screeninga & 5.7 & 0.0 & 0.0 & 2.0 & 7.3 & 9.5 & 11.9 & 9.5 & 6.9 & 6.6 & 9.3 & 7.6 & & & \\
\hline HIV care and treatmenta & 2.9 & 5.4 & 14.3 & 7.1 & 11.3 & 10.8 & 11.0 & 11.1 & 9.3 & 9.2 & 11.7 & 10.1 & & & \\
\hline STI care and treatment & 0.0 & 0.0 & 3.4 & 1.0 & 4.8 & 1.2 & 2.0 & 2.8 & 3.6 & 0.8 & 2.3 & 2.3 & & & \\
\hline
\end{tabular}

$* * * \mathrm{p}<.001 ; * * \mathrm{p}<.01 ; * \mathrm{p}<.05 ; \mathrm{p}<.10 ; \mathrm{n} / \mathrm{a}=$ not applicable for outcome

$A=\operatorname{Arms~} 1 \& 2, B=$ Arms $1 \& 3, C=$ Arms $2 \& 3$

Note: two cases are excluded for answering these questions for a six-week window instead of a six-month window.

Note: Sample sizes for client outcomes vary as each outcome is restricted to certain entry sites and a few participants chose to not disclose receipt of certain services.

Note: All tests are chi-square tests, unless otherwise noted.

a Tested using Fisher's exact test due to small cell sizes. 
The results for cervical cancer screening uptake are comparable between the six-week and six-month interval, with the experimental arms having significantly higher uptake rates than the standard of care arm. It is interesting to note, however, that the levels of CCS remained fairly stable in the experimental arms, while women were increasingly exposed to screening in the control arm. That said, women in the experimental arms were still more than twice as likely to have received cervical cancer screening if they received additional referral counseling than if they did not. This result remained highly statistically significant at $p<.001$ level.

The HIV care and treatment results indicate a consistent marginally higher uptake of general access to HIV services within a few percentage points among intervention clients relative to the controls. The effect seemed marginally more pronounced among women, but these results were not statistically significant at any level. There were, however, meaningful differences in the uptake of services for both females in the uptake of TB testing (although only statistically significant among females and in the total) and CD4 testing (although only statistically significant among males at the $p<.10$ level). By six months, females in the intervention arms were significantly $(p<.05)$ more likely to receive TB testing than were females in the standard of care, and this effect was significantly higher $(p<.05)$ in the full sample of males and females when an escort is provided. For instance, $37 \%$ of clients who were provided an escort received TB services by six months, nearly double that of the standard of care and $52 \%$ higher of a percentage of women than the enhanced referral arm without the escort. The results were less statistically impressive for CD4 testing uptake (being only significant at the $p<.10$ level only for men), but a consistent pattern was observed of higher service utilization.

For partners, the intervention also showed some, but not consistent effects by six months. For instance, there was a statistically significant $(p<.05)$ difference of about $8 \%$ between the uptake of HTC services for partners of female clients by six months when comparing the standard of care to the enhanced referral and escort arm; a somewhat smaller difference was found between intervention arms, suggesting the importance of the escort component alone for increasing HTC service uptake among partners. These results were largely the same when both males and females were pooled. In addition, there was a marginal increase in the uptake of VMMC by six months among partners of female clients in the experimental arms compared to the standard of care. Although marginally different at $p<.10$, it still implied a doubling of the rate of uptake, albeit at a very low percentage of cases. Partner HIV care and treatment also showed that the intervention arms had marginally higher uptake by partners of clients, but these results were minimal and do not reach any level of statistical significance. For children aged 15 and older of clients, there are small sample sizes to use to assess impact. Some of the results are consistent with expectations, and at least one (FP) marginally significant between intervention arms, but some are not. Overall, very little can be said about the impact of the program on children aged 15 and older of clients.

\section{Behavioral outcomes and satisfaction with services at six months}

The primary outcome of the intervention was an increase in the uptake of services within six months of exposure. That said, through the increase in service utilization, one should expect healthier outcomes for clients. For instance, women who were exposed to FP should have greater use of contraceptive methods; clients who were referred to male circumcision should be more likely to be circumcised; clients who were counseled on HIV prevention messaging, should have lower rates of higher risk sexual behavior, etc. Further, it was expected that clients who were provided more detailed, comprehensive and interactive services should reflect greater satisfaction with those services than those who had not received enhanced services. Bivariate associations assessing such outcomes are presented in Table 11 below for the six-month follow-up interview. Because of the similarity of results, a table of results for the six-week observations is included as Appendix Table A4. 
TABLE 11 Descriptive statistics of client behavioral outcomes at six months by study arm

\begin{tabular}{|c|c|c|c|c|c|c|c|c|c|c|c|c|c|c|c|}
\hline \multirow[b]{3}{*}{ Sample size } & \multicolumn{4}{|c|}{ Males } & \multicolumn{4}{|c|}{ Females } & \multicolumn{4}{|c|}{ Totals } & \multicolumn{3}{|c|}{ Tests } \\
\hline & $\begin{array}{c}1 . \\
\text { Standard } \\
\text { of care }\end{array}$ & $\begin{array}{c}2 . \\
\text { Enhanced } \\
\text { referral }\end{array}$ & $\begin{array}{c}3 . \\
\text { Enhanced } \\
\text { referral } \\
\& \\
\text { escort }\end{array}$ & Total & $\begin{array}{c}1 . \\
\text { Standard } \\
\text { of care }\end{array}$ & $\begin{array}{c}2 . \\
\text { Enhanced } \\
\text { referral }\end{array}$ & $\begin{array}{c}3 . \\
\text { Enhanced } \\
\text { referral } \\
\& \\
\text { escort }\end{array}$ & Total & $\begin{array}{c}1 . \\
\text { Standard } \\
\text { of care }\end{array}$ & $\begin{array}{c}2 . \\
\text { Enhanced } \\
\text { referral }\end{array}$ & $\begin{array}{c}3 . \\
\text { Enhanced } \\
\text { referral } \\
\& \\
\text { escort }\end{array}$ & Total & Males & Females & Total \\
\hline & 509 & 525 & 507 & 1,541 & 562 & 556 & 547 & 1,665 & 1071 & 1081 & 1054 & 3,206 & 1,541 & 1,665 & 3,206 \\
\hline \multicolumn{16}{|l|}{ Contraception } \\
\hline $\begin{array}{l}\text { Ever used } \\
\text { modern } \\
\text { contraception }\end{array}$ & $\mathrm{n} / \mathrm{a}$ & $\mathrm{n} / \mathrm{a}$ & $\mathrm{n} / \mathrm{a}$ & $\mathrm{n} / \mathrm{a}$ & 98.9 & 98.7 & 98.1 & 98.6 & $\mathrm{n} / \mathrm{a}$ & $\mathrm{n} / \mathrm{a}$ & $\mathrm{n} / \mathrm{a}$ & $\mathrm{n} / \mathrm{a}$ & $\mathrm{n} / \mathrm{a}$ & & $\mathrm{n} / \mathrm{a}$ \\
\hline $\begin{array}{l}\text { Currently using } \\
\text { contraception }\end{array}$ & $\mathrm{n} / \mathrm{a}$ & $\mathrm{n} / \mathrm{a}$ & $\mathrm{n} / \mathrm{a}$ & $\mathrm{n} / \mathrm{a}$ & 79.9 & 74.8 & 77.1 & 77.3 & $\mathrm{n} / \mathrm{a}$ & $\mathrm{n} / \mathrm{a}$ & $\mathrm{n} / \mathrm{a}$ & $\mathrm{n} / \mathrm{a}$ & $\mathrm{n} / \mathrm{a}$ & $A^{*}$ & $\mathrm{n} / \mathrm{a}$ \\
\hline $\begin{array}{l}\text { Currently using } \\
\text { modern } \\
\text { contraceptiona }\end{array}$ & $\mathrm{n} / \mathrm{a}$ & $\mathrm{n} / \mathrm{a}$ & $\mathrm{n} / \mathrm{a}$ & $\mathrm{n} / \mathrm{a}$ & 79.4 & 73.7 & 76.4 & 76.5 & $\mathrm{n} / \mathrm{a}$ & $\mathrm{n} / \mathrm{a}$ & $\mathrm{n} / \mathrm{a}$ & $\mathrm{n} / \mathrm{a}$ & $\mathrm{n} / \mathrm{a}$ & $A^{*}$ & $\mathrm{n} / \mathrm{a}$ \\
\hline $\begin{array}{l}\text { Currently using a } \\
\text { long-acting form } \\
\text { of contraception }\end{array}$ & $\mathrm{n} / \mathrm{a}$ & $\mathrm{n} / \mathrm{a}$ & $\mathrm{n} / \mathrm{a}$ & $\mathrm{n} / \mathrm{a}$ & 53.7 & 50.7 & 53.3 & 52.6 & $\mathrm{n} / \mathrm{a}$ & $\mathrm{n} / \mathrm{a}$ & $\mathrm{n} / \mathrm{a}$ & $\mathrm{n} / \mathrm{a}$ & $\mathrm{n} / \mathrm{a}$ & & $\mathrm{n} / \mathrm{a}$ \\
\hline \multicolumn{16}{|l|}{$\begin{array}{l}\text { Male } \\
\text { circumcision \& } \\
\text { resumption of } \\
\text { sex }\end{array}$} \\
\hline $\begin{array}{l}\text { Currently } \\
\text { circumcisedc }\end{array}$ & 55.7 & 63.6 & 64.7 & 61.4 & $\mathrm{n} / \mathrm{a}$ & $\mathrm{n} / \mathrm{a}$ & $\mathrm{n} / \mathrm{a}$ & $\mathrm{n} / \mathrm{a}$ & $\mathrm{n} / \mathrm{a}$ & $\mathrm{n} / \mathrm{a}$ & $\mathrm{n} / \mathrm{a}$ & $\mathrm{n} / \mathrm{a}$ & $A *, B * *$ & $\mathrm{n} / \mathrm{a}$ & $\mathrm{n} / \mathrm{a}$ \\
\hline $\begin{array}{l}\text { Sexual activity } \\
\text { within six weeks } \\
\text { of circumcision }\end{array}$ & 19.3 & 23.2 & 24.0 & 22.3 & $\mathrm{n} / \mathrm{a}$ & $\mathrm{n} / \mathrm{a}$ & $\mathrm{n} / \mathrm{a}$ & $\mathrm{n} / \mathrm{a}$ & $\mathrm{n} / \mathrm{a}$ & $\mathrm{n} / \mathrm{a}$ & $\mathrm{n} / \mathrm{a}$ & $\mathrm{n} / \mathrm{a}$ & & $\mathrm{n} / \mathrm{a}$ & $\mathrm{n} / \mathrm{a}$ \\
\hline \multicolumn{16}{|l|}{$\begin{array}{l}\text { Sexual activity } \\
\text { (among sexually } \\
\text { active in past } 12 \\
\text { months) }\end{array}$} \\
\hline $\begin{array}{l}\text { Sexually active in } \\
\text { last } 7 \text { days }\end{array}$ & 37.6 & 40.3 & 40.9 & 39.6 & 46.8 & 46.9 & 43.3 & 45.7 & 42.7 & 43.8 & 42.3 & 42.9 & & & \\
\hline $\begin{array}{l}\text { Sexually active in } \\
\text { last } 30 \text { days }\end{array}$ & 64.2 & 70.0 & 68.5 & 67.6 & 74.5 & 79.2 & 76.9 & 76.8 & 69.9 & 74.9 & 73.2 & 72.7 & $\mathrm{~A} \dagger$ & $\mathrm{A} \dagger$ & $A^{*}$ \\
\hline $\begin{array}{l}\text { Unprotected sex } \\
\text { in last } 7 \text { days }\end{array}$ & 21.5 & 19.5 & 21.7 & 20.9 & 27.0 & 25.1 & 26.1 & 26.1 & 24.5 & 22.5 & 24.2 & 23.7 & & & \\
\hline $\begin{array}{l}\text { Unprotected sex } \\
\text { at last sex in } \\
\text { past } 12 \text { months }\end{array}$ & 42.6 & 48.3 & 45.6 & 45.5 & 65.3 & 63.6 & 67.3 & 65.4 & 55.2 & 56.4 & 57.7 & 56.4 & & & \\
\hline $\begin{array}{l}\text { Multiple sexual } \\
\text { partners in past } \\
12 \text { months }\end{array}$ & 27.3 & 28.3 & 25.5 & 27.1 & 9.8 & 11.8 & 12.0 & 11.2 & 17.5 & 19.5 & 18.0 & 18.3 & & & \\
\hline
\end{tabular}


TABLE 11 Descriptive statistics of client behavioral outcomes at six months by study arm (con't)

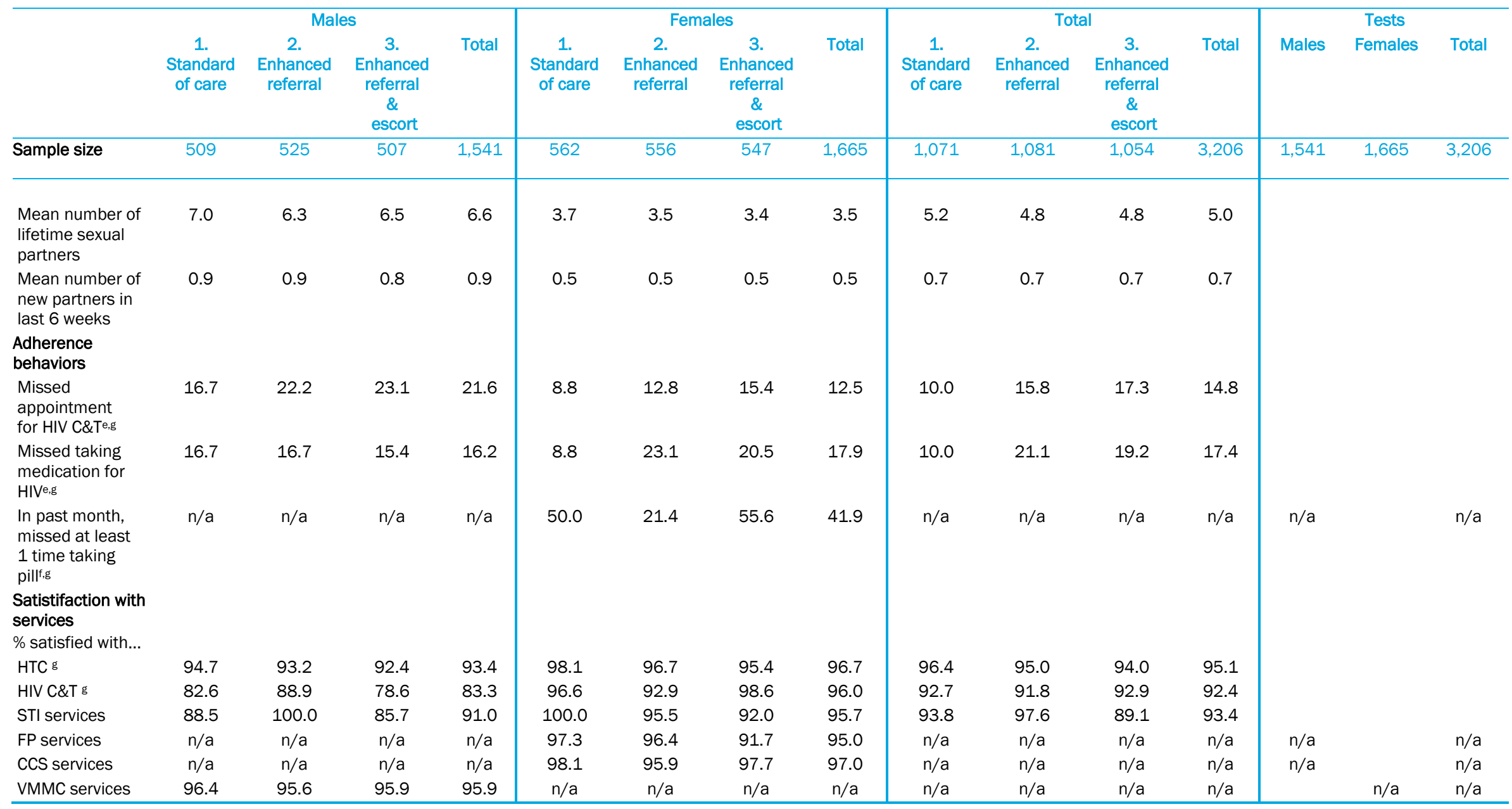

$* * * p<.001 ; * * p<.01 ; * p<.05 ; \uparrow p<.10$

$A=\operatorname{Arms} 1 \& 2, B=$ Arms $1 \& 3, C=$ Arms $2 \& 3$

Note: Sample sizes vary according to outcome.

Note: All tests are chi-square for categorical outcomes or t-tests for continuous outcomes, unless otherwise noted.

a Methods include male or female condom, oral contraceptive pill, injectable, diaphragm, foam/jelly, IUD, implant, lactational amenorrhea and sterilization.

b Methods include IUD, implant, and sterilization. 
Constructed using the client database for male circumcision received at registration, in addition to survey data.

Among all those who got circumcised, although it was not yet 6 weeks post-circumcision for all clients.

e Among those taking ARV.

${ }^{f}$ Among women who went to FP and are currently taking pill, not all women currently taking pill. 
The results in Table 11 for the indicators that could be assessed do not show significant longer term differences in behavioral outcomes from the intervention. ${ }^{16}$ The results for FP in-fact were in a direction opposite to what was originally hypothesized at the start of the study in that a greater percentage of clients in the standard of care arm currently using contraception and currently using any modern method $(p<.05)$. These results were not as anomalous as might be considered at first because, as shown in Tables 9 and 10, the intervention arms did not consistently improve the uptake of FP services among female clients. The outcome results for VMMC, however, were consistent with the service uptake indicators in that by the end of six months a significantly greater percentage of the male sample had been circumcised in both study arms relative to the control arm. Other behavioral indicators, including the resumption of sex after circumcision, sexual risk behaviors, and adherence to HIV regimens did not show any longer term impacts from the intervention. Although one might hope that one or two intensive counseling sessions with $\mathrm{Ml}$ techniques might improve behavioral outcomes, these results provided evidence confirming that client behavior change is not easily achieved with relatively modest exposure to risk reduction.

A final set of indicators tested the hypothesis that a more intensive and involved process in which client needs are properly assessed, more time is afforded the client, materials offered and a more intensive interaction with staff through the counsellors and escorts would lead to greater client's satisfaction with services. The results in the bottom panel of Table 11, however, indicate that client satisfaction with services in all arms was very high to begin with and in some services approaching universal satisfaction. As indicated by the significance tests assessing differences by study arm, client satisfaction did not vary by study arm and did not reach levels of statistical significance for any indicator. These results point to a common finding in the literature regarding client satisfaction in that there is not a strong relationship between quality of services and client assessments of services, mainly because clients have such low expectations of the services provided.[61, 62]

\section{Multivariable logistic regression analysis}

Multivariable analyses were conducted on each of the key uptake indicators. Three separate logistic models were run for each outcome. The first model included indicators only for the two experimental arms, with the standard of care serving as the reference category. In the assessment of the impact of the intervention, these results produced conclusions equivalent to those presented in the pairwise bivariate assessments conducted previously, but were expressed in terms of odds ratios. The second regression model added indicators for each site to see if the intervention outcomes varied by site. The final model added to this a set of key baseline covariates of interest thought to be potentially related to the uptake of services. The indicators were included because of their substantive interest, as well as their potential for increasing the precision of the estimates of intervention impact.

Table 12 indicates that the assessment of the impact of the intervention did not change when site variables and baseline covariates were added to the model. ${ }^{17}$ In particular, where the study results were the strongest, specifically with regard to HTC, VMMC services, cervical cancer screening and uptake of TB and CD4 testing by clients, the results were robust to model specification. As discussed previously in detail by service, the findings provide confirmation that the introduction of enhanced counselling and follow-up of clients, with and without an escort, significantly increased the reported uptake of an array of key health services by six weeks and six months.

\footnotetext{
${ }^{16}$ It should be noted that an assessment of whether the client ever received HTC services was not possible because by six months nearly $100 \%$ of clients had been tested at some point in their lives. This is because all HTC and VMMC clients receive testing as part of services. Also, all FP clients had given birth at least once and HIV testing is mandatory component of antenatal services. A more appropriate indicator would be testing within the previous three months, but this was not asked in the interview at six weeks and six months. The survey instrument also did not include questions about ever been screened for cervical cancer.

${ }^{17}$ The same regression analysis conducted on the six-week outcomes is provided in Appendix Table A5. The results of the analysis using multiple imputation are similar and provided in Appendix Tables A7 and A8.
} 
TABLE 12 Multivariable logistic regression of impact of intervention on six-month service uptake outcomes (Behavioral indicators from descriptive uptake table)

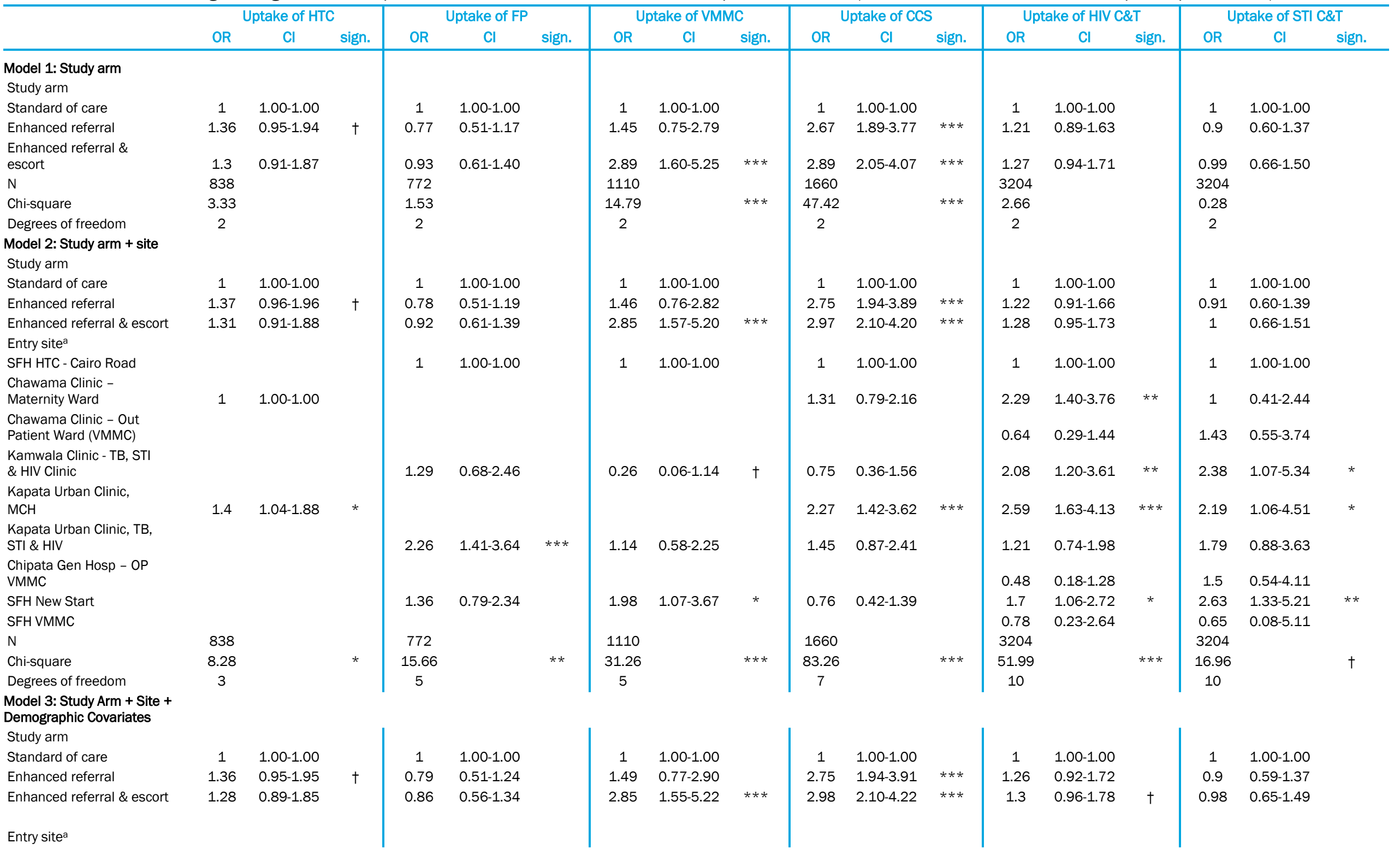


TABLE 12 Multivariable logistic regression of impact of intervention on six-month service uptake outcomes (con't)

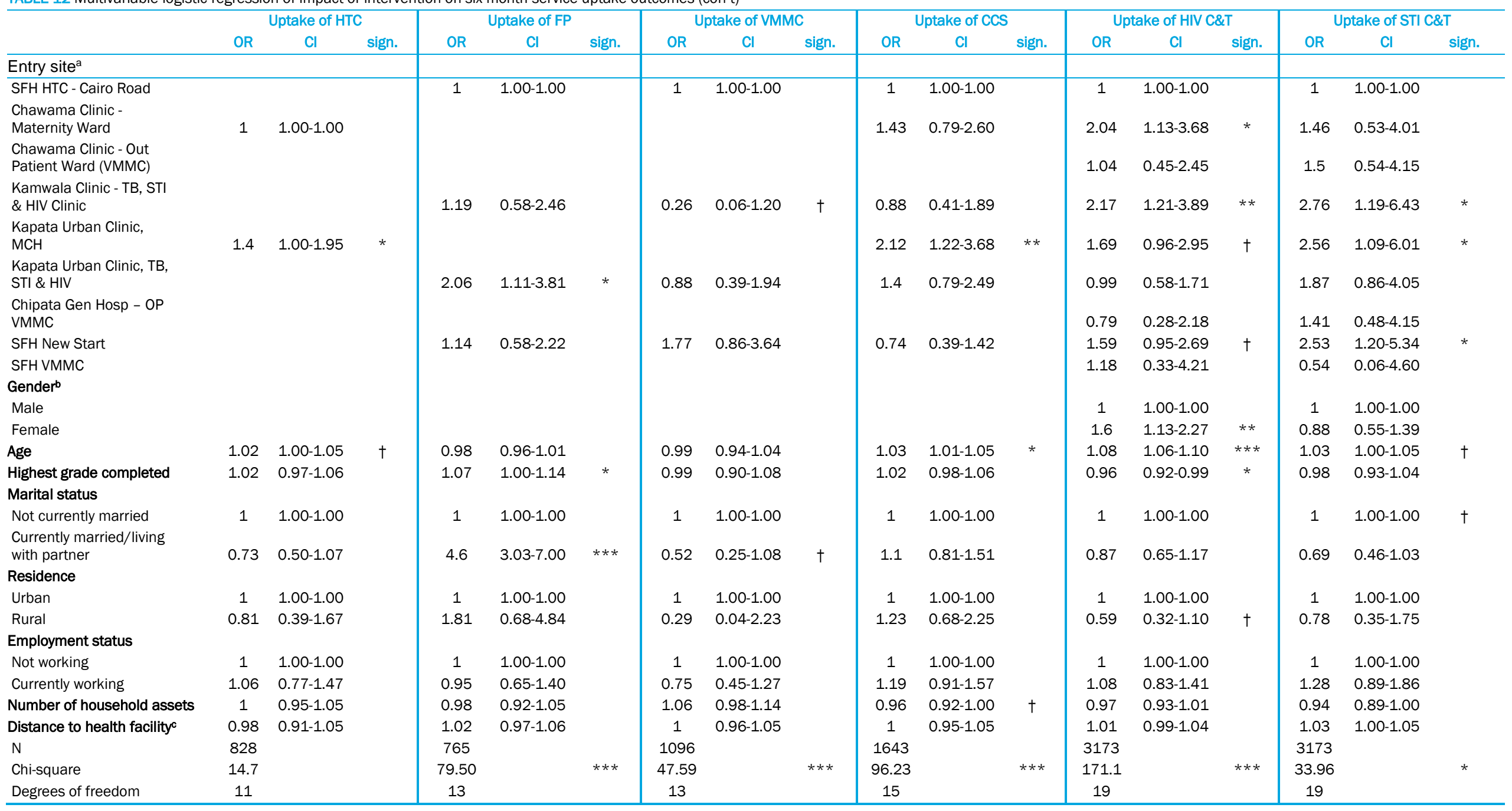

$* * * p<.001 ; * * p<.01 ; * p<.05 ;+p<.10$

a Entry sites included in model dependent on outcome variable.

$\mathrm{b}$ Gender of outcome variable constant if omitted from model.

c 38\% don't know distance, therefore a dummy was also included (1 = Yes if don't know distance) 
The results in Table 12 also reveal significant differences in the success of the services as implemented at different sites. For instance, referrals that originated from the SFH New Start site in Chipata were significantly more likely by a factor of more than three to lead to uptake of VMMC services within six weeks than its counter-part in Lusaka (Appendix Table A5), although the effect diminished to a factor of two by six months. For cervical cancer screening, the Kapata Urban Clinic, Maternal and Child Health department (FP entry point) and its TB, STI \& HIV department (HTC entry point) was also significantly more likely to produce referral uptake than other sites. The nature of these site effects is unknown. They may be attributable to differences in the characteristics of clients who come to these sites relative to others. The results may have had to do with the quality of the staff and implementation at the sites or with the relative ease of access to services. In the case of the latter, distance to the entry point health facility did not seem of matter in terms of uptake of either case of VMMC or CCS or in other services. ${ }^{18}$

There were also some interesting differences in service uptake by baseline demographic characteristics. For instance, men who were referred for VMMC services have a $42 \%$ lower odds $(p<$ .05) of up taking services with six weeks if they were currently employed (Appendix Table A5). The impact of employment on VMMC uptake does reduce over time (to $25 \%$ lower odds at six months) and loses statistical significance, suggesting that employed men are ultimately able to adjust their schedules to accommodate their circumcision. The importance of employment status on VMMC uptake has been indicated in previous research[63] and is also noted in the next section as a key barrier to services. Another set of interesting findings from the baseline characteristics was that females are significantly $(p<.001)$ more likely report accessing HIV care and treatment than were their male counterparts and this effect was persistent over time. Women had $75 \%$ greater odds within six weeks (Appendix Table A5) and 60\% greater odds at six months of reporting access to HIV services than were males. Older participants were also more likely to take up HIV care and treatment, as were participants with a lower number of completed years of education.

\section{QUALITATIVE ANALYSIS}

\section{Client interviews}

Qualitative interviews with clients were collected for the purposes of understanding their interactions with the health facilities and their staff, as well as to detail the barriers and facilitators to service uptake. Understanding how and in what way the various services were provided and how the enhanced service and follow-up models did or did not lead to the uptake of add-on services was useful supplementary information for assessing the study's primary outcomes.

As indicated in Table 13, a total of 120 semi-structured interviews were conducted across nine family planning, HTC, and VMMC sites in Chipata and Lusaka between September 2014 and February 2015. About $18 \%$ of the semi-structured interviews were conducted among FP clients, $73 \%$ among HTC clients and $11 \%$ among VMMC clients, roughly following the pattern of recruitment by service entry point observed during fieldwork.

${ }^{18}$ A more refined indicator of access, specifically distance from the entry point to the referral site will be tested in subsequent analyses as the information remains to be imputed to the data set. 
TABLE 13 Client qualitative interviews sample by study arm \& entry service

\begin{tabular}{lcccc}
\hline & $\begin{array}{c}\text { Standard of care } \\
\text { (Study arm 1) } \\
\mathrm{N}(\%)\end{array}$ & $\begin{array}{c}\text { Enhanced referral \& } \\
\text { follow-up } \\
\text { (Study arm 2) } \\
\mathrm{N}(\%)\end{array}$ & $\begin{array}{c}\text { Enhanced referral \& } \\
\text { follow-up } \\
\text { (Study arm 3) } \\
\mathrm{N}(\%)\end{array}$ & $\begin{array}{c}\text { Total } \\
\mathrm{N}(\%)\end{array}$ \\
\hline FP & $11(23.40)$ & $7(16.67)$ & $4(12.90)$ & $22(18.33)$ \\
HTC & $32(68.09)$ & $31(73.81)$ & $24(77.42)$ & $87(72.50)$ \\
VMMC & $4(8.51)$ & $4(9.52)$ & $3(9.68)$ & $11(9.17)$ \\
Total & $47(100.00)$ & $42(100.00)$ & $31(100.00)$ & $120(100.00)$ \\
\hline
\end{tabular}

\section{Referral experience}

As indicated in Figure 1, across all three study arms, at least 95\% of clients reported that their entry service provider counseled them on one or more add-on service. Usually the provider asked if the client or his/her partner had ever accessed the add-on service; discussed the benefits of the service; and indicated where the services were provided. Counselors provided information, education, and communication (IEC) materials in approximately $23 \%$ of the encounters in the standard of care and enhanced referrals and follow-up with escort services (study arm 3), and 35\% of the encounters in study arm 2. Often, the clients reported these materials had been given to them for sharing what they learned about the add-on service with their partners, relatives, or friends.

\section{FIGURE 1 SUMMARY OF CLIENT DISCUSSIONS OF REFERRAL, FOLLOW-UP, AND UPTAKE}

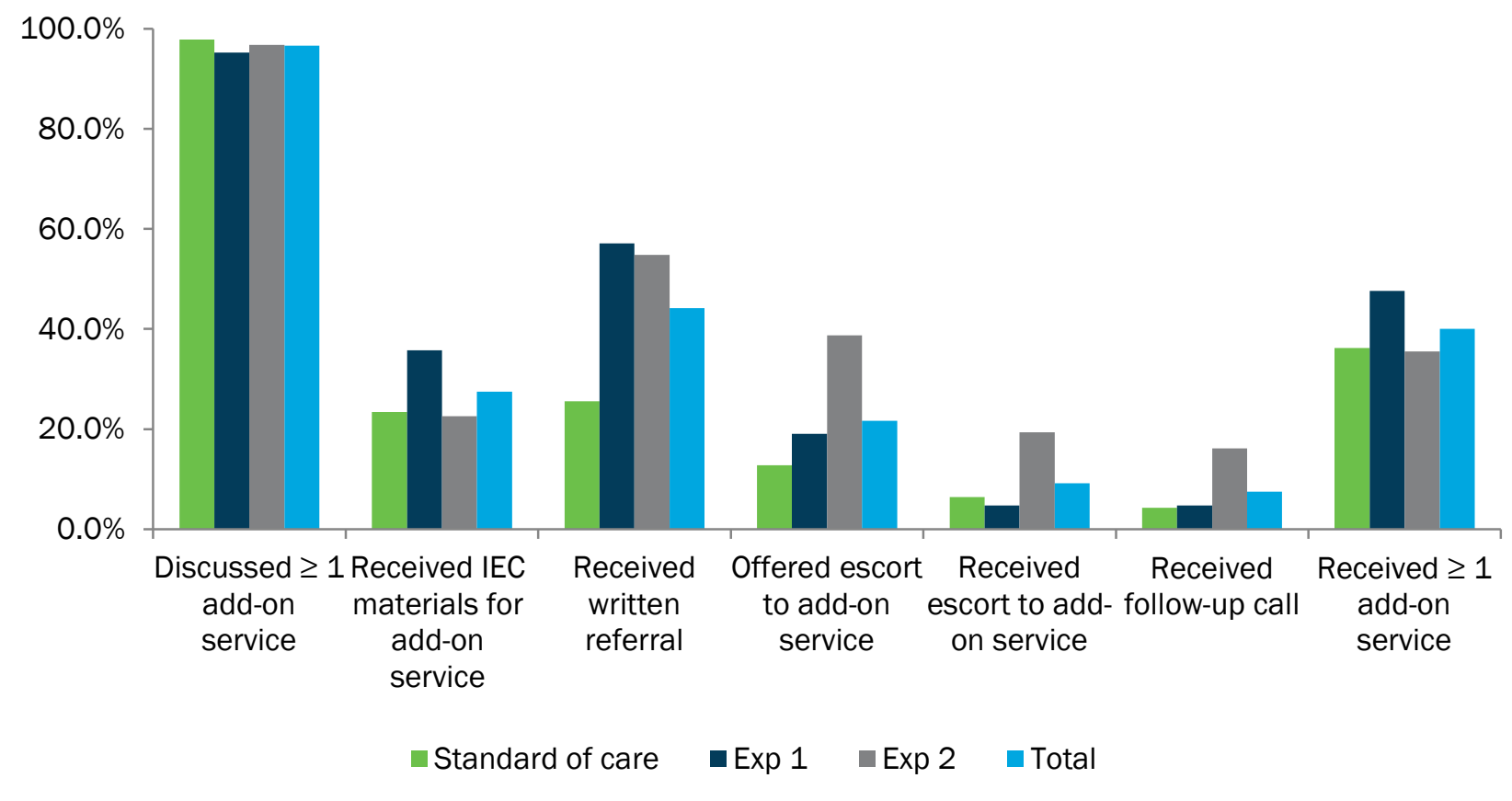

I was given family planning materials and I gave [them to] my wife... she found them useful because she said that [some] methods are better than others."

(ID 07-0161, male, HTC client, study arm three, referred for FP) 
I was told to go and tell my husband to go for circumcision if he agrees to do so. She even gave me some papers [with information about circumcision] to go and give my husband. (ID 07-0201, female, HTC client, standard of care, referred for VMMC)

Though add-on services were reported to be widely discussed across all arms at similar rates, written referrals were more frequently given to clients study arm two (57\%) and study arm three (55\%) compared to those in the standard of care (26\%). Escorts to an add-on service were reported being offered to $39 \%$ of clients in study arm three. Approximately $13 \%$ of clients in the standard of care and $19 \%$ of clients in study arm two also reported being offered an escort to an add-on service. In a number of cases, however, the clients were not yet ready to seek an add-on service on the day of their initial visit and refused the escort altogether or were told to come back when they were ready to be escorted.

She said that when I make up my mind about going for male circumcision, then I [should] come and get the referral slip and a person to escort [me] to the hospital from [the clinic]. (ID 11-0082, male, HTC client, study arm three, referred for VMMC)

Yes, the counsellor told me that if I wanted to go on the same day, he would escort me...he did not escort me because I wanted to consult with my wife first.

(ID 11-0504, male, HTC client, standard of care, referred for VMMC)

Relatively few clients reported receiving follow-up phone calls and only one client reported a home visit. Nearly all of the follow-up contact reported was in relation to male circumcision. Two clients indicated that receiving a phone call about circumcision made them feel that the providers were caring and the service was very important:

Interviewer: So after they had called you, did this explanation that they made, make you feel like you needed to go and get [circumcised]?

Respondent: Yes, because once I was called, then after I just cut the line I was like, "Uh, okay, I'm sure [male circumcision] is very important for them to call me [about it]. I'm sure they are very much caring and they know the benefits of me going that side [to the hospital]."

(ID 01-0113, male, HTC client, standard of care, referred for VMMC)

Interviewer: What did the person who called you tell you?

Respondent: They just told me that, "[Client name], we want you here so that you should come for circumcision..." but that time we were writing tests in school so I told them that I was writing tests, I will come later.

Interviewer: Okay, how did the call make you feel?

Respondent: I felt good after I received this call; it made me feel like these people really want me to go for circumcision so that I am healthy.

(ID 07-0321, male, HTC client, study arm two, referred for VMMC)

\section{Reasons for uptake of add-on services}

The majority of clients $(\geq 82 \%)$ in all three study arms reported that their decision to seek an add-on service was influenced by the referral they received from their provider during the entry service visit. In most cases, clients were not aware of the service or had misconceptions about it prior to being 
counseled by the provider. In a few cases, the clients indicated that they had already decided to seek an add-on service prior to their entry service visit and therefore were not influenced by the provider's referral.

I thought maybe it's only Muslims who go for circumcision; I didn't know that anyone can go. He helped me in a way of teaching me, because I didn't know anything but after counseling me, that's when I knew that I can take my child. I was satisfied because after counseling us, we knew the benefits. At least he opened our minds. You know living in the [high density, low income neighborhoods] you find this one saying this, that one that, so after counseling that's when we knew the truth.

(ID 07-0302, female, HTC client, standard of care, son referred for VMMC)

At first I was afraid because in the compounds where we stay people say a lot of things like "family planning brings cancers"...from what I was told there [at the clinic], I discovered that [family planning] is just okay. I even like the injection that I got because it has not given me any problem.

(ID 02-0321, female HTC client, study arm two, referred for FP)

Interviewer: So when you talked to this person about cervical cancer, is her explanation that made you feel like you want to go for cervical cancer [screening]?

Respondent: No, even before talking to them I wanted [to go for screening] because my sister has done the same. My sister asked me on whether I have done the screening, but I told her that I am afraid because I was told that an object is inserted into the private part. But I was told [by my sister] that is not true and no object is inserted. That's how I had hope that I must go...

(ID 02-0163, female FP client, standard of care, referred for cervical cancer screening)

\section{Barriers to uptake of add-on service}

In all three study arms, the most frequent reason for not seeking an add-on service was that the client, partner or dependents were currently using or had previously received the service. Among those who had not already accessed the add-on service, the top inhibitors cited included lack of free time, client or partner lack of interest, fears about the procedure, and challenges accessing add-on service. 
FIGURE 2 CLIENT REASONS FOR NON-UPTAKE OF ADD-ON SERVICE

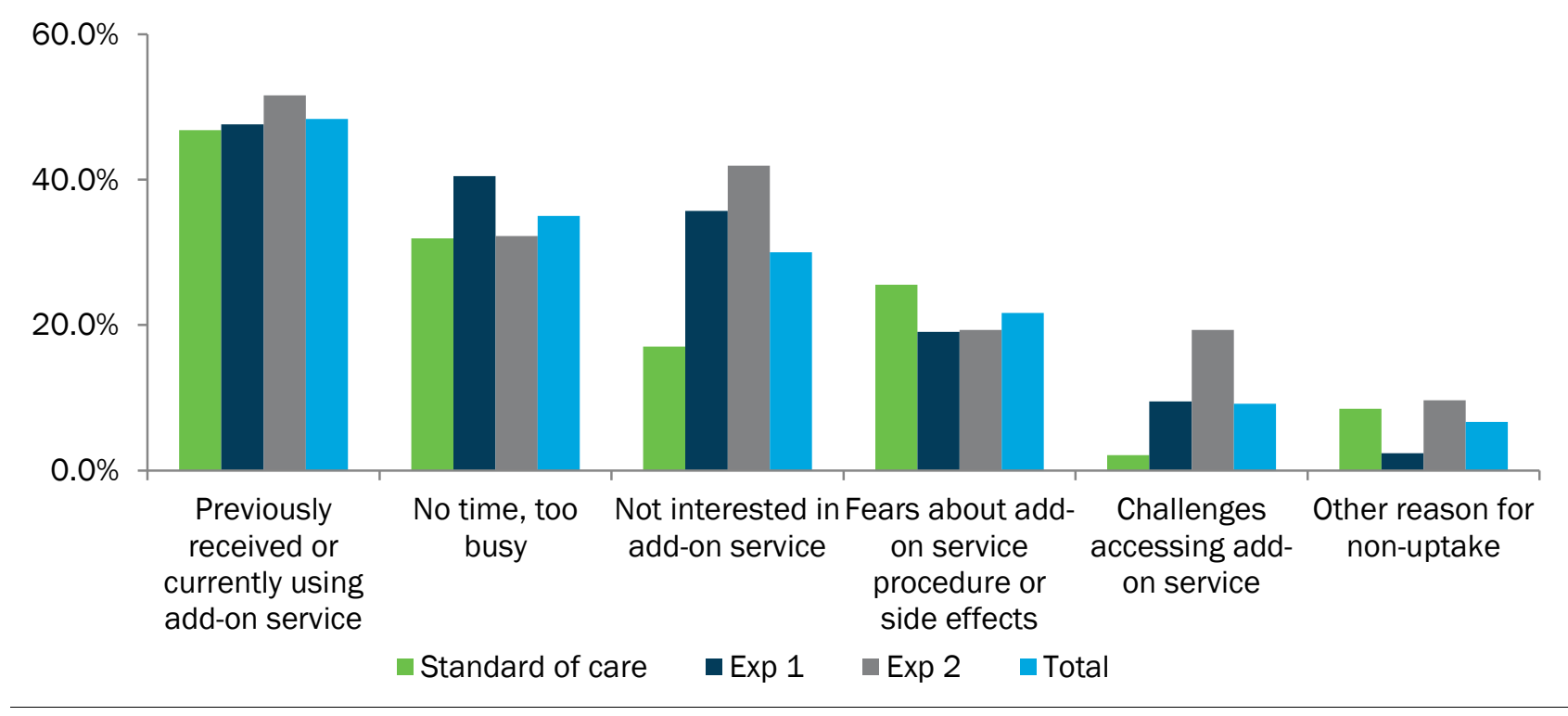

Approximately $32 \%$ of clients in the standard of care arm and study arm three and $41 \%$ in study arm two stated they did not seek the add-on service recommended by the provider because they were too busy or did not have the time. Most of these clients were referred for VMMC and expressed concerns about the healing process leading to lost wages from missing work or absences. A few also mentioned that their expectation of long waiting times at the clinics dissuaded them from seeking an add-on service. These data confirm findings from other studies that have revealed opportunity costs of VMMC on uptake and access to services to be key inhibitors to VMMC uptake.[63]

I was given a referral slip but I didn't go because I am a very busy person. Let me tell you the truth, I hate hospitals and if I go to [the clinic], there are long lines of people and my boss is waiting for me to report for work and if I don't work, they deduct from my salary, so I can't manage to find time.

(ID 01-0269, female, HTC client, study arm two, referred for cervical cancer screening)

I told the counsellor that I am busy with school. I will go for circumcision but I do not have time because I cannot balance studying and taking care of the wound.

(ID 07-0135, male, HTC client, study arm three, referred for VMMC)

For me, money is hard to find. So if I go for male circumcision, it will take one week for wound to heal... [my children] will start suffering and will not have money to pay rentals and you know jobs of these days, if I miss work for a week I may get fired, so this can be a problem to me. My parents stay very far, so no one will help me at home as I wait for the wound to heal. But I want to go for male circumcision because I want to protect myself from diseases. (ID 11-0507, male, HTC client, study arm three, referred for VMMC)

Fewer than $20 \%$ of the clients in the standard of care arm cited lack of interest in the add-on service as a reason for non-uptake compared to $36 \%$ and $42 \%$ in the study arms two and three, respectively. 
Often, these clients explained that the add-on service was necessary due to their reported sexual behaviors or fertility preferences. In many cases, the client's partner's opinion about the add-on service strongly influenced their service-seeking decision.

I was not interested because from the conversation we had, it's not that I wanted family planning, I just wanted to find out...because then if I remember well, I wanted to get pregnant... yes. So I wanted to find out things ... I wasn't really interested in the family planning.

(ID 01-0152, female, HTC client, standard of care, referred for FP)

I did not go because after explaining to my wife she starting saying that I might start being unfaithful to her if I did circumcision.

(ID 11-0504, male, HTC client, standard of care, referred for VMMC)

They said I should go and explain to my husband that circumcision is good, it prevents diseases...so when I went home, I explained to him.... so he said that he does not have any other woman; even if he goes for male circumcision, what would he go there for? (ID 07-0303, female, HTC client, study arm three, husband referred for VMMC)

One fifth of the clients in study arms two and three and one quarter of the clients in the standard of care arm indicated that fear prevented them from seeking an add-on service. In most cases, this related to fears about pain associated with the VMMC procedure and unwanted side effects associated with use of contraception.

I have a neighbor he is a police officer, he went for male circumcision I do not know if it is because of his body or it is the way he was circumcised, he suffered with his wound so that is why I am scared.

(ID 07-0431, male, HTC client, standard of care, referred for VMMC)

I can't advise [my partner] to take family planning while she doesn't have any child or what because I heard that the family planning, sometimes it affect the woman in the stomach. (ID 03-0084, male, VMMC client, standard of care, referred for family planning)

Like my children, I had gone with them [taken them to get circumcised] but I came back because they were scared after hearing their friends [other children getting circumcised] screaming so they said, 'it seems that it is painful let us go back home.' (ID 07-0352, female, HTC client, study arm two, referred for VMMC)

Almost $20 \%$ of clients in study arm three faced challenges accessing an add-on service and, as a result, did not receive the service. Comparatively, only $10 \%$ and $2 \%$ of clients in study arm two and the standard of care arm reported such challenges, respectively. In many cases, long queues and the distance between the client's home and the health facility created barriers to service-seeking. Some clients also reported issues related to service availability, particularly related to cervical cancer screening.

The day that I came here so that I can start the process [get circumcised], there were so many people. I thought it was going to take a long time waiting before I could get circumcised, so from that day since I have not had time to come and get circumcised... 
(ID 11-0250, male, HTC client, study arm two, referred for VMMC)

Interviewer: Do you want your son to go for circumcision?

Respondent: Yes, I do, but then we are limited with transport from the village to here.

(ID 11-0250, male, HTC client, study arm two, son referred for VMMC)

They asked me if I have tested for [cervical] cancer and I said "no," then they advised me to go for screening and took me to the room where this was done, but it was locked...I have tried going there twice now but I have found the place locked on both occasions.

(ID 02-0361, female, FP client, study arm three, referred for cervical cancer screening)

\section{PROVIDER INTERVIEWS}

A total of 20 (71\%) out of 28 of the FP, male circumcision, and HTC providers from six clinics in Lusaka and Chipata participated in qualitative interviews. ${ }^{19}$ Those not interviewed were no longer working at the site, on leave, or unreachable. This sample of providers comprised four FP nurses, five VMMC psychosocial counselors, and eleven HTC psychosocial counselors. Four of the interviewed providers participated in the standard of care arm of the evaluation, while sixteen participated in the experimental arms.

\section{Barriers to recommending add-on services}

\section{Facility and provider preparedness}

Half the providers noted that inadequate space in the facilities served as a barrier to recommending add-on services to their clients. Due to this limited space, rooms were often used for multiple services and, at times, spaces such as the clinic store room or kitchen were used for counseling. The providers felt that these constraints compromised their clients' privacy and comfort.

I would say space was a challenge for the study, because you find that the rooms that they have given you at a particular clinic, there are other activities taking place so there wouldn't be that much confidentiality there or maybe they give you a store room and maybe it's not conducive. So at least if there is a good space and clean environment at least the service could have been better than the way it was. (FP-CHAWAMA-ID2-

EXPERIMENTAL ARM)

The majority of providers also cited human resource shortages and the consequent heavy workload as a barrier to recommending add-on services. The respondents reported that the number of counselors on duty was often insufficient for dealing with the high client volumes at the clinics. The providers often felt the need to lead group counseling sessions paired with brief individual counseling in order to maximize the number of clients they could attend to in a day. As a result, the providers had limited time to counsel and answer questions about the add-on services that they were recommending to their clients. 19 The sites in Lusaka included SFH New Start HTC, Kamwala and Chawama clinics. The sites in Chipata PSi
included SFH VMMC, Kapata clinic and Chipata General Hospital. 
It's not easy if you have a lot of clients... there are some who really need information because there are some who get information easy and some who don't get it easily, so you need enough time. You need to be patient with them so it's quite difficult there; especially if there are a lot of clients. But if there [are] not too many clients, it's easy to give out information. (HTC-KAMWALA-ID2-EXPERIMENTAL ARM)

While most providers felt that they knew enough about add-on services to refer and discuss basic information with their clients, some noted that their knowledge of add-on services was limited and potentially outdated.

I think every now and then [providers need] to be updated on the new techniques, whatever is there on the market now....now we have old people in the service [and] we have the new ones [recently trained providers] so that level [of knowledge] is not there. So if we can be at the same level with adequate information, then we can still work well. (FPKAPATA-ID1-EXPERIMENTAL ARM)

\section{Client willingness and attitudes toward add-on services}

More than half the providers indicated that clients' negative attitudes, fears, and misconceptions about certain health services served as a barrier to utilizing add-on services. For example, providers experienced challenges referring clients who did not know their HIV status to HTC and HIV-positive clients to ART services due to the client denial, fear, and suspicion about the accuracy of the test.

Clients that refuse results, it's very difficult. They just refuse if they come out positive and for those we cannot refer for CD4, because in the first place they don't accept that [result]. They would rather go to do another HIV test somewhere and they can do maybe three or four times in different organizations and they still don't accept. (HTC-SFH-ID1-

EXPERIMENTAL ARM)

Similarly, some providers reported that clients referred for TB screening felt stigmatized due to the frequent association between HIV positive status and TB.

If we tell someone to go for TB screening, first of all they say, "How is this person looking at me? Maybe am I sick or something else?" They will have questions like you are judging them. (HTC-SFH-ID2-EXPERIMENTAL ARM)

The barriers that providers faced in recommending FP services to clients included client fears about side effects such as weight gain, cancer, and infertility; client beliefs that unmarried women should not use contraception; and lack of support for FP from the clients' partners.

On family planning it was difficult especially when they come for HTC because you discover that they also need the family planning but they are not ready and they want [to] get married and have kids, but you see that there is need for them to get. (HTC-KAMWALA-ID2EXPERIMENTAL ARM)

Some of the men, those who were rigid, there were some challenges because maybe you tell the woman [about FP], [but] the man there wants that every time they should be having children... It's so important that we have to continue talking to the men folk so that 
they can also align with whatever is happening concerning family planning. (HTC-KAPATAID4-STANDARD OF CARE)

For referrals to VMMC services, providers were confronted by negative attitudes towards circumcision; fears about the procedure's side effects; and the challenges to accessing the service due to other client obligations.

When you ask them, "Why don't you like MC?" They say "Sister, [I don't want] to be circumcised...God made us this way." (FP-CHAWAMA-ID2-EXPERIMENTAL ARM)

Due to the fact that they are committed in one or two things, you find that it becomes a bit of a challenge [referring clients for VMMC]... they would rather access that service at a later stage in life, yes, due to their commitment in whatever they were doing, so basically that was the biggest challenge that we had.

(HTC-CAIRO-ID1-EXPERIMENTAL ARM)

\section{Facilitators to recommending add-on services}

The providers felt that standardized needs assessment form was useful, since it helped efficiently guide discussions with their clients and ensure that they were adequately screened for add-on services.

[The needs assessment form] was very helpful. Sometimes you find that as a service provider, you tend to forget other things, but once you are ticking you come up very sharp to see that this is the service this client needs. Maybe they might come for something else, especially if they come for HTC, they need STI screening, so once you are ticking you discover that they need this other service. That's when you advise them to also take the other service, so it was very helpful. (HTC-KAMWALA-ID2-EXPERIMENTAL ARM)

Additionally, many providers reported that the referrals slips provided clear information that helped their clients to feel confident about independently seeking an add-on service. Furthermore, some noted that the referral slips offered a mechanism for providers to keep track of the number of clients referred and receive feedback on how many referred clients accessed the add-on services.

[The referral slip] was helpful because some clients when you refer them, they don't want to go and ask much there [at the clinics]...so it was very helpful because they just give that referral form to the nurse...then the nurse is just going to look at it, then they are going to know that "oh, you have come for family planning, you can go this way..." That referral form used to make the work easier. (HTC-CAIRO-ID3-EXPERIMENTAL ARM)

The referral slips were helpful because once you refer them, you are able to get a feedback. So we were able to assess and account that the client has really received the service you referred them to.

(MC-SFH-ID1-STANDARD OF CARE ARM)

The providers also indicated that IEC materials improved their ability to discuss and recommend addon services to their clients. Not only did these materials help providers to offer their clients more 
comprehensive information, they also could be taken home by the clients and used to inform their partners, family members, and friends about the recommended add-on services.

At least [the IEC materials] also provided a revision for us. Before you even go to the session, you go through it so that when you are with a client, you know what you are talking about. (HTC-CAIRO-ID3-EXPERIMENTAL ARM)

[The IEC materials] were helpful; even people would just come to say, "I saw a friend with this material. I want to find out more. Can I have this material?" They are really helpful because that person will even talk to the friend, maybe that friend even knows how to read and upon seeing that material they have keen interest to find out more about family planning. (HTC-SFH-ID2-EXPERIMENTAL ARM)

Providers indicated it was easiest to ensure that clients access the recommended add-on services when the service was offered at the same site as the entry service. In these cases, providers could quickly show the clients the appropriate location in the clinic to access the add-on service. By contrast, add-on services off-site required available transportation and more of the client's time.

Most things are done just within the hospital, so it's very easy. I just move from corner to corner to make a simple handover, "Oh, this is where you are going to go..." if that other provider there for the service that you have given is not very busy then you say, "I have got this client who came for this service but he's also interested in this service. Please takeover and I will make a handover." (MC Chipata General-ID1-EXPERIMENTAL ARM)

\section{Recommendations for improved add-on service referral process}

When asked what could be done to improve the referral process and utilization of add-on services, providers indicated that service quality could be improved by (a) increasing the amount of space and staffing at clinics and (b) offering regular refresher trainings to ensure providers knowledge and skills are up-to-date.

I think they should just employ a lot of people since [in] some [places] like here there is only one counselor. They should bring some more to reduce the workload. The HTC rooms are few, so you will find a lot of people and only one counseling room, so they should improve by building some more.

(HTC-KAPATA-ID2-STANDARD OF CARE ARM)

I think trainings are important you can't just say you have all the information that [you] need. It keeps on changing, so I think trainings are important in one's life. I think before sometime 2007 or 2008 , we used to have training every year-year ends, we do refresher training on family planning, we did have MC even HTC. We used to have those training, so that when you are beginning a year you start on a fresh note you know, "Okay this is what needs to be done. This information is it still vital or not." So I think trainings are very important I can't rely on the information that I have. (HTC-SFH-ID2-EXPERIMENTAL ARM)

Additionally, the providers suggested that utilization of add-on services could be improved by offering all add-on services within the same site on a daily basis. According to the providers, the current 
system of offering services on certain days and requiring clients to travel to other facilities limits accessibility.

I think if at the clinic setup all the services were provided daily, I think it would be easy...where even if you refer them you just go, "There, that's where you will be attended to," [rather] than where you refer them to another center...they won't even try to maybe go that side. (HTC-KAMWALA-ID2-EXPERIMENTAL ARM) 


\section{ECONOMIC EVALUATION}

\section{Component 1: Technical efficiency analysis}

This component of the economic evaluation compares the costs of providing vertical services to the costs of service provision at an integrated, stand-alone site. Operations are considered technically efficient when SFH is able to provide the same service using the least input, thereby minimizing costs.

Table 14 summarizes costs per client obtained from the 'ingredients' or micro-costing exercise at the vertical and integrated service sites. The vertical service sites in Lusaka were SFH Cairo (HTC), SFH ChaChaCha (VMMC) and Chawama Clinic (FP). The vertical service sites in Chipata were the SFH Platform (HTC), Chipata General Hospital (VMMC) and Kapata Clinic (FP). The integrated comparator site was SFH YWCA in Lusaka. All referral services were costed at Chawama Clinic.

TABLE 14 Cost per client of vertical services in urban and rural service sites compared to integrated provision, 2013 USD

\begin{tabular}{|c|c|c|c|}
\hline & $\begin{array}{l}\text { Cost per client } \\
\text { (vertical urban site) }\end{array}$ & $\begin{array}{l}\text { Cost per client } \\
\text { (vertical rural site) }\end{array}$ & $\begin{array}{l}\text { Cost per client } \\
\text { (comparator site) }\end{array}$ \\
\hline \multicolumn{4}{|l|}{ Voluntary counseling and testing (VCT) } \\
\hline $\mathrm{HR}$ & $\$ 9$ & $\$ 3$ & $\$ 2$ \\
\hline Overhead costs and general supplies & $\$ 5$ & $\$ 8$ & $\$ 3$ \\
\hline Medical consumables & $\$ 107$ & $\$ 107$ & $\$ 107$ \\
\hline VCT total & $\$ 121$ & $\$ 118$ & $\$ 112$ \\
\hline \multicolumn{4}{|l|}{ Voluntary medical male circumcision (VMMC) } \\
\hline HR & $\$ 43$ & $\$ 5$ & $\$ 8$ \\
\hline Overhead costs and general supplies & $\$ 21$ & $\$ 15$ & $\$ 3$ \\
\hline Medical consumables & $\$ 11$ & $\$ 12$ & $\$ 13$ \\
\hline VMMC total & $\$ 76$ & $\$ 31$ & $\$ 25$ \\
\hline \multicolumn{4}{|l|}{ IUD insertion } \\
\hline $\mathrm{HR}$ & $\$ 2$ & $\$ 69$ & $\$ 5$ \\
\hline Overhead costs and general supplies & $\$ 2$ & $\$ 5$ & $\$ 3$ \\
\hline Medical consumables - general & $\$ 4$ & $\$ 53$ & $\$ 5$ \\
\hline Medical consumables - procedure-specific & $\$ 2$ & $\$ 15$ & $\$ 2$ \\
\hline IUD insertion total & $\$ 9$ & $\$ 142$ & $\$ 16$ \\
\hline \multicolumn{4}{|l|}{ Implant insertion } \\
\hline $\mathrm{HR}$ & $\$ 2$ & $\$ 69$ & $\$ 5$ \\
\hline Overhead costs and general supplies & $\$ 2$ & $\$ 5$ & $\$ 3$ \\
\hline Medical consumables - general & $\$ 4$ & $\$ 53$ & $\$ 5$ \\
\hline Medical consumables - procedure-specific & $\$ 1$ & $\$ 7$ & $\$ 0$ \\
\hline Implant insertion total & $\$ 8$ & $\$ 134$ & $\$ 14$ \\
\hline \multicolumn{4}{|l|}{ Post-partum IUD } \\
\hline $\mathrm{HR}$ & $\$ 2$ & $\$ 69$ & $\$ 5$ \\
\hline Overhead costs and general supplies & $\$ 2$ & $\$ 5$ & $\$ 3$ \\
\hline Medical consumables - general & $\$ 4$ & $\$ 53$ & $\$ 5$ \\
\hline
\end{tabular}




\begin{tabular}{|c|c|c|c|}
\hline Medical consumables - procedure-specific & $\$ 1$ & $\$ 18$ & $\$ 1$ \\
\hline Post-partum IUD total & $\$ 8$ & $\$ 135$ & $\$ 15$ \\
\hline \multicolumn{4}{|l|}{ Referral services $†$} \\
\hline Cervical cancer screening & $\$ 85$ & & \\
\hline CD4 count & $\$ 7$ & & \\
\hline Tuberculosis testing & $\$ 8$ & & \\
\hline Antiretroviral therapy & $\$ 10$ & & \\
\hline STI testing & $\$ 8$ & & \\
\hline
\end{tabular}

†Cost per consultation, excluding any patient-specific costs such as drugs, medical supplies and additional diagnostic tests

These results highlight the potential technical efficiency gains to be made by integrating HTC, VMMC and FP, particularly in rural areas. The integrated comparator site appeared to be operating with lower unit costs than all the vertical SFH-operated sites (urban HTC and VMMC, rural HTC and FP). Unsurprisingly, the difference between the comparator site and the SFH-operated vertical sites were driven by the largely fixed costs of human resources, followed by the costs of administration and dayto-day operations (overheads) and general supplies). These costs could potentially be spread over a larger number of clients by integrating provision, thus lowering the average costs of service delivery and achieving economies of scale in the long-run. FP at Kapata Clinic appears to be the service with the highest unit costs, mainly driven by the costs of human resources spread over an insufficient annual number of clients.

A word of caution is in order when interpreting the results from the two government facilities. While it appeared that Chawama clinic incurred the lowest costs in providing FP and Chipata General Hospital in providing VMMC, the low unit costs could also signal a resource shortage. Government facilities had a much larger annual number of patients over which to spread shared fixed costs (e.g., utilities, costs of administrative staff, buildings and maintenance). However, their costs for human resources and medical supplies were much lower than those of the SFH-operated sites and might be due to an under-supply of skilled staff and equipment as well as to drug stock-outs. This conclusion can certainly be drawn from the qualitative data collected from providers at government run sites, who point to physical and human resources as well as supplies being important barriers to providing add-on services.

\section{Component 2: Cost-effectiveness analysis of trial interventions}

Based on the World Health Organization's cost-effectiveness thresholds, an intervention is highly costeffective if its cost per DALY averted, also known as the incremental cost-effectiveness ratio (ICER), is lower than three times the country's gross domestic product (GDP) per capita. The World Bank estimated that the GDP per capita in Zambia in 2013 was US\$1845. All interventions in the REacH trial were therefore highly cost-effective compared to the standard of care with the exception of HTC through enhanced referral (study arm 2). 
TABLE 15 Summary of cost-effectiveness results

a. HIV/AIDS

\begin{tabular}{|c|c|c|c|c|c|c|c|c|}
\hline & & $\begin{array}{l}\text { Effect } \\
\text { HIV/AIDS } \\
\text { deaths }\end{array}$ & ness, per & 00 clients & DALYs & $\begin{array}{r}\text { Costs p } \\
\text { VCT }\end{array}$ & $\begin{array}{l}\text { DALY ave } \\
\text { VMMC }\end{array}$ & $\begin{array}{l}\text { HIV care } \\
\text { and } \\
\text { treatment }\end{array}$ \\
\hline \multicolumn{9}{|l|}{ Study arm } \\
\hline SOC & 4.16 & 4,160 & 16,884 & 79,912 & 96,796 & & - & - \\
\hline Arm 2 & 4.24 & 4,240 & 21,153 & 62,817 & 83,970 & $\$ 7,890$ & $\$ 377$ & $\$ 81$ \\
\hline Arm 3 & 3.71 & 3,708 & 12,050 & 53,028 & 65,078 & $\$ 3,180$ & $\$ 162$ & $\$ 33$ \\
\hline \multicolumn{9}{|l|}{ Difference } \\
\hline SOC- Arm2 & $\mathrm{N} / \mathrm{A}$ & $\mathrm{N} / \mathrm{A}$ & 16,882 & 17,095 & 12,826 & & & \\
\hline SOC-Arm 3 & 0.45 & 452 & 4,834 & 26,884 & 31,718 & & & \\
\hline
\end{tabular}

\section{b. Cervical cancer}

\begin{tabular}{|c|c|c|c|c|c|c|}
\hline & & \multicolumn{4}{|c|}{ Effectiveness, per 1000 clients } & \multirow{2}{*}{\begin{tabular}{|c|} 
Costs per \\
DALY \\
averted, \\
US $\$$ \\
Cervical \\
cancer \\
screening
\end{tabular}} \\
\hline & & \begin{tabular}{|c|}
$\begin{array}{c}\text { Cervical cancer } \\
\text { deaths }\end{array}$ \\
\end{tabular} & YLDs & YLLS & DALYs & \\
\hline \multicolumn{7}{|l|}{ Study arm } \\
\hline SOC & 1.91 & 1,913 & 34,803 & 49,162 & 83,966 & $\$-$ \\
\hline Arm 2 & 1.83 & 1,828 & 35,163 & 43,646 & 78,808 & $\$ 607$ \\
\hline Arm 3 & 1.70 & 1,699 & 34,906 & 42,835 & 77,741 & $\$ 106$ \\
\hline Difference & & deaths averted & YLDs & YLLs & DALYS & \\
\hline SOC - Arm 2 & 0.42 & 415.36 & N/A & 5,517 & 5,157 & \\
\hline SOC - Arm 3 & 0.51 & 511.37 & N/A & 6,327 & 6,224 & \\
\hline
\end{tabular}

Note: The cost of the intervention does not include the costs to the programme of training counsellors to deliver enhanced referral nor any extra costs for escorting patients in study arm three, respectively. These costs were considered negligible with respect to the additional costs of service provision from increases in the uptake of referral services.

A health intervention in Zambia is considered cost-effective if its costs per DALY averted is less than three times the GDP per capita ( $\$ 1845 \times 3=\$ 5,535)$. The CE results indicate that this amount is significantly higher than the costs of providing HCT in the third study arm, equal to $\$ 3,180$. Similarly, providing VMMC and CCS in both study arms is highly cost-effective. In the second study arm, however, HCT is not cost-effective, as its cost per DALY averted of $\$ 7,890$ is higher than three times GDP per capita. A potential reason for this is the considerably lower uptake of HTC services at six months in study arm two, particularly among the partners of clients and among children above 15 years of age. Given the higher incidence assumptions in younger age groups and the lower estimated protective effect of HCT among serodiscordant couples, lower uptake among these groups results in study arm two clients experiencing nearly double the amount of YLDs than those in study Arm three. 


\section{Implementation challenges}

Some important implementation challenges affected the REacH study and ultimately the analysis that could be conducted. These issues were discussed in detail during USAID monthly management conference calls and resulted in recommendations made to adapt to issues as much as possible during the course of the study and analysis period.

A key challenge was the pace of recruitment for the study that affected the study timeline and the distribution of participants by entry point services. Projections of client flow at the study sites were based on the previous six months of site service statistics. To account for potential seasonality, a second set of projections were also made on service statistics from the same time period in the previous year. In addition to client flow, recruitment rates were determined by the percentage of clients willing to participate in the study. At one site in particular, the SFH-HTC site at Cairo Road, the recruitment rate of eligible clients was significantly lower than expected. The enrollment rate at the Cairo site was only $21 \%$ of eligible participants, much lower than the $65 \%$ average eligible enrollment rate from the other sites. Anecdotal evidence from the site obtained indicated that the site served largely mobile and professional clients who came to town for work and did not have sufficient time or interest in participating in the study. Client reimbursement rates for participation time were not sufficient to offset client opportunity costs. Despite increased demand creation efforts by SFH, the efforts did little to fundamentally alter client enrollment rates over the course of fieldwork. Client flow estimates for VMMC were also lower than had historically been the case and well below what was projected for demand on a national scale. ${ }^{20}$ Despite SFH demand-generating activities at and in the catchment areas of the VMMC study sites, client flow remained a significant problem for recruitment.

Other day-to-day operational issues in both the service and research components of the study resulted in lost days in recruitment. For instance, a national shortage of HIV test kits occurred and the HTC sites could not conduct recruitment when test kits were not available. SFH responded ably by shifting HIV test kits around as best they could to meet the needs of testing sites, but with limited supplies, recruitment could not be conducted on a number of days. Contracting and funding of services providers, provider absences and lateness, and power outages all had an impact on the ability of the project to recruit participants at particular sites. Software and hardware issues with the CTD computers, while limited given the scope of the effort, also led to an added number of days of recruitment lost at particular sites. In reaction to these challenges, an additional three HTC and VMMC study entry point sites were established to increase enrollment into the study. While these changes led to faster enrollment, they did imply greater implementation costs.

A second challenge during the period involved data quality issues with the standard of care or control group data in the CTD. As per study protocol, clients were randomized to one of three study arms, the standard of care and two intervention arms. After clients were randomized to study arm and received the services they came for that day at the health facility they were expected to undergo an exit registration process that included recording of services rendered and any referrals received for add-on services. This information was to be entered in the CTD. For clients in the two intervention arms,

\footnotetext{
20 National projections of $\mathrm{VMMC}$ service provision at the time suggested that a significant scale up of services during the course of the study would occur. Another related complication that undermined the formulation of realistic projections and timelines was that historical data provided by Jhpiego proved to be a gross over-estimate of client flow for the sites, since the data provided contained client numbers from their outreach sites.
} 
referrals were documented on a study form and a referral number provided for tracking. These forms were handed to the data manager at each site for recording in the electronic CTD. For the standard of care arm, it was decided that written documentation of referrals would not be required, because we did not want to influence or alter the default behavior of counselors in the control arm. The impact of study implementation on behavior is called the Hawthorne or observer effect and can undermine the detection of experimental impact. In this case, a paper record introduced in the control arm where one did not exist previously could have caused the standard of care counsellors to offer and document more referrals than they would have under normal conditions.

As an alternative to a written form, it was therefore determined that the client flow manager would escort the client to the data manager who was to ask in person about referrals received and record the information in the client tracking database. Although the exit registration process dictated that clients were to be escorted to the data manager and asked about services received that day as per protocol, the data managers consistently failed to ask clients in the standard of care arm about referrals received. As a consequence, the CTD did not contain information for the standard of care clients on referrals for comparative purposes. The lack of a paper record for recording referrals had a secondary impact on information collected at the referral point sites. As clients entered referral point facilities if they did not present with a study referral voucher, they were to be asked if they were participants in the study. A search was to be conducted by name and NRC number to record their entry at the referral point. As the standard of care clients did not have a paper record, the search was to be conducted for every client not showing a referral form and number. The record search was not systematically conducted for every client at every site, again limiting the information on standard of care clients in the client database.

The study personnel subsequently contacted clients in the standard of care to ask about the referrals received and services obtained, but this source of information was subject to recall bias and hence was of lesser quality. It was decided that the data quality issues were too great to make effective use of the standard of care data in the CTD. Instead, it was decided that the survey interview data at six weeks and six months would be used for assessing the primary objectives and outcomes of the study. 


\section{Discussion}

The REacH study was an implementation science randomized evaluation of interventions to improve the uptake of many critical health services offered in the Zambian context. The study's rationale asserted that by providing enhanced services directed towards lowering the barriers of access and improving quality would be a cost-effective way of improving the uptake of FP/HIV services. The intervention approach was to mimic as best as possible the provision of integrated services where they currently existed in the context of vertical service provision. Information about and access to services could be obtained quickly by the client, with little additional cost in terms of time and effort. The study evaluated innovative ways of providing information and counseling about add-on services that included standardized methods of assessing need, dedicated time for counseling about additional services, on-hand informational materials, and $\mathrm{Ml}$ techniques developed to address psychological barriers to access. For some clients, it also meant the provision of an escort to the addon service. The intervention also tracked clients to determine whether after seven days they had accessed services, and if not, provided another opportunity to interact with and engage the client about the referral service through a follow-up call. The study focused on four core client add-on services, including HTC, VMMC, FP and CCS. It also evaluated an additional set of HIV care and treatment outcomes for clients who were eligible to receive such services, including tuberculosis (TB) and CD4 antibody testing, psychosocial counseling and the initiation of ART. Service uptake was evaluated among clients and among their spouses and children when applicable.

The client level randomization design assured the highest degree of rigor and attribution in assessing the study's primary objectives. The primary study quantitative analysis was based on an intent-to-treat approach where assignment to experimental arm served as the primary estimate of impact. Study endpoints were measured in survey interviews that were conducted with participants at six weeks and six months after recruitment. The surveys asked about whether or not the clients, spouses and children had accessed the relevant services within the period and, if so, - for the primary clients details about the nature and experiences associated with those services. Qualitative in-depth interviews with clients supplemented the survey interviews and focused on client experiences with health services and any barriers to uptake of services. Discounted DALY measures and projected lifetime treatment costs derived were used to calculate incremental cost-effectiveness ratios, which provided cost and cost-effectiveness comparisons between the experimental and control service models.

The study's findings indicated that the enhanced client add-on service referral and follow-up arm with and without the escort had an impact on many of the primary outcomes targeted as part of the study. For instance, the intervention increased the uptake of HTC services among women who had entered at FP entry points. The effect of the intervention on improving uptake was greater in the shorter term, within six weeks, but nonetheless remained important though not significant through six months. Knowing one's status as soon as possible is vital and testing every six months for those at risk is recommended, thus, these results are important for suggesting that the intervention was effective in getting clients into care and treatment, as appropriate, as soon as possible after HIV acquisition. As many FP clients in the study were married (82\%) and may not otherwise feel at risk, such women may not feel comfortable accessing HTC services at vertical service provision sites or may not feel such services are necessary. The results suggest that using FP sites to facilitate HTC testing among clients is an important method for reaching this niche of women. 
The REacH intervention also significantly increased the uptake of VMMC services among men, at times doubling uptake when compared to the standard of care. Given that VMMC is an invasive HIV prevention medical intervention and the barriers to increasing the demand for VMMC are high, the study results point to the value of the offering men add-on VMMC services through comprehensive counselling at HTC sites for eliciting uptake. The results also indicated that adding an escort to these services enhanced uptake even further. Given that the sample of men in the study was older than the general population of men receiving VMMC services in Zambia, and given that older men have been difficult to reach with VMMC services, these findings suggest an additional productive and costeffective route through which to reach older men with VMMC services. Both the quantitative results data and the qualitative interviews point to employment and the opportunity costs of VMMC as a significant barrier to further uptake by men. Efforts to further address men's concerns through legal protections and offsetting the costs of VMMC would be viable options for improving uptake of these services among men. Studies in Kenya have indicated that cost-offset approaches are effective ways to improve uptake of VMMC[64, 65], although in other settings and cultural contexts such interventions may be less effective.[66] VMMC advocacy with employers and at work places employers could be an avenue to overcome this barrier.

The study findings indicated marginal improvements in HIV positive clients accessing HIV care and treatment in the intervention arms, although this result does not consistently reach the designated levels of statistical significance. For those who have accessed HIV care and treatment during the study observation period, the intervention does indicate an increase in access to TB and CD4 testing services. For instance, by six months post-enrollment the enhanced referral arm with escort had a $20 \%$ higher prevalence of HIV positive women accessing TB testing services compared to the standard-of-care. Similar differences were observed in the prevalence of males accessing CD4 testing. Further, the embedded economic evaluation indicated that the interventions are cost-effective in reducing the HIV and AIDS disease burden. While drawing definitive conclusions is not possible due the small sample sizes and the lack of consistency in the results, these findings do provide a rationale for future studies that include all or some of the elements of the intervention among HIV positive populations where higher sample sizes can be achieved.

The REacH evaluation showed significant increases in uptake when enhanced services were offered to women for cervical cancer screening. Women who presented for services at HTC sites and at MCH and HIV clinics in Lusaka and Chipata were provided detailed information about cervical cancer and asked if they would be interested in being screened. The study results indicated that when cervical cancer was the focus of enhanced package of counselling, referral and follow-up services for every one woman screened in the standard of care, three women were screened in the enhanced services and referrals models. These positive results were particularly pronounced at Kapata urban clinic. The result points to potentially issues of service provision quality, as proximity does not seem to be an issue given that Chawama clinic has most CCS on sight, but has a lower impact on uptake. As with the package of HIV prevention and care and treatment services and given the magnitude of impact found, the provision of these services was highly cost-effective in the Zambian context.

One area in which the intervention was not successful in improving client outcomes was in the provision of counselling and referral for add-on FP services for women at HIV care and treatment and HTC sites. The study's intervention did not realize any gains in the uptake of FP services among women and at the end of six months in the intervention arms women were not more likely to use modern contraception or use a long-acting contraception than the women in the standard of care. The lack of results in uptake translated into no added utilization of modern or long-acting contraception 
the intervention arms. In fact, more current use of modern contraception was observed in the standard of care arm. These results may be driven, in part, by the fact that a largely proportion (roughly 58\%) of women seeking HTC services are already using modern contraception (Table 7). Results from the qualitative interviews suggest that poor FP outcomes may largely be due to cultural barriers to FP such as the belief that modern contraception is inappropriate for unmarried and nulliparous women rather than lack of knowledge about or challenges to accessing FP services among clients

The results for recruited client's partners and children aged 15 years and older were mixed, although in the latter case certainly affected by a small number of observations in the sample. Male spouses of female clients were, at times, more likely to access HTC and VMMC services. For instance, spouses of female clients in the intervention arm that included an escort, were approximately $26 \%$ more likely to access HTC services at six months than the standard of care and $19 \%$ more likely to access services than the intervention arm without escort. Similarly, such clients were between $50 \%$ and $75 \%$ more likely to access VMMC services in the intervention arms, but the differences are based on a very low absolute prevalence of uptake of VMMC services among spouses in the standard of care at $4 \%$. These findings do provide some promise for future evaluations to further delineate how best to reach men through counselling and providing referrals through women.

There were no statistically significant differences at the $p<.05$ level in the uptake of services among participant's children aged 15 and older. Partially, this is a function of sample size, particularly for the men recruited into the study. While for the females there are a slightly greater number of observations and there does seem to be some patterns in the data to suggest and treatment effect, without greater precision in the estimates and without any of the results reaching accepted levels of statistical significance, it is not possible to draw further inferences from these findings. 


\section{Recommendations}

Given the REacH study findings and the conclusions drawn, some practical recommendations are suggested for program and service implementers, including the following:

- While adding FP counselling and referral services to HTC entry points has an intuitive appeal given that women seeking HTC services are young, unmarried and sexually active, the study findings suggest that adding the study's intervention components at HTC sites contributes does not significantly contribute to the uptake of family planning. Hence, changes to the standard of care are recommended.

- The study does suggest that women seeking FP services - the predominant majority of whom are currently married - have an interest and willingness to determine their HIV status. Providing readily available HTC services to such women will lead to an increase in the number of women recently tested and reach women who may be less likely to enter directly testing through vertical HTC service sites.

- While providing an escort to additional services is not always effective, it does have a significant impact on linking men to VMMC services. This implies that assuring that VMMC services are near HTC sites, such as is the case at the YWCA comparator site, and immediately linking men receiving HTC to VMMC services will increase the acceptance of VMMC.

- A key barrier to the uptake of VMMC services found elsewhere is men's concerns about the negative consequences of lost days of work and the opportunity costs of wages forgone. Advocacy and recruitment efforts that work hand-in-glove with employers to address these concerns and to promote VMMC are recommended. Studies have also shown that efforts to offset the economic impact of VMMC on overall income through in-kind transfers are effective in increasing uptake. Both of these potential interventions would likely attract older men who have proven difficult to recruit through other means.

- Although by no means conclusive, the study findings are suggestive that enhanced counseling and follow-up of HIV positive clients improves uptake of HIV care and treatment, such as TB screening and CD4 testing. As with VMMC services, an escort to such services when a positive test is obtained at HTC sites is a potential cost-effective mechanism for improving access to care and to improve the potential of treatment as prevention.

- Integrating cervical cancer screening counselling to other reproductive health services leads to a significant increase in women exposed to such screening and is highly cost-effective in reducing women's reproductive health burden. Given that there is little difference between the intervention arms, the results suggest that a driving factor to uptake is the provision of high quality information and referral to CCS services.

- It is appealing to think that the provision of information and referrals to clients to reach their spouses and children would lead to greater uptake of services for secondary clients, but the $\mathrm{REacH}$ study findings suggest that this method of outreach is not effective in improving service uptake. As such, resources are better spent on efforts that reach the client directly with information about services. One exception to this general finding is when women are provided spousal referrals for VMMC; additionally, service uptake is enhanced when it comes with the offer of an escort to the VMMC site. - A key limiting factor for the uptake of services as reported by both clients and providers is the
ready access of clients to providers, the time commitment of client assessment, as well as referrapi 
to add-on services. Addressing the human resource constraints by increasing the number of providers, task shifting where appropriate, reducing client wait times and assuring that facility services adhere to schedule hours would improve client satisfaction and also increase the uptake of services.

There are some limitations of the analysis and results presented in this report suggesting future areas of research and evaluation. First, the quantitative data presented was based solely on the survey interviews collected at six weeks and six months using an ITT analysis. It specifically assessed whether the full intervention package was more effective in leading to service uptake than the standard of care. The other study data source, the client tracking data, could not be used to assess impact. This limitation was a result of the lack of fidelity to study protocol and methods in the standard of care arm that had an impact of the quality of data. ${ }^{21}$ As a consequence, the client tracking data was not of sufficient quality to use with confidence in the quantitative analysis. Given that the CTD was designed to record information of certain client events not observed in the survey data, including whether a client received a referral, the CHAMP follow-up call, or an escort to the referral site, the analysis could not use this data for assessment of impact on an as-treated basis. In short, while analysis of the survey data was able to quantitatively test the overall impact of the intervention on uptake of services, it was less useful for understanding of specifics why the impacts were observed. ${ }^{22}$ Given that the study results indicate that the package of intervention components can have a significant impact on service utilization, it would be worthwhile for future evaluations to unpack these interventions to provide a more precise assessment of relative impact of individualized components.

A second limitation of the quantitative analysis and presentation of results is that it is based on selfreported service utilization at the six week and six month interview. Similarly, the qualitative client interviews relied on respondent recall of the details of a clinical encounter that occurred six to seven months prior to the interview. As with any study that relies on self-reporting from participants, the data may be affected by recall biases or biases that derive from the participant wanting to being perceived as more compliant to health conscious behaviors than is actually the case. In the case of recall bias, it is possible that the participant is confusing uptake to include their original health facility visit, despite being specifically prompted in the question to exclude that visit and despite the fact that the add-on service is for a different type of services altogether. This bias may lead to a greater prevalence of client uptake observed then occurred. The same outcome of higher reported uptake would occur if clients over-reported uptake because they felt that this was what the interviewer wanted to hear or felt some psychological need to be perceived as adhering to the counselling messaging and referrals. We do believe, however, that with the randomization of clients to study arms that these errors would be reasonably equally distributed across study arms and not affect the attribution of effect of the intervention, although a reasonable assumption this is not a testable assertion with the data at hand.

A final study limitation is the relatively small sample sizes for the analysis of impact on HIV care and treatment uptake for those clients who are HIV positive, as well as add-on service uptake among client's spouses and children. As discussed in the results section, there are some promising indications that the intervention was effective in increasing the linkage of HIV positive clients to care and treatment, for instance increasing linkages to TB and CD4 testing. The results, while suggestive were, however, not sufficiently consistent for broad inferences about the impact of the intervention on

${ }^{21}$ This issue and its impact on the client tracking data was discussed in detail in the "Implementation Challenges" section of the report.

${ }^{22}$ Despite the limitations of the CTD and the associated quantitative analysis, the qualitative client data and results discussed in the report provided insight into client perceptions of what components of the interven were important in their calculus to uptake add-on services. 
uptake of the range of HIV care and treatment services. The results do provide a basis to propose further research focused on this sub-population to evaluate similar intervention mechanisms. The same can be said of the spouses of female clients, as there does to be some indication from study results that males spouse can be reached through their wives or partners to improve the uptake of HTC and VMMC services. Additional research or other studies already conducted that address this issue directly may provide additional confirmation of these findings, providing more confidence in the potential cost-effectiveness of this type of client targeting.

The Government of the Republic of Zambia and PEPFAR are eager to identify the most cost-efficient and effective mix of FP and HIV service linkage and integration strategies suitable for large-scale implementation. The REacH study addressed these interests by evaluating two distinct models of enhanced service provision and referrals in the Zambian context. We believe that the results of this evaluation will contribute to the evidence-base used to inform FP and HIV service integration programming in Zambia and in other PEPFAR priority countries as it suggests that integrated services are a cost-effective mechanism from which to reach the population with life-sustaining interventions. 


\section{References}

1. USAID, Family Planning/HIV Integration: Technical Guidance for USAID-Supported Field Programs. 2003, USAID: Washington, D.C.

2. WHO, Strengthening linkages between sexual and reproductive health and HIV. Bulletin of the World Health Organization, 2009. 87(11): p. 805-884.

3. Central Statistical Office Zambia, M.o.H.Z., and ICF International, Zambia Demographic and Health Survey 2013-14. 2014: Rockville, Maryland, USA.

4. Strachan M, K.-A.A., Harde K, Subramaniam S, Judice N, Agarwal K., An analysis of family planning content in HIV/AIDS, VCT, and PMTCT policies in 16 countries. 2004: Washington, D.C.

5. Rutenberg N, B.A., Kaona F., Reproductive Decision-Making in the Context of HIV and AIDS: A Qualitative Study in Ndola, Zambia. International Family Planning Perspectives, 2000. 26(3): p. 124-130.

6. Chanda E, M.F., Coleman M, Sikaala C, Katebe C, MacDonald M, et al., Integrated vector management: the Zambian experience. . Malaria Journal, 2008. 7: p. 164.

7. Central Statistical Office (CSO), M.o.H.M., Tropical Diseases Resaerch Centre (TDRC), University of Zambia, Macro International, Inc., Zambian Demographic and Health Survey 2007. 2009:

Calverton, MD.

8. ZNAC, Zambia HIV prevention response and modes of transmission analysis. Epi-synthesis final report July 2009. 2009, Lusaka, Zambia.

9. WHO, U., IPPF, UNAIDS, Sexual and reproductive health and HIV/AIDS: a framework for priority linkages. 2005, WHO.

10. Chikamata DM, C.O., Jones H, Ramarao S., Dual Needs: Contraceptive and Sexually Transmitted Infection Protection in Lusaka, Zambia. International Family Planning Perspectives, 2002. 28(2): p. 96-104.

11. Ministry of Health of Zambia, National Health Strategic Plan 2012-2015. 2011, Ministry of Health of Zambia: Lusaka, Zambia.

12. Ministry of Health of Zambia, National HIV/AIDS Prevention Strategy 2012-2015. 2011, Ministry of Health of Zambia: Lusaka, Zambia.

13. IPPF, U., UNAIDS, UNFPA, WHO, Sexual and reproductive health and HIV linkages: evidence review and recommendations. 2009, IPPF: London.

14. WHO, Glion consultation on strengthening the linkages between reproductive health and HIV/AIDS: family planning and HIV/AIDS in women and children. 2006: Geneva.

15. Stekelenburg J, K.S., Mukelabai M, Wolffers I, van Roosmalen J., Waiting too long: low use of maternal health services in Kalabo, Zambia. Tropical Medicine and International Health, 2004. 9(3): p. 390-398. 
16. Mackeith N, C.O., Ahmed Y, Murray SF., Zambian women's experiences of urban maternity care: results from a community survey in Lusaka. African Journal of Reproductive Health., 2003. 7(1): p. 92-102.

17. Gabrysch S, C.O., Still too far to walk: Literature review of the determinants of delivery service use. . BMC Pregnancy and Childbirth, 2009. 9-34.

18. Mayhew S, L.L., Cleland J, Walt G., Implementing the integration of component services for reproductive health. . Studies in Family Planning, 2001. 31(2): p. 151-62.

19. Ministry of Health of Zambia, Workforce Optimization Analysis: Optimal Healthcare Worker Allocation for Healthcare Facilities Across Zambia. 2009, Ministry of Health of Zambia: Lusaka Zambia.

20. Society for Family Health, Management Information System (MIS) service data, Society for Family Health, Editor. 2012: Lusaka, Zambia.

21. Foreit KF, H.K., Agarwal K., When does it make sense to consider integrating STI and HIV services with family planning services? Issues in Perspective: Integrating HIV/STI and Family Planning Services. International Family Planning Perspectives, 2002. 28(2): p. 105-107.

22. Lush L, W.G., Cleland J, Mayhew S. , The role of MCH and Family Planning services in HIV/STD control: Is integration the answer? African Journal of Reproductive Health / La Revue Africaine de la Santé Reproductive, 2001. 5(3): p. 29-46.

23. Shelton JD, F.N., Opportunities and pitfalls in integration of family planning and HIV prevention efforts in developing countries. Public Health Reports, 2004. 119(12-15).

24. Mullick S, K.D., Askew I, Maluka T, Menziwa M. , Integrating counseling and testing into family planning services: what happens to the existing quality of family planning when HIV services are integrated in South Africa?, in Presentation at Linking Reproductive Health, Family Planning, and HIV/AIDS in Africa. 2006: Addis Ababa.

25. International Planned Parenthood Federation (IPPF), HIV prevention and family planning: Integration improves client services in Jamaica. AIDS Summary, 2002. 5(2): p. 3.

26. Stover J, F.N., Halperin D, Gibbons A, Gillespie D., Adding family planning to PMTCT sites increases the benefits of PMTCT. Population and Reproductive Health Issue Brief. 2003, USAID: Washington, D.C.

27. Peck R, F.D., Liautaud B, Deschamps MM, Verdier RI, Beaulieu ME, et al., The feasibility, demand, and effect of integrating primary care services with HIV voluntary counseling and testing: evaluation of a 15-year experience in Haiti, 1985-2000. Journal of Acquired Immune Deficiency Syndromes, 2003. 33(470-475).

28. Boonstra H., The role of reproductive health providers in preventing HIV. Guttmacher Report on Public Policy. 2006: New York,.

29. Rasch V, Y.F., Massawe S. , Postabortion care and voluntary HIV counselling and testing: an example of integrating HIV prevention into reproductive health services. Tropical Medicine and International Health, 2006. 11: p. 697-704.

30. Coyne KM, H.F., Desmond N., Sexual and reproductive health in HIV-positive women: a dedicated clinic improves service. International Journal of STD and AIDS, 2007. 18: p. 420-421. 
31. Lush L., Integrating HIV/STI and family planning services. International Family Planning Perspectives, 2002. 28(2): p. 71-76.

32. Shears, K.H., Integrating services. Network, 2004. 23(3): p. 30.

33. Kennedy CE, S.A., Brickley DB, Almers L, Mirjahangir J, Packel L, et al., Linking sexual and reproductive health and HIV interventions: a systematic review. Journal of the International AIDS Society, 2010. 13(26): p. 1-10.

34. Spaulding AB, B.D., Kennedy C, Almers L, Packel L, Mirjahangir J, et al., Linking family planning with HIV/AIDS interventions: a systematic review of the evidence. AIDS Summary, 2009. 23(Supplement)(S79-S88).

35. Family Health International, P.C., Zimbabwe National Family Planning Council, University of Harare, The Costs of Integrating Reproductive Health Services: An Example Using Syndromic Management of STIs in Family Planning Clinics in Zimbabwe. 1999: Harare, Zimbabwe.

36. Askew I, B.M., The contribution of sexual and reproductive health services to the fight against HIV/AIDS: a review. Reproductive Health Matters, 2003. 11: p. 51-73.

37. Berer M, HIV/AIDS, sexual and reproductive health: intersections and implications for national programmes. Health Policy and Planning, 2004. 19: p. i62-i70.

38. Shelton JD, Prevention first: a three pronged strategy to integrate family planning program efforts against HIV and sexually transmitted infections. International Family Planning Perspectives, 1999. 25: p. 147-152.

39. PEPFAR, Fiscal Year 2012 Country Operational Plan Guidance. 2001: Washington, D.C.

40. Dehne KL, S.R., O'Reilly KR, Integration of prevention and care of sexually transmitted infections with family planning services: what is the evidence for public health benefits? . Bulletin of the World Health Organization, 2000. 78(5): p. 628-639.

41. Farrell BL, Family planning-integrated HIV services: A framework for integrating family planning and antiretroviral therapy services. 2007: New York, New York.

42. Stringer EM, K.C., Levy J, Sinkala M, Goldenberg RL, Chi BH, et al, A randomized trial of the intrauterine contraceptive device vs hormonal contraception in women who are infected with the human immunodeficiency virus. American Journal of Obstetrics and Gynecology, 2007. 197(144): p. e141-144 e8.

43. King R, E.J., Allen $\mathrm{S}$, Wolf $\mathrm{W}$, Valentine $\mathrm{C}$, Serufilira $\mathrm{A}, \mathrm{A}$ family planning intervention to reduce vertical transmission of HIV in Rwanda. AIDS, 1995. 9: p. S45-S51.

44. Banda HN, B.S., Hardee K, Provision and use of family planning in the context of HIV/AIDS in Zambia: perspectives of providers, family planning and antenatal care clients, and HIV-positive women. 2004: Washington, D.C>.

45. Rutenberg N, B.C., Field experiences integrating family planning into programs to prevent mother-to-child transmission of HIV. Studies in Family Planning, 2005. 36(3): p. 235-245.

46. Rosenstock IM, Why people use health services. The Millbank Memorial Fund Quarterly, 1966. 44(3): p. S94-S127.

47. Glanz K, R.B., Viswanath K, Health Behavior and Health Education: Theory, Research and Practice. 2008, New Jersey: John Wiley \& Sons. 
48. Green MS, W.M., Kohi, T.W., Mujaya, S.N., Lasway C, Mpangile G, Baumgartner JN, Using facilitated referrals to integrate family planning into HIV care and treatment clinics in Tanzania, in Oral abstract at 6th International AIDS Society Conference on HIV Pathogenesis, Treatment and Prevention. 2011, International AIDS Society: Rome.

49. Drummond, M.F., et al., Methods for the economic evaluation. 2005, Oxford, UK: Oxford University Press.

50. Guinness, L. and V. Wiseman, Introduction to health economics. 2nd ed. Understanding public health. 2011: Maidenhead : McGraw-Hill/Open University Press.

51. Drummond MF, S.M., Torrance GW, O'Brien BJ, Stoddart GL, Methods for the economic evaluation of health care programmes. 2005, Oxford: Oxford University Press.

52. Gupta, S.K., Intention-to-treat concept: A review. Pespectives in Clinical Research, 2011. 2(3): p. 109-112.

53. Walker, D., et al., An incremental cost-effectiveness analysis of the first, second and third sputum examination in the diagnosis of pulmonary tuberculosis. International Journal of Tuberculosis Lung Disease, 2000. 4(3): p. 246-251.

54. Murray, C.J.L. and A.D. Lopez, Evidence-Based Health Policy---Lessons from the Global Burden of Disease Study. Science, 1996. 274(5288): p. 740-743.

55. UNAIDS, Zambia Country Report in Monitoring the Declaration of Commitment on HIV and AIDS and the Universal Access. 2014, UNAIDS: Washington, D.C.

56. Lozanao, R., et al., Global and regional mortality from 235 causes of death for 20 age groups in 1990 and 2010: a systematic analysis for the Global Burden of Disease Study. Lancet, 2012. 280: p. 2095-2128.

57. Allen, S., et al., Couples' Voluntary HIV Counseling and Testing (CVCT) Followed by Treatment as Prevention (TasP) for Discordant Couples: The Impact of Each Step. AIDS Research and Human Retroviruses 2014. 30(Suppl S1): p. A285-286.

58. Sankaranarayanan, R. and J. Ferlay, Worldwide burden of gynaecological cancer:The size of the problem. Best Practice \& Research Clinical Obstetrics and Gynaecology, 2006. 20(2): p. 207255.

59. Mandelblatt, J.S., et al., Benefits and costs of using HPV testing to screen for cervical cancer. . JAMA, 2002. 287(18): p. 2372-2381.

60. Hewett, P.C., Barbara S. Mensch, Manoel C.S. de A. Ribeiro, Heidi Jones, Sheri Lippman, Mark R. Montgomery, Janneke van de Wijgert, Using Sexually Transmitted Infection Biomarkers to Validate Reporting of Sexual Behavior within a Randomized, Experimental Evaluation of Interviewing Methods. American Journal of Epidemiology 2008. 168(2): p. 202-211.

61. Creel, L.C., Justine V. Sass, and N.V. Yinger Client-Centered Quality: Clients' Perspectives and Barriers to Receiving Care. New Perspectives on Quality of Care, 2002.

62. Mensch, B.S., et al., Family Planning in Nairobi: A Situation Analysis of the City Commission Clinics Family Planning Perspectives, 1994. 20(2): p. 48-54.

63. Price, J.E., et al., Behavior Change Pathways to Voluntary Medical Male Circumcision: Narrative Interviews with Circumcision Clients in Zambia. PLOS One, 2014. 9(11): p. e111602. 
64. Harsha Thirumurthy, et al., Effect of Providing Conditional Economic Compensation on Uptake of Voluntary Medical Male Circumcision in Kenya. JAMA, 2014. 312(7): p. 703-711.

65. Harsha Thirumurthy, et al. The effect of conditional economic compensation and lottery-based rewards on uptake of medical male circumcision in Kenya: a randomized trial. in International AIDS Confference. 2015. Vancouver, Canda.

66. Chinkhumba, J., S. Godlonton, and R. Thorton, The demand for medical male circumcsion. American Economic Journal, 2014. 6(2): p. 152-177. 


\section{Appendices}

\section{APPENDIX TABLE 1. STUDY SERVICE ENTRY POINTS AND REFERRAL POINTS}

Entry services Referral services provided Site run by

provided

\section{Entry points}

\section{Lusaka}

SFH HTC-Cairo Road

Chawama Clinic- $-\mathrm{MCH}$

Chawama Clinic-Out Patient Ward (VMMC)

Kamwala Clinic-TB, STI \& HIV Clinic

\section{Chipata}

Kapata Urban Clinic- $\mathrm{MCH}$

Kapata Urban Clinic-TB, STI \& HIV

Chipata Gen Hospital-OP VMMC

SFH New Start

SFH VMMC

Referral points

Lusaka

Chawama Clinic-TB, STI \& HIV Clinic
HTC

FP

VMMC

HTC

FP

HTC

VMMC

HTC

VMMC

Psychosocial support

CD4 testing

ART provision

TB testing

HTC/Couples HTC

HTC/Couples HTC

FP Psychosocial support

CD4 testing

ART provision

TB testing

FP CD4 testing

ART provision

TB testing

VMMC

HTC/Couples HTC

HTC/Couples HTC

Psychosocial support

CD4 testing

ART provision

TB testing

VMMC
$\mathrm{SFH}$

Government

Government

STI assessment and treatment

Government

STI assessment and treatment

Government

Government

STI assessment and treatment

$\mathrm{SFH}$

STI assessment and treatment

Government 
APPENDIX TABLE 1. Study service entry points and referral points (cont'd)

\begin{tabular}{|c|c|c|c|}
\hline & $\begin{array}{l}\text { Entry services } \\
\text { provided }\end{array}$ & Referral services provided & Site run by \\
\hline SFH - VMMC -Chachacha Rd & & $\begin{array}{l}\text { VMMC } \\
\text { HTC/Couples HTC } \\
\text { STI assessment and treatment }\end{array}$ & SFH \\
\hline \multicolumn{4}{|l|}{ Chipata } \\
\hline Chipata Gen Hospital-MCH & & $\begin{array}{l}\text { FP } \\
\text { CCS }\end{array}$ & Government \\
\hline Chipata Gen Hospital-TB, STI \& HIV & & $\begin{array}{l}\text { HTC/Couples HTC } \\
\text { STI assessment and treatment } \\
\text { CD4 testing } \\
\text { ART provision } \\
\text { TB testing }\end{array}$ & Government \\
\hline $\begin{array}{l}\text { External comparator site } \\
\text { Lusaka }\end{array}$ & & & \\
\hline YWCA & HTC, VMMC, FP & $\begin{array}{l}\text { HTC } \\
\text { VMMC } \\
\text { FP } \\
\text { Psychosocial support } \\
\text { STI assessment and treatment }\end{array}$ & SFH \\
\hline
\end{tabular}


APPENDIX TABLE 2. BASELINE DEMOGRAPHIC CHARACTERISTICS OF STUDY PARTICIPANTS BY SEX AND ENTRY POINT SERVICE (PERCENTAGES UNLESS OTHERWISE INDICATED)

\begin{tabular}{|c|c|c|c|c|c|c|c|c|c|c|c|c|}
\hline & \multicolumn{3}{|c|}{ Male } & \multicolumn{3}{|c|}{ Female } & \multicolumn{4}{|c|}{ Total } & \multicolumn{2}{|c|}{ Tests } \\
\hline & HTC & VMMC & Total & FP & HTC & Total & FP & HTC & VMMC & Total & Males & Females \\
\hline Sample size & 1,398 & 522 & 1,920 & 1,034 & 1,009 & 2,043 & 1,034 & 2,407 & 522 & 3,963 & 1,920 & 2,043 \\
\hline Mean age in years & 26.9 & 23.9 & 26.1 & 26.6 & 27.1 & 26.8 & 26.6 & 27.0 & 23.9 & 26.5 & $A^{* * *}$ & $\mathrm{~B} \dagger$ \\
\hline Age groups & & & & & & & & & & & $A^{* * *}$ & $B^{*}$ \\
\hline $18-24$ & 46.1 & 64.2 & 51.0 & 45.7 & 43.9 & 44.8 & 45.7 & 45.2 & 64.2 & 47.8 & & \\
\hline $25-29$ & 23.2 & 20.1 & 22.4 & 23.9 & 23.8 & 23.8 & 23.9 & 23.5 & 20.1 & 23.1 & & \\
\hline $30-34$ & 15.2 & 9.4 & 13.6 & 17.6 & 16.8 & 17.2 & 17.6 & 15.9 & 9.4 & 15.5 & & \\
\hline $35-39$ & 9.2 & 4.4 & 7.9 & 9.4 & 9.1 & 9.3 & 9.4 & 9.2 & 4.4 & 8.6 & & \\
\hline $40+$ & 6.2 & 1.9 & 5.1 & 3.4 & 6.3 & 4.8 & 3.4 & 6.3 & 1.9 & 4.9 & & \\
\hline \multicolumn{13}{|l|}{ Schooling } \\
\hline Currently attending & 26.3 & 35.4 & 28.7 & 7.0 & 20.9 & 13.9 & 7.0 & 24.0 & 35.4 & 21.1 & $A^{* * *}$ & $\mathrm{~B}^{* * *}$ \\
\hline Mean grade completed & 10.5 & 10.2 & 10.4 & 7.3 & 8.7 & 8.0 & 7.3 & 9.7 & 10.2 & 9.2 & $\mathrm{~A} \dagger$ & $\mathrm{B}^{* * *}$ \\
\hline Marital status & & & & & & & & & & & $A * * *$ & $\mathrm{~B}^{* * *}$ \\
\hline Never married & 55.7 & 67.2 & 58.9 & 10.5 & 37.2 & 23.7 & 10.5 & 48.0 & 67.2 & 40.7 & & \\
\hline $\begin{array}{l}\text { Currently married/living with } \\
\text { partner }\end{array}$ & 32.9 & 26.4 & 31.1 & 81.5 & 45.6 & 63.8 & 81.5 & 38.2 & 26.4 & 48.0 & & \\
\hline Div/Sep/Widowed & 11.4 & 6.3 & 10.0 & 7.9 & 17.2 & 12.5 & 7.9 & 13.8 & 6.3 & 11.3 & & \\
\hline $\begin{array}{l}\text { Among unmarried, has regular } \\
\text { sexual partner }\end{array}$ & & & & & & & & & & & & $B^{*}$ \\
\hline No & 33.7 & 33.3 & 33.6 & 22.5 & 32.1 & 29.6 & 22.5 & 33.1 & 33.3 & 32.2 & & \\
\hline Yes & 66.3 & 66.7 & 66.4 & 77.5 & 67.9 & 70.4 & 77.5 & 66.9 & 66.7 & 67.8 & & \\
\hline $\begin{array}{l}\text { Mean number of biological children } \\
\text { Residence }\end{array}$ & 1.2 & 0.7 & 1.0 & 2.9 & 2.0 & 2.5 & 2.9 & 1.5 & 0.7 & 1.8 & $A^{* * *}$ & $\mathrm{~B}^{* * *}$ \\
\hline Urban & 93.1 & 93.5 & 93.2 & 95.2 & 95.7 & 95.4 & 95.2 & 94.2 & 93.5 & 94.4 & & \\
\hline Rural & 6.9 & 6.5 & 6.8 & 4.8 & 4.3 & 4.6 & 4.8 & 5.8 & 6.5 & 5.6 & & \\
\hline Tribe & & & & & & & & & & & $A^{* * *}$ & $\mathrm{~B}^{* * *}$ \\
\hline Lozi & 3.7 & 1.9 & 3.2 & 3.2 & 3.8 & 3.5 & 3.2 & 3.7 & 1.9 & 3.4 & & \\
\hline Ngoni & 27.4 & 31.4 & 28.5 & 34.3 & 31.0 & 32.7 & 34.3 & 28.9 & 31.4 & 30.6 & & \\
\hline Tonga & 4.1 & 9.0 & 5.5 & 6.2 & 4.6 & 5.4 & 6.2 & 4.3 & 9.0 & 5.4 & & \\
\hline Bemba & 13.8 & 12.6 & 13.5 & 17.6 & 10.6 & 14.2 & 17.6 & 12.5 & 12.6 & 13.8 & & \\
\hline Other & 50.9 & 45.0 & 49.3 & 38.7 & 50.1 & 44.3 & 38.7 & 50.6 & 45.0 & 46.7 & & \\
\hline Religion & & & & & & & & & & & & $\mathrm{B}^{* * *}$ \\
\hline Catholic & 21.9 & 19.7 & 21.3 & 17.3 & 16.7 & 17.0 & 17.3 & 19.7 & 19.7 & 19.1 & & \\
\hline Christian & 72.2 & 74.9 & 72.9 & 80.4 & 77.4 & 78.9 & 80.4 & 74.4 & 74.9 & 76.0 & & \\
\hline Other & 5.9 & 5.4 & 5.8 & 2.3 & 5.9 & 4.1 & 2.3 & 5.9 & 5.4 & 4.9 & & \\
\hline
\end{tabular}


APPENDIX TABLE 2 Baseline demographic characteristics of study participants by sex and entry point service (percentages unless otherwise indicated) (cont'd)

\begin{tabular}{|c|c|c|c|c|c|c|c|c|c|c|c|c|}
\hline & \multicolumn{3}{|c|}{ Male } & \multicolumn{3}{|c|}{ Female } & \multicolumn{4}{|c|}{ Total } & \multicolumn{2}{|c|}{ Tests } \\
\hline & HTC & VMMc & Total & FP & HTC & Total & FP & HTC & VMMC & Total & Males & Females \\
\hline Employment status & & & & & & & & & & & $A^{* *}$ & $\mathrm{~B}^{* * *}$ \\
\hline Not working & 41.5 & 49.2 & 43.6 & 67.7 & 59.8 & 63.8 & 67.7 & 49.2 & 49.2 & 54.0 & & \\
\hline Currently working & 58.5 & 50.8 & 56.4 & 32.3 & 40.2 & 36.2 & 32.3 & 50.8 & 50.8 & 46.0 & & \\
\hline $\begin{array}{l}\text { Mean number of household } \\
\text { assets (0-15) }\end{array}$ & 8.3 & 8.2 & 8.3 & 6.8 & 7.4 & 7.1 & 6.8 & 7.9 & 8.2 & 7.7 & & $\mathrm{~B}^{* * *}$ \\
\hline Household assets & & & & & & & & & & & & $\mathrm{B}^{* * *}$ \\
\hline Lowest quintile & 16.5 & 16.3 & 16.4 & 30.7 & 25.4 & 28.0 & 30.7 & 20.2 & 16.3 & 22.4 & & \\
\hline Middle quintiles & 68.5 & 70.7 & 69.1 & 64.8 & 63.3 & 64.1 & 64.8 & 66.3 & 70.7 & 66.5 & & \\
\hline Highest quintile & 15.0 & 13.0 & 14.5 & 4.5 & 11.3 & 7.9 & 4.5 & 13.5 & 13.0 & 11.1 & & \\
\hline Has own mobile phone & & & & & & & & & & & $\mathrm{A} \dagger$ & $\mathrm{B}^{* * *}$ \\
\hline No & 11.7 & 14.6 & 12.4 & 27.3 & 15.4 & 21.4 & 27.3 & 13.2 & 14.6 & 17.1 & & \\
\hline Yes & 88.3 & 85.4 & 87.6 & 72.7 & 84.6 & 78.6 & 72.7 & 86.8 & 85.4 & 82.9 & & \\
\hline \multicolumn{13}{|l|}{ Type of water source } \\
\hline Piped & 82.2 & 81.0 & 81.9 & 78.9 & 81.0 & 79.9 & 78.9 & 81.7 & 81.0 & 80.9 & & \\
\hline Well/Spring & 8.7 & 9.6 & 8.9 & 10.5 & 8.4 & 9.5 & 10.5 & 8.6 & 9.6 & 9.2 & & \\
\hline Borehole & 8.8 & 9.2 & 8.9 & 9.2 & 10.0 & 9.6 & 9.2 & 9.3 & 9.2 & 9.3 & & \\
\hline Otherb & 0.4 & 0.2 & 0.3 & 1.4 & 0.6 & 1.0 & 1.4 & 0.5 & 0.2 & 0.7 & & \\
\hline Mean time to water source ( $\mathrm{min})$ & 2.6 & 2.8 & 2.7 & 2.8 & 3.3 & 3.0 & 2.8 & 2.9 & 2.8 & 2.9 & & \\
\hline Type of transport to health facility & & & & & & & & & & & $A^{* * *}$ & $\mathrm{~B} \dagger$ \\
\hline Walking & 63.5 & 52.9 & 60.6 & 57.7 & 61.7 & 59.7 & 57.7 & 62.8 & 52.9 & 60.1 & & \\
\hline Bicycle & 6.7 & 3.8 & 5.9 & 2.7 & 1.9 & 2.3 & 2.7 & 4.7 & 3.8 & 4.0 & & \\
\hline Bus & 26.7 & 40.8 & 30.6 & 38.9 & 35.0 & 37.0 & 38.9 & 30.2 & 40.8 & 33.9 & & \\
\hline Car/Taxi & 3.1 & 2.5 & 2.9 & 0.8 & 1.4 & 1.1 & 0.8 & 2.4 & 2.5 & 2.0 & & \\
\hline Mean distance to health facilityc & 4.5 & 5.1 & 4.7 & 1.6 & 4.0 & 2.7 & 1.6 & 4.3 & 5.1 & 3.8 & & $B^{* * *}$ \\
\hline
\end{tabular}

$* * * p<.001 ; * * p<.01 ; * p<.05 ; \dagger p<.10$

$A=H T C \& V M M C, B=$ FP \& HTC

a Those who are living together considered "married".

${ }^{b}$ Excluded from analysis due to small sample size.

c $38 \%$ don't know distance, are missing on this variable. 


\section{APPENDIX TABLE 3. LOGISTIC REGRESSIONS OF STUDY PARTICIPANT}

ATTRITION, BY INTERVIEW DATE

\begin{tabular}{|c|c|c|c|c|c|c|}
\hline & \multicolumn{2}{|c|}{6 weeks } & \multirow[b]{2}{*}{ sign. } & \multicolumn{2}{|c|}{6 months } & \multirow[b]{2}{*}{ sign } \\
\hline & OR (Attrition) & $\mathrm{Cl}$ & & OR (Attrition) & $\mathrm{Cl}$ & \\
\hline \multicolumn{7}{|l|}{ Model 1: Study Arm } \\
\hline \multicolumn{7}{|l|}{ Study arm } \\
\hline Standard of care & 1 & $1.00-1.00$ & & 1 & $1.00-1.00$ & \\
\hline Enhanced referral & 1.13 & $0.92-1.38$ & & 1.13 & $0.92-1.38$ & \\
\hline Enhanced referral \& escort & 1.21 & $0.99-1.49$ & $\dagger$ & 1.21 & $0.99-1.49$ & $\dagger$ \\
\hline $\mathrm{N}$ & 3963 & & & 3963 & & \\
\hline Chi-square & 3.6 & & & 3.6 & & \\
\hline Degrees of freedom & 2 & & & 2 & & \\
\hline \multicolumn{7}{|l|}{ Model 2: Study Arm + Site } \\
\hline \multicolumn{7}{|l|}{ Study arm } \\
\hline Standard of care & 1 & $1.00-1.00$ & & 1 & $1.00-1.00$ & \\
\hline Enhanced referral & 1.13 & $0.92-1.38$ & & 0.96 & $0.79-1.17$ & \\
\hline Enhanced referral \& escort & 1.21 & $0.99-1.49$ & $\dagger$ & 1.1 & $0.90-1.33$ & \\
\hline \multicolumn{7}{|l|}{ Entry site } \\
\hline SFH HTC - Cairo Road & 1 & $1.00-1.00$ & & 1 & $1.00-1.00$ & \\
\hline Chawama Clinic - Maternity Ward & 0.93 & $0.70-1.24$ & & 1.35 & $1.01-1.81$ & * \\
\hline Chawama Clinic - Out Patient Ward (VMMC) & 0.75 & $0.52-1.09$ & & 0.89 & $0.61-1.31$ & \\
\hline Kamwala Clinic - TB, STI \& HIV Clinic & 1.17 & $0.87-1.59$ & & 1.9 & $1.40-2.57$ & $* * *$ \\
\hline Kapata Urban Clinic, $\mathrm{MCH}$ & 0.3 & $0.21-0.43$ & $* * *$ & 0.59 & $0.43-0.82$ & $* *$ \\
\hline Kapata Urban Clinic, TB, STI \& HIV & 0.56 & $0.42-0.73$ & $* * *$ & 0.8 & $0.60-1.06$ & \\
\hline Chipata Gen Hosp - OP VMMC & 0.42 & $0.26-0.68$ & $* * *$ & 0.61 & $0.38-0.97$ & * \\
\hline SFH New Start & 0.51 & $0.39-0.69$ & $* * *$ & 0.69 & $0.51-0.92$ & * \\
\hline SFH VMMC & 0.75 & $0.43-1.32$ & & 1.66 & $1.01-2.75$ & * \\
\hline $\mathrm{N}$ & 3963 & & & 3,963 & & \\
\hline Chi- square & 96.9 & & $* * *$ & 86.07 & & $* * *$ \\
\hline Degrees of freedom & 10 & & & 10 & & \\
\hline \multicolumn{7}{|l|}{ Model 3: Study Arm + Site + Demographic Covariates } \\
\hline \multicolumn{7}{|l|}{ Study arm } \\
\hline Standard of care & 1 & $1.00-1.00$ & & 1 & $1.00-1.00$ & \\
\hline Enhanced referral & 1.12 & $0.90-1.39$ & & 0.95 & $0.78-1.17$ & \\
\hline Enhanced referral \& escort & 1.22 & $0.99-1.50$ & + & 1.1 & $0.90-1.34$ & \\
\hline \multicolumn{7}{|l|}{ Entry site } \\
\hline SFH HTC - Cairo Road & 1 & $1.00-1.00$ & & 1 & $1.00-1.00$ & \\
\hline Chawama Clinic - Maternity Ward & 0.84 & $0.57-1.24$ & & 1.15 & $0.78-1.69$ & \\
\hline Chawama Clinic - Out Patient Ward (VMMC) & 0.56 & $0.37-0.84$ & $* *$ & 0.7 & $0.46-1.06$ & + \\
\hline Kamwala Clinic - TB, STI \& HIV Clinic & 0.9 & $0.64-1.27$ & & 1.66 & $1.19-2.31$ & $* *$ \\
\hline Kapata Urban Clinic, MCH & 0.26 & $0.17-0.40$ & $* * *$ & 0.51 & $0.33-0.76$ & $* *$ \\
\hline Kapata Urban Clinic, TB, STI \& HIV & 0.46 & $0.33-0.66$ & $* * *$ & 0.7 & $0.50-0.99$ & * \\
\hline Chipata Gen Hosp - OP VMMC & 0.3 & $0.17-0.52$ & $* * *$ & 0.44 & $0.26-0.75$ & $* *$ \\
\hline SFH New Start & 0.37 & $0.26-0.53$ & $* * *$ & 0.53 & $0.37-0.75$ & $* * *$ \\
\hline SFH VMMC & 0.48 & $0.26-0.90$ & * & 1.19 & $0.68-2.07$ & \\
\hline \multicolumn{7}{|l|}{ Genderb } \\
\hline Male & 1 & $1.00-1.00$ & & 1 & $1.00-1.00$ & \\
\hline Female & 0.72 & $0.57-0.91$ & ** & 0.78 & $0.62-0.98$ & * \\
\hline Age & 0.99 & 0.98-1.01 & & 0.97 & 0.95-0.99 & $* *$ \\
\hline \multicolumn{7}{|l|}{ Schooling } \\
\hline Not currently attending school & 1 & $1.00-1.00$ & & 1 & $1.00-1.00$ & \\
\hline Currently attending school & 0.95 & $0.75-1.22$ & & 0.89 & $0.70-1.13$ & \\
\hline Highest grade completed & 0.93 & $0.90-0.96$ & $* * *$ & 0.96 & 0.93-0.99 & $* *$ \\
\hline
\end{tabular}


APPENDIX TABLE 3 Logistic regressions of study participant attrition, by interview date (cont'd)

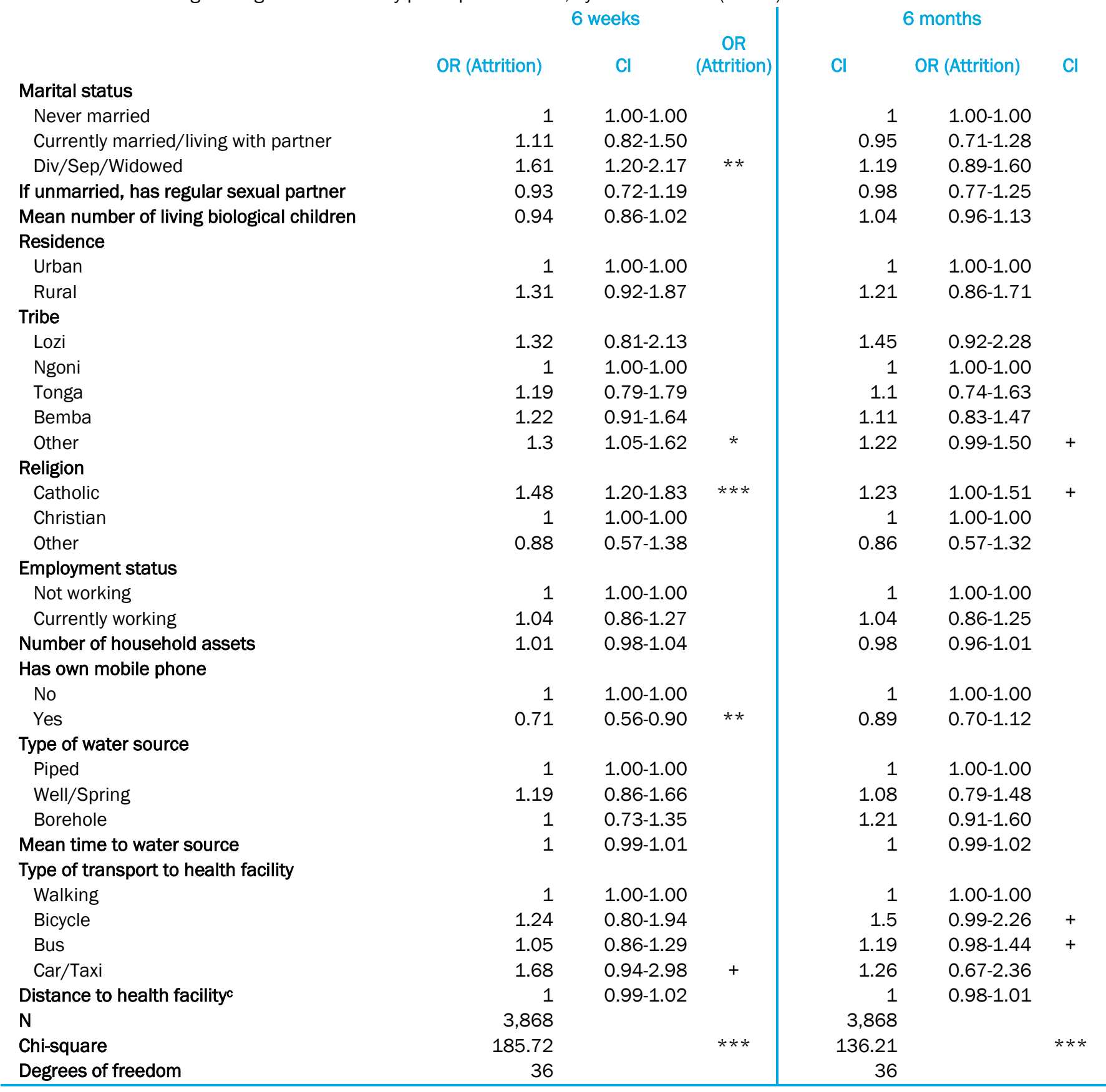

$* * * p<.001 ; * * p<.01 ; * p<.05 ; \uparrow p<.10$

a Entry sites included in model dependent on outcome variable.

b Gender of outcome variable constant if omitted from model.

c $38 \%$ of baseline sample don't know distance, therefore a dummy was also included ( 1 = Yes if don't know distance). 
APPENDIX TABLE 4. DESCRIPTIVE STATISTICS OF CLIENT BEHAVIORAL OUTCOMES AT SIX WEEKS BY STUDY ARM

\begin{tabular}{|c|c|c|c|c|c|c|c|c|c|c|c|c|c|c|c|}
\hline \multirow{2}{*}{ Arm } & \multicolumn{4}{|c|}{ Males } & \multicolumn{4}{|c|}{ Females } & \multicolumn{4}{|c|}{ Totals } & \multicolumn{3}{|c|}{ Tests } \\
\hline & 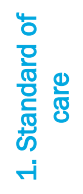 & 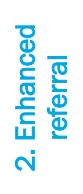 & 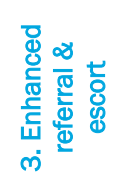 & 胥 & 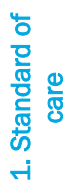 & 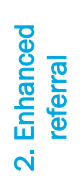 & 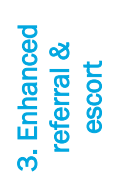 & 可 & 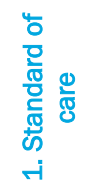 & 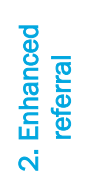 & 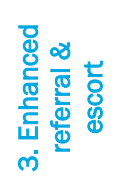 & 可 & $\frac{\frac{\mathscr{E}}{\pi}}{\sum}$ & 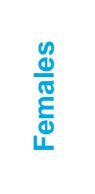 & 흄 \\
\hline Sample size & 529 & 515 & 509 & 1,553 & 578 & 574 & 562 & 1,714 & 1,107 & 1,089 & 1,071 & 3,267 & 1,553 & 1,714 & 3,267 \\
\hline $\begin{array}{l}\text { Contraception } \\
\text { Ever used modern } \\
\text { contraception }\end{array}$ & $n / a$ & $n / a$ & $n / a$ & $n / a$ & 98.1 & 97.9 & 97.2 & 97.7 & $n / a$ & $n / a$ & $\mathrm{n} / \mathrm{a}$ & $n / a$ & $\mathrm{n} / \mathrm{a}$ & & $\mathrm{n} / \mathrm{a}$ \\
\hline $\begin{array}{l}\text { Currently using } \\
\text { contraception } \\
\text { Currently using modern }\end{array}$ & $\mathrm{n} / \mathrm{a}$ & $n / a$ & $\mathrm{n} / \mathrm{a}$ & $n / a$ & 78.0 & 75.4 & 73.6 & 75.7 & $\mathrm{n} / \mathrm{a}$ & $\mathrm{n} / \mathrm{a}$ & $\mathrm{n} / \mathrm{a}$ & $\mathrm{n} / \mathrm{a}$ & $\mathrm{n} / \mathrm{a}$ & $\mathrm{B} \dagger$ & $\mathrm{n} / \mathrm{a}$ \\
\hline $\begin{array}{l}\text { contraception } \\
\text { Currently using a long- } \\
\text { acting form of } \\
\text { contraception }^{\mathrm{b}}\end{array}$ & $\mathrm{n} / \mathrm{a}$ & $\mathrm{n} / \mathrm{a}$ & $\mathrm{n} / \mathrm{a}$ & $\mathrm{n} / \mathrm{a}$ & 77.6 & 73.8 & 73.4 & 75.0 & $\mathrm{n} / \mathrm{a}$ & $\mathrm{n} / \mathrm{a}$ & $\mathrm{n} / \mathrm{a}$ & $\mathrm{n} / \mathrm{a}$ & $\begin{array}{l}n / a \\
n / a\end{array}$ & $\mathrm{~B} \dagger$ & $\mathrm{n} / \mathrm{a}$ \\
\hline $\begin{array}{l}\text { Male circumcision \& } \\
\text { resumption of sex }\end{array}$ & & & & & & & & & & & & & & & \\
\hline Currently circumcised ${ }^{c}$ & 53.3 & 60 & 60.3 & 57.8 & $\mathrm{n} / \mathrm{a}$ & $\mathrm{n} / \mathrm{a}$ & $\mathrm{n} / \mathrm{a}$ & $\mathrm{n} / \mathrm{a}$ & $\mathrm{n} / \mathrm{a}$ & $\mathrm{n} / \mathrm{a}$ & $\mathrm{n} / \mathrm{a}$ & $\mathrm{n} / \mathrm{a}$ & $A^{*}, B^{*}$ & $\mathrm{n} / \mathrm{a}$ & $\mathrm{n} / \mathrm{a}$ \\
\hline $\begin{array}{l}\text { Sexual activity within 6- } \\
\text { weeks of circumcisiond }\end{array}$ & 30.7 & 28.4 & 29.9 & 29.6 & $\mathrm{n} / \mathrm{a}$ & $n / a$ & $n / a$ & $n / a$ & $\mathrm{n} / \mathrm{a}$ & $n / a$ & $\mathrm{n} / \mathrm{a}$ & $n / a$ & & $\mathrm{n} / \mathrm{a}$ & $\mathrm{n} / \mathrm{a}$ \\
\hline $\begin{array}{l}\text { Sexual activity (among sexu } \\
\text { active in past } 12 \text { months) }\end{array}$ & & & & & & & & & & & & & & & \\
\hline $\begin{array}{l}\text { Sexually active in last } 7 \\
\text { days }\end{array}$ & 39.5 & 37.5 & 37.6 & 38.2 & 54.2 & 50.5 & 51.1 & 52.0 & 47.7 & 44.7 & 45.2 & 45.8 & & & \\
\hline $\begin{array}{l}\text { Sexually active in last } \\
30 \text { days } \\
\text { Unprotected sex in last }\end{array}$ & 66.8 & 65.0 & 63.5 & 65.2 & 81.6 & 77.3 & 78.1 & 79.0 & 75.0 & 71.8 & 71.7 & 72.8 & & $\mathrm{~A} \dagger$ & \\
\hline $\begin{array}{l}\text { Unprotected sex in last } \\
7 \text { days } \\
\text { Unprotected sex at last }\end{array}$ & 16.4 & 15.1 & 19.2 & 16.9 & 35.3 & 28.9 & 28.9 & 31.1 & 26.8 & 22.6 & 24.5 & 24.6 & & $A^{*}, B^{*}$ & $A^{*}$ \\
\hline $\begin{array}{l}\text { Unprotected sex at last } \\
\text { sex in past } 12 \text { months }\end{array}$ & 45.2 & 40.8 & 45.2 & 43.7 & 54.0 & 58.7 & 56.0 & 56.2 & 50.1 & 50.7 & 51.2 & 50.6 & & & \\
\hline $\begin{array}{l}\text { Multiple sexual partners } \\
\text { in past } 12 \text { months }\end{array}$ & 34.2 & 31.6 & 36.2 & 34.0 & 35.6 & 40.7 & 40.8 & 39.0 & 35.0 & 36.6 & 38.8 & 36.8 & & & \\
\hline $\begin{array}{l}\text { Mean number of lifetime } \\
\text { sexual partners }\end{array}$ & 6.9 & 6.4 & 6.1 & 6.5 & 3.7 & 3.5 & 3.5 & 3.6 & 5.2 & 4.8 & 4.7 & 4.9 & & & $\mathrm{~B} \dagger$ \\
\hline $\begin{array}{l}\text { Mean number of new } \\
\text { partners in last } 6 \text { weeks }\end{array}$ & 0.7 & 0.7 & 0.7 & 0.7 & 0.5 & 0.6 & 0.5 & 0.5 & 0.6 & 0.6 & 0.6 & 0.6 & & & \\
\hline
\end{tabular}


APPENDIX TABLE 4 Descriptive statistics of client behavioral outcomes at six weeks by study arm (cont'd)

\begin{tabular}{|c|c|c|c|c|c|c|c|c|c|c|c|c|c|c|c|}
\hline \multirow{2}{*}{ Arm } & \multicolumn{4}{|c|}{ Males } & \multicolumn{4}{|c|}{ Females } & \multicolumn{4}{|c|}{ Totals } & \multicolumn{3}{|c|}{ Tests } \\
\hline & 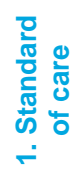 & 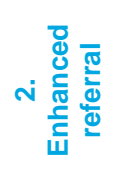 & 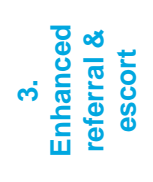 & సँّ & 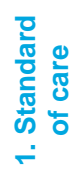 & 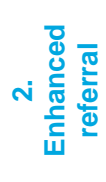 & 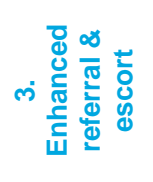 & 䙲 & 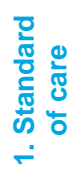 & N & 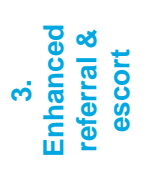 & 흄 & $\frac{\mathscr{e}}{\sum^{\pi /}}$ & 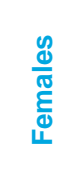 & 氶 \\
\hline \multicolumn{16}{|l|}{ Adherence behaviors } \\
\hline $\begin{array}{l}\text { Missed appointment for } \\
\text { HIV C\&T }\end{array}$ & 0.0 & 0.0 & 0.0 & 0.0 & 0.0 & 0.0 & 10.0 & 3.6 & 0.0 & 0.0 & 7.1 & 2.4 & & & \\
\hline $\begin{array}{l}\text { Missed taking } \\
\text { medication for HIVe,g }\end{array}$ & 0.0 & 10.0 & 12.5 & 7.4 & 15.4 & 13.6 & 35.0 & 21.8 & 9.1 & 12.5 & 28.6 & 17.1 & & & \\
\hline $\begin{array}{l}\text { In past month, missed } \\
\text { at least } 1 \text { time taking } \\
\text { pillf,g }\end{array}$ & $\mathrm{n} / \mathrm{a}$ & $\mathrm{n} / \mathrm{a}$ & $\mathrm{n} / \mathrm{a}$ & $\mathrm{n} / \mathrm{a}$ & 50.0 & 28.6 & 16.7 & 33.3 & $\mathrm{n} / \mathrm{a}$ & $\mathrm{n} / \mathrm{a}$ & $\mathrm{n} / \mathrm{a}$ & $\mathrm{n} / \mathrm{a}$ & $\mathrm{n} / \mathrm{a}$ & & $\mathrm{n} / \mathrm{a}$ \\
\hline \multicolumn{16}{|l|}{$\begin{array}{l}\text { Satistifaction with } \\
\text { services }\end{array}$} \\
\hline $\begin{array}{l}\text { Satisfied with HTC } \\
\text { services }^{g}\end{array}$ & 89.6 & 91.4 & 95.6 & 91.8 & 98.8 & 93.8 & 96.3 & 96.2 & 93.9 & 92.7 & 96.0 & 94.2 & & & \\
\hline $\begin{array}{l}\text { Satisfied with HIV C\&T } \\
\text { services }^{g}\end{array}$ & 93.5 & 85.3 & 97.1 & 91.9 & 92.3 & 93.7 & 90.0 & 91.9 & 92.8 & 90.7 & 92.3 & 91.9 & & & \\
\hline $\begin{array}{l}\text { Satisfied with STI } \\
\text { services }^{g}\end{array}$ & 95.7 & 73.1 & 70.0 & 79.7 & 78.6 & 100.0 & 95.5 & 93.2 & 89.2 & 85.7 & 83.3 & 85.9 & $A \dagger, B^{*}$ & A† & \\
\hline $\begin{array}{l}\text { Satisfied with FP } \\
\text { services }^{g}\end{array}$ & $\mathrm{n} / \mathrm{a}$ & $\mathrm{n} / \mathrm{a}$ & $\mathrm{n} / \mathrm{a}$ & $\mathrm{n} / \mathrm{a}$ & 93.9 & 93.8 & 89.6 & 92.8 & $\mathrm{n} / \mathrm{a}$ & $\mathrm{n} / \mathrm{a}$ & $\mathrm{n} / \mathrm{a}$ & $\mathrm{n} / \mathrm{a}$ & $\mathrm{n} / \mathrm{a}$ & & $\mathrm{n} / \mathrm{a}$ \\
\hline $\begin{array}{l}\text { Satistified with CCS } \\
\text { services }^{g}\end{array}$ & $\mathrm{n} / \mathrm{a}$ & $\mathrm{n} / \mathrm{a}$ & $\mathrm{n} / \mathrm{a}$ & $\mathrm{n} / \mathrm{a}$ & 95.8 & 94.9 & 94.2 & 94.6 & $\mathrm{n} / \mathrm{a}$ & $\mathrm{n} / \mathrm{a}$ & $\mathrm{n} / \mathrm{a}$ & $\mathrm{n} / \mathrm{a}$ & $\mathrm{n} / \mathrm{a}$ & & $\mathrm{n} / \mathrm{a}$ \\
\hline $\begin{array}{l}\text { Satisfied with VMMC } \\
\text { servcies }^{g}\end{array}$ & 95.9 & 93.9 & 92.5 & 93.9 & $\mathrm{n} / \mathrm{a}$ & $\mathrm{n} / \mathrm{a}$ & $\mathrm{n} / \mathrm{a}$ & $\mathrm{n} / \mathrm{a}$ & $\mathrm{n} / \mathrm{a}$ & $\mathrm{n} / \mathrm{a}$ & $\mathrm{n} / \mathrm{a}$ & $\mathrm{n} / \mathrm{a}$ & & $\mathrm{n} / \mathrm{a}$ & $\mathrm{n} / \mathrm{a}$ \\
\hline
\end{tabular}

${ }^{* \star *} \mathrm{p}<.001 ;{ }^{* *} \mathrm{p}<.01 ;{ }^{*} \mathrm{p}<.05 ; \mathrm{p}<.10$

$A=$ Arms $1 \& 2, B=$ Arms $1 \& 3, C=$ Arms $2 \& 3$

Note: Sample sizes vary according to outcome.

${ }^{a}$ Methods include male or female condom, oral contraceptive pill, injectable, diaphragm, foam/jelly, IUD, implant, lactational amenorrhea and sterilization.

${ }^{\mathrm{b}}$ Methods include IUD, implant, and sterilization.

c Constructed using the client database for male circumcision received at registration, in addition to survey data.

${ }^{d}$ Among all those who got circumcised, although it was not yet 6 weeks post-circumcision for all clients.

e Among those taking ARV.

${ }^{\dagger}$ Among women who went to FP and are currently taking pill, not all women currently taking pill.

${ }^{g}$ Tested using Fisher's exact test due to small cell sizes. 
APPENDIX TABLE 5. MULTIVARIABLE LOGISTIC REGRESSION OF IMPACT OF INTERVENTION ON SIX-WEEK SERVICE UPTAKE OUTCOMES (BEHAVIORAL INDICATORS FROM DESCRIPTIVE UPTAKE TABLE)

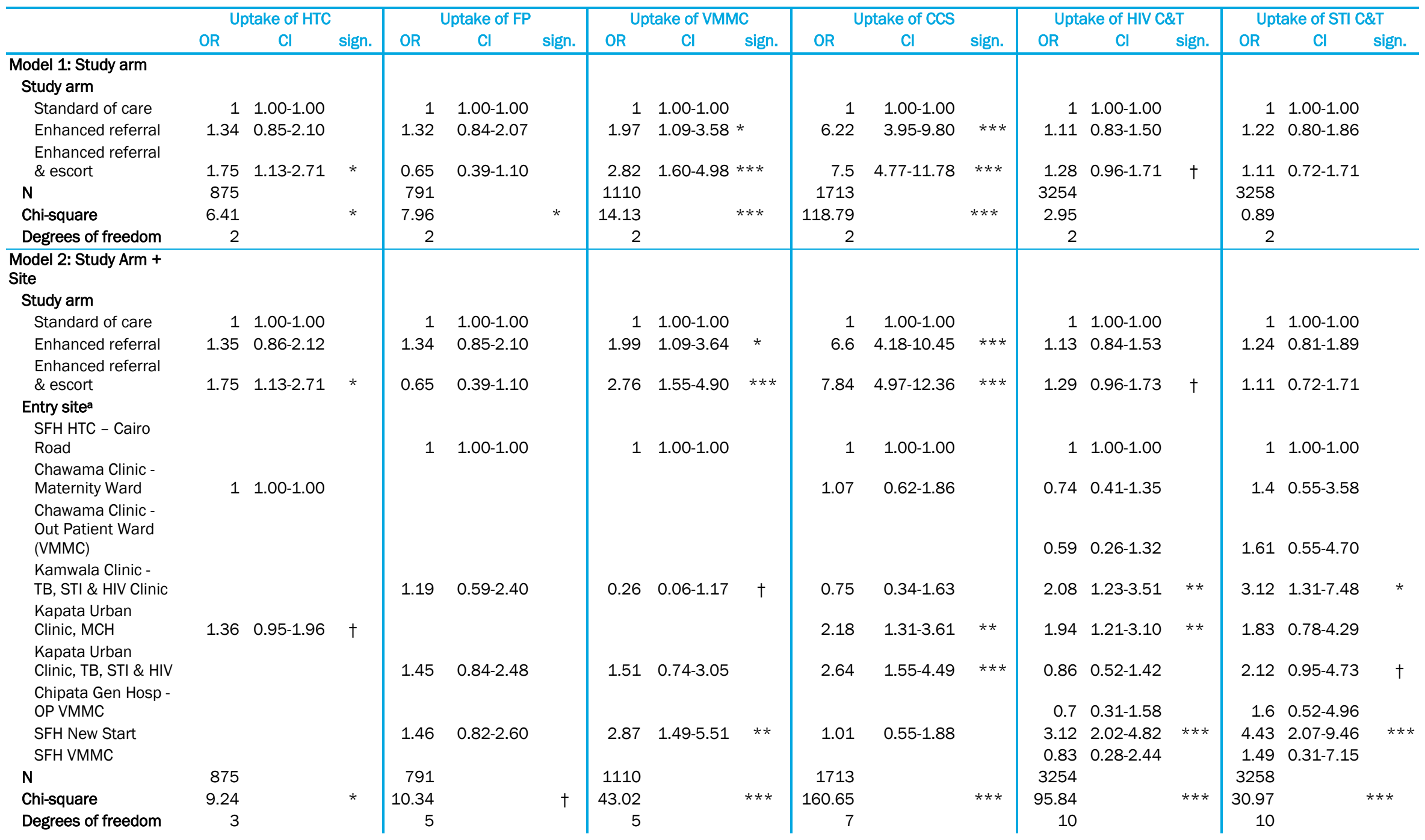


APPENDIX TABLE 5 Multivariable logistic regression of impact of intervention on six-week service uptake outcomes (behavioral indicators from descriptive uptake table) (cont'd)

\begin{tabular}{|c|c|c|c|c|c|c|c|c|c|c|c|c|c|c|c|c|c|c|}
\hline \multirow{3}{*}{$\begin{array}{l} \\
\text { Model 3: Study Arm + } \\
\text { Site + Demographic } \\
\text { Covariates }\end{array}$} & \multicolumn{3}{|c|}{ Uptake of HTC } & \multicolumn{3}{|c|}{ Uptake of FP } & \multicolumn{3}{|c|}{ Uptake VMMC } & \multicolumn{3}{|c|}{ Uptake of CCS } & \multicolumn{3}{|c|}{ Uptake of HIV C\&T } & \multicolumn{3}{|c|}{ Uptake of STI C\&T } \\
\hline & OR & $\mathrm{Cl}$ & sign. & OR & $\mathrm{Cl}$ & sign. & OR & $\mathrm{Cl}$ & Sign. & OR & $\mathrm{Cl}$ & sign. & OR & $\mathrm{Cl}$ & sign. & OR & $\mathrm{Cl}$ & sign. \\
\hline & & & & & & & & & & & & & & & & & & \\
\hline Study arm & & & & & & & & & & & & & & & & & & \\
\hline Standard of care & 1 & $1.00-1.00$ & & 1 & $1.00-1.00$ & & 1 & $1.00-1.00$ & & 1 & $1.00-1.00$ & & 1 & $1.00-1.00$ & & 1 & $1.00-1.00$ & \\
\hline Enhanced referral & 1.34 & $0.85-2.12$ & & 1.34 & $0.84-2.12$ & & 2.09 & $1.13-3.85$ & * & 6.6 & $4.16-10.45$ & $* * *$ & 1.17 & $0.86-1.59$ & & 1.27 & $0.83-1.94$ & \\
\hline $\begin{array}{l}\text { Enhanced referral } \\
\& \text { escort }\end{array}$ & 1.73 & $1.11-2.69$ & * & 0.62 & $0.37-1.06 \dagger$ & & 3 & $1.67-5.39$ & $* * *$ & 7.75 & $4.91-12.23$ & $* * *$ & 1.3 & $0.96-1.75$ & $\dagger$ & 1.13 & $0.73-1.75$ & \\
\hline Entry site & & & & & & & & & & & & & & & & & & \\
\hline $\begin{array}{l}\text { SFH HTC - Cairo } \\
\text { Road }\end{array}$ & & & & 1 & $1.00-1.00$ & & 1 & $1.00-1.00$ & & 1 & $1.00-1.00$ & & 1 & $1.00-1.00$ & & 1 & $1.00-1.00$ & \\
\hline $\begin{array}{l}\text { Chawama Clinic - } \\
\text { Maternity Ward } \\
\text { Chawama Clinic- } \\
\text { Out Patient Ward } \\
\text { (VMMC) }\end{array}$ & 1 & $1.00-1.00$ & & & & & & & & 0.92 & $0.48-1.76$ & & 0.46 & $0.24-0.90$ & * & 1.93 & $0.68-5.48$ & \\
\hline $\begin{array}{l}\text { Kamwala Clinic - } \\
\text { TB, STI \& HIV Clinic } \\
\text { Kapata Urban }\end{array}$ & & & & 0.86 & $0.40-1.85$ & & 0.3 & $0.06-1.39$ & & 0.76 & $0.34-1.70$ & & 1.82 & $1.04-3.18$ & * & 3.42 & $1.39-8.45$ & ** \\
\hline $\begin{array}{l}\text { Clinic, MCH } \\
\text { Kapata Urban }\end{array}$ & 1.33 & $0.89-1.99$ & & & & & & & & 1.71 & $0.95-3.07$ & $\dagger$ & 1.02 & $0.59-1.76$ & & 2.13 & $0.82-5.54$ & \\
\hline $\begin{array}{l}\text { Clinic, TB, STI \& HIV } \\
\text { Chipata Gen Hosp - } \\
\text { OP VMMC }\end{array}$ & & & & 1.11 & $0.57-2.15$ & & 1.48 & $0.67-3.27$ & & 2.2 & $1.21-3.99$ & ** & $\begin{array}{r}0.63 \\
1\end{array}$ & $\begin{array}{l}0.36-1.09 \\
0.42-2.37\end{array}$ & & $\begin{array}{r}2 \\
1.39\end{array}$ & $\begin{array}{l}0.85-4.71 \\
0.42-4.57\end{array}$ & \\
\hline $\begin{array}{l}\text { SFH New Start } \\
\text { SFH VMMC }\end{array}$ & & & & 1.12 & $0.56-2.22$ & & 3.13 & $1.51-6.51$ * & & 0.84 & $0.43-1.65$ & & $\begin{array}{l}2.71 \\
1.34\end{array}$ & $\begin{array}{l}1.67-4.39 \\
0.44-4.08\end{array}$ & $* * *$ & $\begin{array}{l}4.31 \\
1.44\end{array}$ & $\begin{array}{l}1.92-9.68 \\
0.29-7.18\end{array}$ & $* * *$ \\
\hline Gender & & & & & & & & & & & & & & & & & & \\
\hline $\begin{array}{l}\text { Male } \\
\text { Female }\end{array}$ & & & & & & & & & & & & & $\begin{array}{r}1 \\
1.74\end{array}$ & $\begin{array}{l}1.00-1.00 \\
1.26-2.40\end{array}$ & $* * *$ & $\begin{array}{r}1 \\
0.81\end{array}$ & $\begin{array}{l}1.00-1.00 \\
0.51-1.28\end{array}$ & \\
\hline Age & 0.99 & $0.96-1.03$ & & 0.99 & 0.96-1.02 & & 1 & 0.96-1.04 & & 1 & 0.98-1.03 & & 1.06 & $1.04-1.08$ & $* * *$ & 1.04 & $1.01-1.07$ & * \\
\hline $\begin{array}{l}\text { Highest grade } \\
\text { completed }\end{array}$ & 0.99 & $0.94-1.05$ & & 0.96 & $0.91-1.03$ & & 0.99 & $0.91-1.08$ & & 1 & $0.96-1.05$ & & 0.93 & $0.89-0.96$ & $* * *$ & 1.01 & $0.96-1.07$ & \\
\hline $\begin{array}{l}\text { Marital status } \\
\text { Not currently } \\
\text { married }\end{array}$ & 1 & $1.00-1.00$ & & 1 & $1.00-1.00$ & & 1 & $1.00-1.00$ & & 1 & $1.00-1.00$ & & 1 & $1.00-1.00$ & & 1 & $1.00-1.00$ & \\
\hline $\begin{array}{l}\text { Currently married/ } \\
\text { living with partner }\end{array}$ & 0.85 & $0.54-1.33$ & & 2.73 & $1.74-4.29$ & $* * *$ & 1.13 & $0.59-2.16$ & & 1.28 & $0.93-1.78$ & & 0.95 & $0.71-1.26$ & & 0.77 & $0.51-1.16$ & \\
\hline Residence & & & & & & & & & & & & & & & & & & \\
\hline Urban & 1 & $1.00-1.00$ & & 1 & $1.00-1.00$ & & 1 & $1.00-1.00$ & & 1 & $1.00-1.00$ & & 1 & $1.00-1.00$ & & 1 & $1.00-1.00$ & \\
\hline Rural & 0.54 & $0.20-1.44$ & & 1.66 & $0.63-4.36$ & & 0.97 & $0.32-2.99$ & & 1.11 & $0.58-2.11$ & & 0.92 & $0.54-1.59$ & & 1.03 & $0.48-2.23$ & \\
\hline
\end{tabular}


APPENDIX TABLE 5 Multivariable logistic regression of impact of intervention on six-week service uptake outcomes (behavioral indicators from descriptive uptake table) (cont'd)

\begin{tabular}{|c|c|c|c|c|c|c|c|c|c|c|c|c|c|c|c|c|c|c|}
\hline & \multicolumn{3}{|c|}{ Uptake of HTC } & \multicolumn{3}{|c|}{ Uptake of FP } & \multicolumn{3}{|c|}{ Uptake VMMC } & \multicolumn{3}{|c|}{ Uptake of CCS } & \multicolumn{3}{|c|}{ Uptake of HIV C\&T } & \multicolumn{3}{|c|}{ Uptake of STI C\&T } \\
\hline & OR & $\mathrm{Cl}$ & sign. & OR & $\mathrm{Cl}$ & sign. & OR & $\mathrm{Cl}$ & sign. & OR & $\mathrm{Cl}$ & sign. & OR & $\mathrm{Cl}$ & sign. & OR & $\mathrm{Cl}$ & sign. \\
\hline \multicolumn{19}{|l|}{$\begin{array}{l}\text { Employment } \\
\text { status }\end{array}$} \\
\hline Not working & 1 & $1.00-1.00$ & & 1 & $1.00-1.00$ & & 1 & $1.00-1.00$ & & 1 & $1.00-1.00$ & & 1 & $1.00-1.0$ & & 1 & $1.00-1.00$ & \\
\hline Currently working & 1.38 & $0.94-2.03$ & $\dagger$ & 1.12 & $0.74-1.70$ & & 0.58 & $0.35-0.96$ & * & 1.38 & $1.04-1.84$ & * & 1.18 & $0.90-1.5$ & & 1.04 & $0.72-1.51$ & \\
\hline $\begin{array}{l}\text { Number of } \\
\text { household assets }\end{array}$ & 0.97 & $0.92-1.03$ & & 1.05 & $0.98-1.12$ & & 1.11 & $1.03-1.20$ & ** & 0.96 & $0.92-1.00$ & * & 0.99 & $0.95-1.0$ & & 0.94 & $0.89-1.00$ & * \\
\hline $\begin{array}{l}\text { Distance to health } \\
\text { facilityc }\end{array}$ & 1 & $0.91-1.10$ & & 0.99 & $0.94-1.04$ & & 1.02 & $0.98-1.06$ & & $\begin{array}{r}0.99 \\
1696\end{array}$ & 0.94-1.04 & & $\begin{array}{r}0.98 \\
3219\end{array}$ & $0.95-1.0$ & & $\begin{array}{r}1 \\
3223\end{array}$ & $0.97-1.04$ & \\
\hline$N$ & 865 & & & $\begin{array}{r}784 \\
3594\end{array}$ & & & 1092 & & & $\begin{array}{r}1696 \\
17227\end{array}$ & & & $\begin{array}{r}3219 \\
19853\end{array}$ & & & $\begin{array}{r}3223 \\
4522\end{array}$ & & \\
\hline $\begin{array}{l}\text { Chi-square } \\
\text { Degrees of } \\
\text { freedom }\end{array}$ & 15.08 & & & $\begin{array}{r}35.94 \\
13\end{array}$ & & *** & $\begin{array}{r}56.82 \\
13\end{array}$ & & 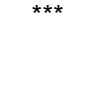 & $\begin{array}{r}172.27 \\
15\end{array}$ & & *** & $\begin{array}{r}198.53 \\
19\end{array}$ & & 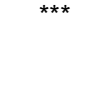 & $\begin{array}{r}45.22 \\
19\end{array}$ & & $\star \star * *$ \\
\hline
\end{tabular}

${ }^{* \star \star} \mathrm{p}<.001 ;{ }^{* \star} \mathrm{p}<.01 ;{ }^{*} \mathrm{p}<.05 ; \mathrm{\dagger} \mathrm{p}<.10$

${ }^{\text {a }}$ Entry sites included in model dependent on outcome variable.

${ }^{\mathrm{b}}$ Gender of outcome variable constant if omitted from model.

c $38 \%$ of baseline sample don't know distance, therefore a dummy was also included ( $1=$ Yes if don't know distance). 


\section{APPENDIX TABLE 6. MULTIVARIABLE LOGISTIC REGRESSION OF IMPACT OF INTERVENTION ON SERVICE UPTAKE OUTCOMES (AMONG ELIGIBLE SUB-POPULATIONS), BEHAVIORAL INDICATORS FROM DESCRIPTIVE UPTAKE}

TABLE

\begin{tabular}{|c|c|c|c|c|c|c|c|c|c|c|c|}
\hline & \multicolumn{3}{|c|}{$\begin{array}{l}\text { Uptake of HTCa: } \\
6 \text { weeks }\end{array}$} & \multicolumn{3}{|c|}{$\begin{array}{l}\text { Uptake of HTCa: } \\
6 \text { months }\end{array}$} & \multicolumn{2}{|c|}{$\begin{array}{l}\text { Uptake of FPb: } \\
6 \text { weeks }\end{array}$} & \multicolumn{3}{|c|}{$\begin{array}{l}\text { Uptake of FPb: } \\
6 \text { months }\end{array}$} \\
\hline & OR & $\mathrm{Cl}$ & sign. & OR & $\mathrm{Cl}$ & sign. & OR & sign. & OR & $\mathrm{Cl}$ & sign. \\
\hline \multicolumn{11}{|l|}{ Model 1: Study Arm } & \\
\hline Standard of care & 1 & $1.00-1.00$ & & 1 & $1.00-1.00$ & & 1 & $1.00-1.00$ & 1 & $1.00-1.00$ & \\
\hline Enhanced referral & 1.28 & $0.77-2.11$ & & 1.33 & $0.90-1.95$ & & 2.28 & $0.68-7.66$ & 0.63 & $0.25-1.55$ & \\
\hline Enhanced referral \& escort & 1.81 & $1.12-2.93$ & * & 1.4 & $0.95-2.06$ & $\dagger$ & 2.05 & $0.59-7.04$ & 1.11 & $0.49-2.51$ & \\
\hline $\mathrm{N}$ & 755 & & & 725 & & & 285 & & 276 & & \\
\hline Chi-square & 6.25 & & * & 3.42 & & & 2.12 & & 1.76 & & \\
\hline Degrees of Freedom & 2 & & & 2 & & & 2 & & 2 & & \\
\hline \multicolumn{11}{|l|}{ Model 2: Study Arm + Site } & \\
\hline Standard of care & 1 & $1.00-1.00$ & & 1 & $1.00-1.00$ & & 1 & $1.00-1.00$ & 1 & $1.00-1.00$ & \\
\hline Enhanced referral & 1.27 & $0.77-2.10$ & & 1.32 & $0.90-1.94$ & & 2.22 & $0.65-7.54$ & 0.63 & $0.26-1.57$ & \\
\hline Enhanced referral \& escort & 1.8 & 1.12-2.92 & * & 1.4 & $0.95-2.06$ & $\dagger$ & 2 & $0.57-6.93$ & 1.09 & $0.48-2.49$ & \\
\hline $\begin{array}{l}\text { Entry site } \\
\text { SFH HTC - Cairo Road }\end{array}$ & 1 & $1.00-1.00$ & & 1 & $1.00-1.00$ & & & & & & \\
\hline $\begin{array}{l}\text { Chawama Clinic - Maternity Ward } \\
\text { Chawama Clinic - Out Patient Ward } \\
\text { (VMMC) }\end{array}$ & 1.45 & $0.98-2.16$ & $\dagger$ & 1.44 & $1.05-1.97$ & * & 0.94 & $0.29-3.01$ & 1.18 & $0.39-3.56$ & \\
\hline $\begin{array}{l}\text { Kamwala Clinic - TB, STI \& HIV Clinic } \\
\text { Kapata Urban Clinic, MCH }\end{array}$ & & & & & & & 0.37 & $0.11-1.27$ & 1.6 & $0.65-3.96$ & \\
\hline $\begin{array}{l}\text { Kapata Urban Clinic, TB, STI \& HIV } \\
\text { Chipata Gen Hosp - OP VMMC } \\
\text { SFH New Start } \\
\text { SFH VMMC }\end{array}$ & & & & & & & 0.35 & $0.09-1.37$ & 0.92 & $0.32-2.61$ & \\
\hline $\mathrm{N}$ & 755 & & & 725 & & & 285 & & 276 & & \\
\hline Chi-square & 9.74 & & * & 8.52 & & * & 6.61 & & 3.43 & & \\
\hline Degrees of freedom & 3 & & & 3 & & & 5 & & 5 & & \\
\hline \multicolumn{12}{|l|}{$\begin{array}{l}\text { Model 3: Study Arm + Site + Demographic } \\
\text { Covariates }\end{array}$} \\
\hline Study arm & & & & & & & & & & & \\
\hline Standard of care & 1 & $1.00-1.00$ & & 1 & $1.00-1.00$ & & 1 & $1.00-1.00$ & 1 & $1.00-1.00$ & \\
\hline Enhanced referral & 1.28 & $0.77-2.14$ & & 1.31 & $0.89-1.94$ & & 2.35 & $0.67-8.24$ & 0.6 & $0.23-1.54$ & \\
\hline Enhanced referral \& escort & 1.76 & $1.08-2.87$ & * & 1.37 & $0.93-2.02$ & & 2.01 & $0.56-7.18$ & 1 & $0.42-2.35$ & \\
\hline
\end{tabular}




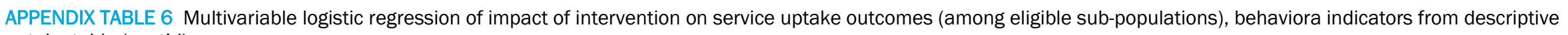
uptake table (cont'd)

\begin{tabular}{|c|c|c|c|c|c|c|c|c|c|c|c|c|}
\hline & \multicolumn{3}{|c|}{$\begin{array}{l}\text { Uptake of HTCa: } \\
6 \text { weeks }\end{array}$} & \multicolumn{3}{|c|}{$\begin{array}{l}\text { Uptake of HTCa: } \\
6 \text { months }\end{array}$} & \multicolumn{3}{|c|}{$\begin{array}{l}\text { Uptake of FPb: } \\
\quad 6 \text { weeks }\end{array}$} & \multicolumn{3}{|c|}{$\begin{array}{l}\text { Uptake of FPb: } \\
6 \text { months }\end{array}$} \\
\hline & OR & $\mathrm{Cl}$ & sign. & OR & $\mathrm{Cl}$ & sign. & OR & $\mathrm{Cl}$ & sign. & OR & $\mathrm{Cl}$ & sign. \\
\hline \multicolumn{13}{|l|}{ Entry site ${ }^{c}$} \\
\hline SFH HTC - Cairo Road & & & & & & & 1 & $1.00-1.00$ & & 1 & $1.00-1.00$ & \\
\hline $\begin{array}{l}\text { Chawama Clinic - Maternity Ward } \\
\text { Chawama Clinic - Out Patient Ward } \\
\text { (VMMC) }\end{array}$ & 1 & $1.00-1.00$ & & 1 & $1.00-1.00$ & & & & & & & \\
\hline Kamwala Clinic - TB, STI \& HIV Clinic & & & & & & & 0.72 & $0.20-2.59$ & & 0.66 & $0.19-2.30$ & \\
\hline Kapata Urban Clinic, MCH & 1.49 & $0.96-2.32$ & $\dagger$ & 1.44 & $1.01-2.05$ & * & & & & & & \\
\hline $\begin{array}{l}\text { Kapata Urban Clinic, TB, STI \& HIV } \\
\text { Chipata Gen Hosp - OP VMMC }\end{array}$ & & & & & & & 0.23 & $0.05-1.06$ & $\dagger$ & 0.63 & $0.19-2.10$ & \\
\hline $\begin{array}{l}\text { SFH New Start } \\
\text { SFH VMMC }\end{array}$ & & & & & & & 0.22 & $0.04-1.08$ & $\dagger$ & 0.32 & $0.08-1.22$ & $\dagger$ \\
\hline Age & 0.99 & 0.95-1.02 & & 1.02 & $1.00-1.05$ & $\dagger$ & 0.96 & $0.89-1.04$ & & 0.95 & $0.90-1.01$ & $\dagger$ \\
\hline Highest grade completed & 0.97 & $0.92-1.03$ & & 1.02 & $0.97-1.07$ & & 0.98 & $0.84-1.14$ & & 0.91 & $0.81-1.02$ & \\
\hline \multicolumn{13}{|l|}{ Marital status } \\
\hline Not currently married & 1 & $1.00-1.00$ & & 1 & $1.00-1.00$ & & 1 & $1.00-1.00$ & & 1 & $1.00-1.00$ & \\
\hline Currently married/living with partner & 0.75 & $0.45-1.24$ & & 0.69 & $0.45-1.05$ & $\dagger$ & 1.45 & $0.47-4.45$ & & 3.24 & $1.43-7.36$ & $* *$ \\
\hline \multicolumn{13}{|l|}{ Residence } \\
\hline Urban & 1 & $1.00-1.00$ & & 1 & $1.00-1.00$ & & 1 & $1.00-1.00$ & & 1 & $1.00-1.00$ & \\
\hline Rural & 0.28 & $0.06-1.25$ & $\dagger$ & 0.68 & $0.29-1.63$ & & 1 & $1.00-1.00$ & & 1 & $1.00-1.00$ & \\
\hline \multicolumn{13}{|l|}{ Employment status } \\
\hline Not working & 1 & $1.00-1.00$ & & 1 & $1.00-1.00$ & & 1 & $1.00-1.00$ & & 1 & $1.00-1.00$ & \\
\hline Currently working & 1.41 & $0.93-2.15$ & & 0.96 & $0.68-1.37$ & & 1.33 & $0.50-3.52$ & & 0.77 & $0.35-1.69$ & \\
\hline Number of household assets & 0.99 & 0.93-1.05 & & 1 & 0.95-1.05 & & 0.99 & $0.84-1.17$ & & 1 & $0.88-1.13$ & \\
\hline Distance to health facilityd & 0.99 & $0.90-1.10$ & & 0.98 & 0.91-1.06 & & 0.9 & $0.74-1.10$ & & 0.99 & 0.89-1.09 & \\
\hline $\mathrm{N}$ & 746 & & & 716 & & & 275 & & & 265 & & \\
\hline Chi-square & 18.33 & & $\dagger$ & 14.78 & & & 10.57 & & & 15.78 & & \\
\hline Degrees of freedom & 11 & & & 11 & & & 12 & & & 12 & & \\
\hline
\end{tabular}

$* * * p<.001 ; * * p<.01 ; * p<.05 ; \dagger p<.10$

a $\mathrm{HTC}$ analysis restricted to those who were sexually active in past 12 months

${ }^{\mathrm{b}} \mathrm{FP}$ analysis restricted to those not currently pregnant, able to get pregnant, not currently using modern method of family planning, and who wanted to wait at least two years before having a child.

c Entry sites included in model dependent on outcome variable.

d $38 \%$ of baseline sample don't know distance, therefore a dummy was also included ( 1 = Yes if don't know distance). 


\section{APPENDIX TABLE 7. MULTIPLE IMPUTATION MULTIVARIABLE LOGISTIC REGRESSION OF IMPACT OF INTER VENTION ON SIX-WEEK SERVICE UPTAKE OUTCOMES (BEHAVIORAL INDICATORS FROM DESCRIPTIVE UPTAKE TABLE)}

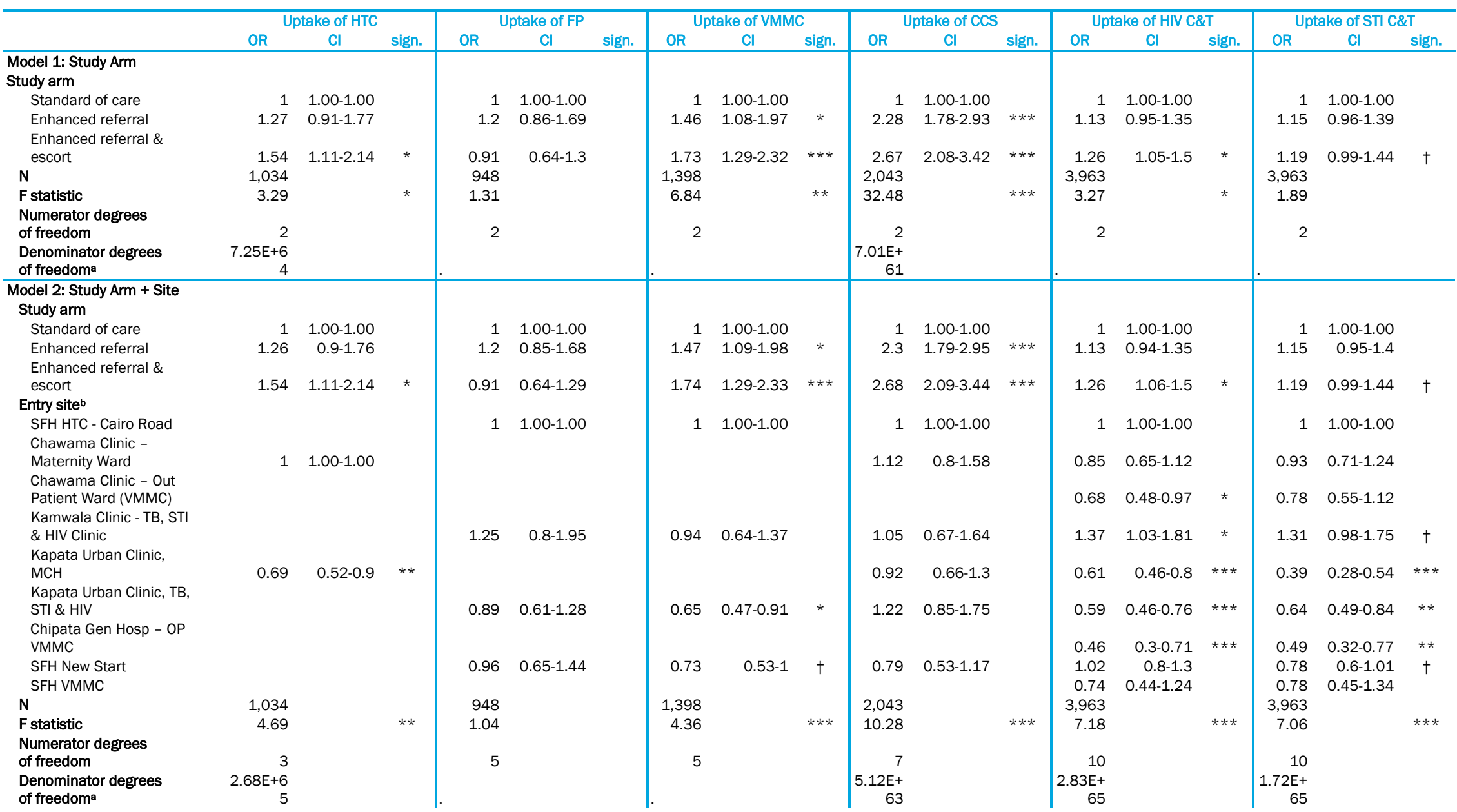


APPENDIX TABLE 7 Multiple imputation multivariable logistic regression of impact of intervention on six-week service uptake outcomes (behavioral indicators from descriptive uptake table) (cont'd)

\begin{tabular}{|c|c|c|c|c|c|c|c|c|c|c|c|c|c|c|c|c|c|c|}
\hline \multirow{3}{*}{$\begin{array}{l}\text { Model 3: Study Arm + Site + } \\
\text { Demographic Covariates }\end{array}$} & \multicolumn{3}{|c|}{ Uptake of HTC } & \multicolumn{3}{|c|}{ Uptake of FP } & \multicolumn{3}{|c|}{ Uptake of VMMC } & \multicolumn{3}{|c|}{ Uptake of CCS } & \multicolumn{3}{|c|}{ Uptake of HIV C\&T } & \multicolumn{3}{|c|}{ Uptake of STI C\&T } \\
\hline & $\mathrm{OR}$ & $\mathrm{Cl}$ & sign. & OR & $\mathrm{Cl}$ & sign. & $\mathrm{OR}$ & $\mathrm{Cl}$ & sign. & OR & $\mathrm{Cl}$ & sign. & OR & $\mathrm{Cl}$ & sign. & OR & $\mathrm{Cl}$ & sign. \\
\hline & & & & & & & & & & & & & & & & & & \\
\hline Standard of care & 1 & $1.00-1.00$ & & 1 & $1.00-1.00$ & & 1 & $1.00-1.00$ & & 1 & $1.00-1.00$ & & 1 & $1.00-1.00$ & & 1 & $1.00-1.00$ & \\
\hline $\begin{array}{l}\text { Enhanced referral } \\
\text { Enhanced referral \& }\end{array}$ & 1.26 & $0.90-1.77$ & & 1.19 & $0.85-1.68$ & & 1.51 & $1.11-2.04$ & $* *$ & 2.29 & $1.78-2.94$ & $* * *$ & 1.14 & $0.95-1.37$ & & 1.16 & $0.96-1.41$ & \\
\hline $\begin{array}{l}\text { escort } \\
\text { Entry site }^{\mathrm{b}}\end{array}$ & 1.57 & $1.12-2.19$ & $* *$ & 0.89 & $0.63-1.27$ & & 1.74 & $1.29-2.34$ & $* * *$ & 2.68 & $2.09-3.44$ & $* * *$ & 1.27 & $1.06-1.51$ & $* *$ & 1.19 & $0.98-1.44$ & $\dagger$ \\
\hline $\begin{array}{l}\text { SFH HTC - Cairo Road } \\
\text { Chawama Clinic - }\end{array}$ & & & & 1 & $1.00-1.00$ & & 1 & $1.00-1.00$ & & 1 & $1.00-1.00$ & & 1 & $1.00-1.00$ & & 1 & $1.00-1.00$ & \\
\hline $\begin{array}{l}\text { Maternity Ward } \\
\text { Chawama Clinic - Out }\end{array}$ & 1 & $1.00-1.00$ & & & & & & & & 0.91 & $0.60-1.37$ & & 0.64 & $0.46-0.90$ & $* *$ & 0.9 & $0.64-1.28$ & \\
\hline $\begin{array}{l}\text { Patient Ward (VMMC) } \\
\text { Kamwala Clinic - TB, STI }\end{array}$ & & & & & & & & & & & & & 0.61 & $0.42-0.89$ & * & 0.61 & $0.41-0.89$ & * \\
\hline $\begin{array}{l}\text { \& HIV Clinic } \\
\text { Kapata Urban Clinic, }\end{array}$ & & & & 0.99 & $0.61-1.62$ & & 0.77 & $0.51-1.16$ & & 0.93 & $0.58-1.49$ & & 1.12 & $0.83-1.51$ & & 1.09 & $0.80-1.48$ & \\
\hline $\begin{array}{l}\text { MCH } \\
\text { Kapata Urban Clinic, TB, }\end{array}$ & 0.69 & $0.51-0.93$ & * & & & & & & & 0.73 & $0.49-1.09$ & & 0.41 & $0.29-0.57$ & $* * *$ & 0.34 & $0.23-0.50$ & $* * *$ \\
\hline $\begin{array}{l}\text { STI \& HIV } \\
\text { Chipata Gen Hosp - OP }\end{array}$ & & & & 0.69 & $0.43-1.09$ & & 0.61 & $0.42-0.89$ & * & 1.01 & $0.67-1.52$ & & 0.47 & $0.35-0.62$ & $* * *$ & 0.54 & $0.40-0.72$ & $* * *$ \\
\hline VMMC & & & & & & & & & & & & & 0.4 & $0.25-0.63$ & $* * *$ & 0.35 & $0.22-0.57$ & $* * *$ \\
\hline SFH New Start & & & & 0.72 & $0.45-1.17$ & & 0.63 & $0.44-0.91$ & * & 0.62 & $0.40-0.97$ & * & 0.8 & $0.61-1.05$ & & 0.61 & $0.46-0.81$ & $* *$ \\
\hline SFH VMMC & & & & & & & & & & & & & 0.69 & $0.40-1.19$ & & 0.59 & $0.34-1.04$ & $\dagger$ \\
\hline Gender ${ }^{c}$ & & & & & & & & & & & & & & & & & & \\
\hline Male & & & & & & & & & & & & & 1 & $1.00-1.00$ & & 1 & $1.00-1.00$ & \\
\hline Female & & & & & & & & & & & & & 1 & $0.82-1.21$ & & 0.72 & $0.58-0.88$ & $* *$ \\
\hline Age & 0.99 & $0.96-1.01$ & & 0.99 & $0.97-1.01$ & & 1 & $0.98-1.02$ & & 0.99 & $0.98-1.01$ & & 1.02 & $1.01-1.03$ & $* *$ & 1 & 0.99-1.01 & \\
\hline Highest grade completed & 0.96 & $0.92-1.00$ & * & 0.95 & 0.91-0.99 & * & 0.92 & $0.89-0.96$ & $* * *$ & 0.97 & $0.94-1.00$ & * & 0.92 & $0.90-0.94$ & $* * *$ & 0.94 & 0.91-0.96 & $* * *$ \\
\hline Marital status & & & & & & & & & & & & & & & & & & \\
\hline $\begin{array}{l}\text { Not currently married } \\
\text { Currently married/living }\end{array}$ & 1 & $1.00-1.00$ & & 1 & $1.00-1.00$ & & 1 & $1.00-1.00$ & & 1 & $1.00-1.00$ & & 1 & $1.00-1.00$ & & 1 & $1.00-1.00$ & \\
\hline $\begin{array}{l}\text { with partner } \\
\text { Residence }\end{array}$ & 0.8 & $0.56-1.13$ & & 1.53 & $1.12-2.08$ & $* *$ & 1.02 & $0.74-1.39$ & & 1.06 & $0.84-1.33$ & & 0.94 & $0.79-1.12$ & & 0.94 & $0.77-1.13$ & \\
\hline Urban & 1 & $1.00-1.00$ & & 1 & $1.00-1.00$ & & 1 & $1.00-1.00$ & & 1 & $1.00-1.00$ & & 1 & $1.00-1.00$ & & 1 & $1.00-1.00$ & \\
\hline Rural & 0.95 & $0.48-1.87$ & & 1.41 & $0.70-2.84$ & & 1.16 & $0.73-1.85$ & & 1.3 & $0.82-2.06$ & & 1.17 & $0.86-1.60$ & & 1.28 & $0.92-1.77$ & \\
\hline Employment status & & & & & & & & & & & & & & & & & & \\
\hline Not working & 1 & $1.00-1.00$ & & 1 & $1.00-1.00$ & & 1 & $1.00-1.00$ & & 1 & $1.00-1.00$ & & 1 & $1.00-1.00$ & & 1 & $1.00-1.00$ & \\
\hline Currently working & 1.11 & $0.82-1.50$ & & 1.04 & $0.77-1.40$ & & 0.98 & $0.74-1.29$ & & 1.1 & $0.90-1.36$ & & 1.09 & $0.93-1.28$ & & 1.06 & $0.89-1.26$ & \\
\hline $\begin{array}{l}\text { Number of household } \\
\text { assets }\end{array}$ & 1 & $0.96-1.05$ & & 1.02 & $0.97-1.07$ & & 1.02 & $0.98-1.06$ & & 0.98 & $0.95-1.01$ & & 1 & $0.97-1.02$ & & 0.99 & 0.96-1.01 & \\
\hline $\begin{array}{l}\text { Distance to health } \\
\text { facilityd } \\
N\end{array}$ & $\begin{array}{r}1.01 \\
1034\end{array}$ & $0.94-1.09$ & & $\begin{array}{r}1 \\
948\end{array}$ & $0.97-1.03$ & & $\begin{array}{r}1.01 \\
1398\end{array}$ & $0.99-1.03$ & & $\begin{array}{r}1 \\
2043\end{array}$ & $0.97-1.03$ & & $\begin{array}{r}1 \\
3963\end{array}$ & $0.99-1.02$ & & $\begin{array}{r}1.01 \\
3963\end{array}$ & $0.99-1.02$ & \\
\hline F statistic & 2.11 & & * & 1.54 & & $\dagger$ & 3.15 & & $* * *$ & 5.52 & & $* * *$ & 8.3 & & $* * *$ & 5.98 & & $* * *$ \\
\hline
\end{tabular}


APPENDIX TABLE 7 Multiple imputation multivariable logistic regression of impact of intervention on six-week service uptake outcomes (behavioral indicators from descriptive uptake table) (cont'd)

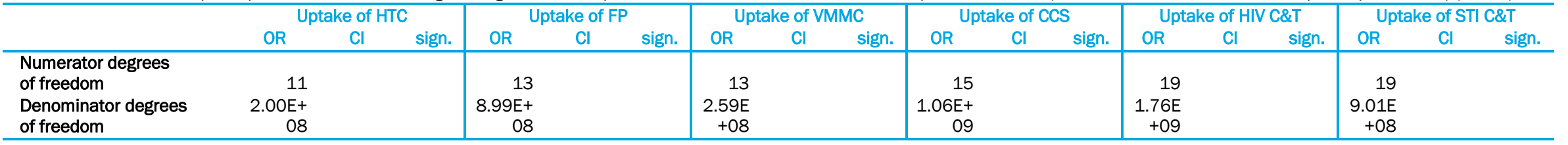

$* * * p<.001 ; * * p<.01 ; * p<.05 ; \uparrow p<.10$

a Denominator degrees of freedom in some models are missing. Per Stata results: "This may happen when the estimated (average) relative variance increase due to nonresponse is close enough to zero (low fraction of missings) such that the degrees of freedom approaches infinity. In this case, the normal distribution is used to compute the significance levels of the reported t tests and the chi-

squared distribution is used to compute the significance level of the $\mathrm{F}$ test."

b Entry sites included in model dependent on outcome variable.

c Gender of outcome variable constant if omitted from model.

d $38 \%$ of baseline sample don't know distance, therefore a dummy was also included ( 1 = Yes if don't know distance). 
APPENDIX TABLE 8. MULTIPLE IMPUTATION MULTIVARIABLE LOGISTIC REGRESSION OF IMPACT OF INTERVENTION ON SIX-MONTH SERVICE UPTAKE OUTCOMES (BEHAVIORAL INDICATORS FROM DESCRIPTIVE UPTAKE TABLE)

\begin{tabular}{|c|c|c|c|c|c|c|c|c|c|c|c|c|c|c|c|c|c|}
\hline & \multicolumn{3}{|c|}{ Uptake of HTC } & \multicolumn{3}{|c|}{ Uptake of FP } & \multicolumn{3}{|c|}{ Uptake of VMMC } & \multicolumn{3}{|c|}{ Uptake of CCS } & \multicolumn{3}{|c|}{ Uptake of HIV C\&T } & \multicolumn{2}{|c|}{ Uptake of STI C8 } \\
\hline & OR & $\mathrm{Cl}$ & sign. & OR & $\mathrm{Cl}$ & sign. & OR & $\mathrm{Cl}$ & sign. & $\mathrm{OR}$ & $\mathrm{Cl}$ & sign. & $\mathrm{OR}$ & $\mathrm{Cl}$ & sign. & OR & $\mathrm{Cl}$ \\
\hline \multicolumn{18}{|l|}{ Model 1: Study Arm } \\
\hline \multicolumn{18}{|l|}{ Study arm } \\
\hline Standard of care & 1 & $1.00-1.00$ & & 1 & $1.00-1.00$ & & 1 & $1.00-1.00$ & & 1 & $1.00-1.00$ & & 1 & $1.00-1.00$ & & 1 & $1.00-1.00$ \\
\hline Enhanced referral & 1.26 & $0.93-1.7$ & & 0.92 & $0.67-1.28$ & & 1 & $0.74-1.35$ & & 1.72 & $1.36-2.17$ & $* * *$ & 1.04 & $0.87-1.24$ & & 0.95 & $0.79-1.15$ \\
\hline $\begin{array}{l}\text { Enhanced referral \& } \\
\text { escort }\end{array}$ & 1.27 & $0.94-1.72$ & & 1.03 & $0.74-1.42$ & & 1.44 & $1.08-1.92$ & * & 1.83 & $1.45-2.31$ & $* * *$ & 1.15 & $0.97-1.37$ & & 1.07 & $0.9-1.29$ \\
\hline $\mathrm{N}$ & 1034 & & & 948 & & & 1398 & & & 2043 & & & 3963 & & & 3963 & \\
\hline F statistic & 1.54 & & & 0.22 & & & 4.15 & & * & 15.27 & & $* * *$ & 1.38 & & & 0.82 & \\
\hline $\begin{array}{l}\text { Numerator degrees of } \\
\text { freedom }\end{array}$ & 2 & & & 2 & & & 2 & & & 2 & & & 2 & & & 2 & \\
\hline $\begin{array}{l}\text { Denominator degrees } \\
\text { of freedoma }\end{array}$ & & & & $\begin{array}{r}2.92 E+6 \\
8\end{array}$ & & & $\begin{array}{r}3.44 \mathrm{E}+7 \\
5\end{array}$ & & & . & & & . & & & . & \\
\hline \multicolumn{18}{|l|}{ Model 2: Study Arm + Site } \\
\hline \multicolumn{18}{|l|}{ Study arm } \\
\hline Standard of care & 1 & $1.00-1.00$ & & 1 & $1.00-1.00$ & & 1 & $1.00-1.00$ & & 1 & $1.00-1.00$ & & 1 & $1.00-1.00$ & & 1 & $1.00-1.00$ \\
\hline Enhanced referral & 1.26 & $0.93-1.7$ & & 0.93 & $0.67-1.28$ & & 1 & $0.74-1.35$ & & 1.73 & $1.37-2.18$ & $* * *$ & 1.04 & $0.87-1.24$ & & 0.95 & $0.79-1.14$ \\
\hline $\begin{array}{l}\text { Enhanced referral \& } \\
\text { escort }\end{array}$ & 1.27 & $0.94-1.72$ & & 1.02 & $0.73-1.41$ & & 1.45 & $1.09-1.95$ & * & 1.84 & $1.46-2.32$ & $* * *$ & 1.15 & $0.97-1.37$ & & 1.07 & $0.89-1.28$ \\
\hline \multicolumn{18}{|l|}{ Entry site } \\
\hline $\begin{array}{l}\text { SFH HTC - Cairo Road } \\
\text { Chawama Clinic - }\end{array}$ & & & & 1 & $1.00-1.00$ & & 1 & $1.00-1.00$ & & 1 & $1.00-1.00$ & & 1 & $1.00-1.00$ & & 1 & $1.00-1.00$ \\
\hline Maternity Ward & 1 & $1.00-1.00$ & & & & & & & & 1.35 & $0.97-1.88$ & $\dagger$ & 1.62 & $1.24-2.11$ & $* * *$ & 1.32 & $0.99-1.75$ \\
\hline $\begin{array}{l}\text { Chawama Clinic - Out } \\
\text { Patient Ward (VMMC) }\end{array}$ & & & & & & & & & & & & & 0.82 & $0.57-1.18$ & & 0.94 & $0.65-1.36$ \\
\hline $\begin{array}{l}\text { Kamwala Clinic - TB, STI } \\
\text { \& HIV Clinic }\end{array}$ & & & & 1.52 & $0.99-2.34$ & $\dagger$ & 1.77 & $1.21-2.6$ & ** & 1.22 & $0.8-1.88$ & & 2.01 & $1.51-2.67$ & $* * *$ & 1.98 & $1.48-2.65$ \\
\hline Kapata Urban Clinic, $\mathrm{MCH}$ & 0.9 & $0.7-1.14$ & & & & & & & & 1.21 & $0.87-1.67$ & & 1.02 & $0.78-1.34$ & & 0.75 & $0.55-1$ \\
\hline $\begin{array}{l}\text { Kapata Urban Clinic, TB, } \\
\text { STI \& HIV }\end{array}$ & & & & 1.29 & $0.9-1.83$ & & 1.1 & $0.79-1.54$ & & 0.89 & $0.62-1.27$ & & 0.88 & $0.68-1.14$ & & 0.89 & $0.69-1.17$ \\
\hline $\begin{array}{l}\text { Chipata Gen Hosp - OP } \\
\text { VMMC }\end{array}$ & & & & & & & & & & & & & 0.56 & $0.36-0.87$ & ** & 0.69 & $0.44-1.06$ \\
\hline SFH New Start & & & & 1.11 & $0.76-1.63$ & & 0.92 & $0.65-1.28$ & & 0.8 & $0.54-1.17$ & & 0.91 & $0.7-1.18$ & & 0.89 & $0.68-1.17$ \\
\hline SFH VMMC & & & & & & & & & & & & & 1.46 & $0.9-2.37$ & & 1.54 & $0.94-2.53$ \\
\hline $\mathrm{N}$ & 1034 & & & 948 & & & 1398 & & & 2043 & & & 3963 & & & 3963 & \\
\hline F statistic & 1.29 & & & 0.95 & & & 4.42 & & $* * *$ & 6.48 & & $* * *$ & 8.01 & & $* * *$ & 6.4 & \\
\hline $\begin{array}{l}\text { Numerator degrees of } \\
\text { freedom }\end{array}$ & 3 & & & 5 & & & 5 & & & 7 & & & 10 & & & 10 & \\
\hline
\end{tabular}


APPENDIX TABLE 8 Multiple imputation multivariable logistic regression of impact of intervention on six-month service uptake outcomes (behavioral indicators from descriptive uptake table) (cont'd)

\begin{tabular}{|c|c|c|c|c|c|c|c|c|c|c|c|c|c|c|c|c|c|c|}
\hline \multirow{2}{*}{ 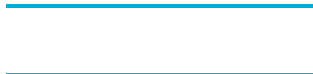 } & \multicolumn{3}{|c|}{ Uptake of HTC } & \multicolumn{3}{|c|}{ Uptake of FP } & \multicolumn{3}{|c|}{ Uptake of VMMC } & \multicolumn{3}{|c|}{ Uptake of CCS } & \multicolumn{3}{|c|}{ Uptake of HIV C\&T } & \multicolumn{3}{|c|}{ Uptake of STI C\&T } \\
\hline & OR & $\mathrm{Cl}$ & sign. & OR & $\mathrm{Cl}$ & sign. & OR & $\mathrm{Cl}$ & sign. & OR & $\mathrm{Cl}$ & sign. & OR & $\mathrm{Cl}$ & sign. & OR & $\mathrm{Cl}$ & sign. \\
\hline $\begin{array}{l}\text { Denominator degrees } \\
\text { of freedom }{ }^{\mathrm{a}}\end{array}$ & & & & $\begin{array}{r}2.48 \mathrm{E}+ \\
65\end{array}$ & & & . & & & $\begin{array}{r}1.14 \mathrm{E}+6 \\
6\end{array}$ & & & & & & $\begin{array}{r}2.36 \mathrm{E}+ \\
66\end{array}$ & & \\
\hline \multirow{2}{*}{\multicolumn{19}{|c|}{$\begin{array}{l}\text { Model 3: Study Arm + Site + } \\
\text { Demographic Covariates } \\
\text { Study arm }\end{array}$}} \\
\hline & & & & & & & & & & & & & & & & & & \\
\hline Standard of care & 1 & $1.00-1.00$ & & 1 & $1.00-1.00$ & & 1 & $1.00-1.00$ & & 1 & $1.00-1.00$ & & 1 & $1.00-1.00$ & & 1 & $1.00-1.00$ & \\
\hline Enhanced referral & 1.26 & $0.93-1.70$ & & 0.93 & $0.66-1.30$ & & 1.01 & $0.74-1.37$ & & 1.72 & $1.36-2.18$ & $* * *$ & 1.04 & $0.87-1.24$ & & 0.95 & $0.79-1.14$ & \\
\hline $\begin{array}{l}\text { Enhanced referral \& } \\
\text { escort }\end{array}$ & 1.28 & $0.94-1.73$ & & 1 & $0.71-1.40$ & & 1.44 & $1.07-1.92$ & * & 1.84 & $1.46-2.32$ & $* * *$ & 1.15 & $0.96-1.37$ & & 1.06 & $0.89-1.28$ & \\
\hline \multicolumn{19}{|l|}{ Entry site $^{b}$} \\
\hline $\begin{array}{l}\text { SFH HTC - Cairo Road } \\
\text { Chawama Clinic- }\end{array}$ & & & & 1 & $1.00-1.00$ & & 1 & $1.00-1.00$ & & 1 & $1.00-1.00$ & & 1 & $1.00-1.00$ & & 1 & $1.00-1.00$ & \\
\hline $\begin{array}{l}\text { Maternity Ward } \\
\text { Chawama Clinic - Out }\end{array}$ & 1 & $1.00-1.00$ & & & & & & & & 1.2 & $0.80-1.79$ & & 1.42 & $1.02-1.96$ & * & 1.25 & $0.88-1.76$ & \\
\hline $\begin{array}{l}\text { Patient Ward (VMMC) } \\
\text { Kamwala Clinic - TB, STI }\end{array}$ & & & & & & & & & & & & & 0.8 & $0.54-1.17$ & & 0.75 & $0.50-1.10$ & \\
\hline \& HIV Clinic & & & & 1.4 & $0.87-2.26$ & & 1.55 & $1.03-2.34$ & * & 1.15 & $0.73-1.81$ & & 1.77 & $1.32-2.39$ & $* * *$ & 1.7 & $1.25-2.31$ & ** \\
\hline Kapata Urban Clinic, MCH & 0.89 & $0.67-1.17$ & & & & & & & & 0.98 & $0.67-1.45$ & & 0.77 & $0.56-1.07$ & & 0.64 & $0.45-0.91$ & * \\
\hline $\begin{array}{l}\text { Kapata Urban Clinic, TB, } \\
\text { STI \& HIV } \\
\text { Chipata Gen Hosp - OP }\end{array}$ & & & & 1.11 & $0.71-1.73$ & & 0.98 & $0.66-1.45$ & & 0.76 & $0.50-1.14$ & & 0.74 & $0.56-0.98$ & * & 0.74 & $0.55-0.99$ & * \\
\hline VMMC & & & & & & & & & & & & & 0.51 & $0.32-0.82$ & ** & 0.49 & $0.31-0.78$ & ** \\
\hline SFH New Start & & & & 0.89 & $0.55-1.43$ & & 0.81 & $0.55-1.18$ & & 0.65 & $0.42-1.00$ & * & 0.75 & $0.57-1.00$ & * & 0.7 & $0.52-0.94$ & * \\
\hline SFH VMMC & & & & & & & & & & & & & 1.38 & $0.83-2.29$ & & 1.16 & 0.69-1.95 & \\
\hline \multicolumn{19}{|l|}{ Genderc } \\
\hline Male & & & & & & & & & & & & & 1 & $1.00-1.00$ & & 1 & $1.00-1.00$ & \\
\hline Female & & & & & & & & & & & & & 1 & $0.82-1.21$ & & 0.81 & $0.66-0.99$ & * \\
\hline Age & 1 & $0.98-1.03$ & & 0.98 & $0.95-1.00$ & * & 0.98 & $0.96-1.01$ & & 1 & 0.98-1.01 & & 1.02 & $1.01-1.03$ & $* *$ & 0.99 & $0.97-1.00$ & $\dagger$ \\
\hline $\begin{array}{l}\text { Highest grade } \\
\text { completed }\end{array}$ & 0.98 & $0.94-1.01$ & & 1.01 & $0.97-1.06$ & & 0.97 & $0.93-1.01$ & & 0.98 & 0.95-1.01 & & 0.95 & $0.93-0.97$ & $* * *$ & 0.96 & $0.93-0.98$ & $* * *$ \\
\hline \multicolumn{19}{|l|}{ Marital status } \\
\hline Not currently married & 1 & $1.00-1.00$ & & 1 & $1.00-1.00$ & & 1 & $1.00-1.00$ & & 1 & $1.00-1.00$ & & 1 & $1.00-1.00$ & & 1 & $1.00-1.00$ & \\
\hline $\begin{array}{l}\text { Currently married/living } \\
\text { with partner }\end{array}$ & 0.74 & $0.53-1.02$ & $\dagger$ & 2.56 & $1.90-3.47$ & $* * *$ & 0.84 & $0.61-1.16$ & & 1.03 & $0.82-1.29$ & & 0.88 & $0.74-1.04$ & & 0.89 & $0.74-1.07$ & \\
\hline \multicolumn{19}{|l|}{ Residence } \\
\hline Urban & 1 & $1.00-1.00$ & & 1 & $1.00-1.00$ & & 1 & $1.00-1.00$ & & 1 & $1.00-1.00$ & & 1 & $1.00-1.00$ & & 1 & $1.00-1.00$ & \\
\hline Rural & 1.05 & $0.58-1.90$ & & 1.95 & $0.97-3.94$ & $\dagger$ & 1.01 & $0.62-1.64$ & & 1.45 & $0.94-2.25$ & $\dagger$ & 1.06 & $0.78-1.45$ & & 1.2 & $0.87-1.66$ & \\
\hline \multicolumn{19}{|l|}{ Employment status } \\
\hline Not working & 1 & $1.00-1.00$ & & 1 & $1.00-1.00$ & & 1 & $1.00-1.00$ & & 1 & $1.00-1.00$ & & 1 & $1.00-1.00$ & & 1 & $1.00-1.00$ & \\
\hline Currently working & 1.01 & $0.77-1.33$ & & 1.09 & $0.81-1.45$ & & 1.1 & $0.83-1.46$ & & 1.1 & $0.90-1.34$ & & 1.05 & $0.90-1.23$ & & 1.11 & $0.94-1.31$ & \\
\hline $\begin{array}{l}\text { Number of household } \\
\text { assets }\end{array}$ & 0.99 & $0.95-1.03$ & & 0.98 & $0.94-1.03$ & & 1 & $0.96-1.04$ & & 0.97 & $0.94-1.00$ & * & 0.97 & $0.95-1.00$ & * & 0.97 & $0.95-0.99$ & * \\
\hline
\end{tabular}


APPENDIX TABLE 8 Multiple imputation multivariable logistic regression of impact of intervention on six-month service uptake outcomes (behavioral indicators from descriptive uptake table) (cont'd)

\begin{tabular}{|c|c|c|c|c|c|c|c|c|c|c|c|c|c|c|c|c|c|c|}
\hline & \multicolumn{3}{|c|}{ Uptake of HTC } & \multicolumn{3}{|c|}{ Uptake of FP } & \multicolumn{3}{|c|}{ Uptake of VMMC } & \multicolumn{3}{|c|}{ Uptake of CCS } & \multicolumn{3}{|c|}{ Uptake of HIV C\&T } & \multicolumn{3}{|c|}{ Uptake of STI C\&T } \\
\hline & OR & $\mathrm{Cl}$ & sign. & OR & $\mathrm{Cl}$ & sign. & OR & $\mathrm{Cl}$ & sign. & OR & $\mathrm{Cl}$ & sign. & OR & $\mathrm{Cl}$ & sign. & OR & $\mathrm{Cl}$ & sign. \\
\hline $\begin{array}{l}\text { Distance to health } \\
\text { facilityd }^{\text {d }}\end{array}$ & 0.97 & $0.90-1.04$ & & 1.02 & 0.99-1.05 & & 1 & $0.97-1.02$ & & 1.01 & $0.98-1.04$ & & 1 & $0.99-1.02$ & & 1.01 & $0.99-1.02$ & \\
\hline $\mathrm{N}$ & 1034 & & & 948 & & & 1398 & & & 2043 & & & 3963 & & & 3963 & & \\
\hline F statistic & 1.02 & & & 3.93 & & $* * *$ & 2.33 & & $\star *$ & 4.01 & & $* * *$ & 7 & & $* * *$ & 5.1 & & $* * *$ \\
\hline $\begin{array}{l}\text { Numerator degrees of } \\
\text { freedom }\end{array}$ & 11 & & & 13 & & & 13 & & & 15 & & & 19 & & & 19 & & \\
\hline $\begin{array}{l}\text { Denominator degrees } \\
\text { of freedom }\end{array}$ & $\begin{array}{r}1.66 \mathrm{E}+ \\
08\end{array}$ & & & $\begin{array}{r}5.85 \mathrm{E} \\
+08\end{array}$ & & & $\begin{array}{r}2.89 \mathrm{E} \\
+08\end{array}$ & & & $\begin{array}{r}1.89 \mathrm{E} \\
+09\end{array}$ & & & $\begin{array}{r}3.12 \mathrm{E} \\
+09\end{array}$ & & & $\begin{array}{r}9.46 \mathrm{E} \\
+08\end{array}$ & & \\
\hline
\end{tabular}

$* * * p<.001 ; * * p<.01 ; * p<.05 ; \dagger p<.10$

a Denominator degrees of freedom in some models are missing. Per Stata results: "This may happen when the estimated (average) relative variance increase due to nonresponse is close enough to zero (low fraction of missings) such that the degrees of freedom approaches infinity. In this case, the normal distribution is used to compute the significance levels of the reported t tests and the chisquared distribution is used to compute the significance level of the F test."

b Entry sites included in model dependent on outcome variable.

c Gender of outcome variable constant if omitted from model.

d $38 \%$ of baseline sample don't know distance, therefore a dummy was also included ( 1 = Yes if don't know distance). 
